Portland State University

PDXScholar

\title{
Gentrification and Displacement Study: Implementing an Equitable Inclusive Development Strategy in the Context of Gentrification
}

Lisa K. Bates

Portland State University, lkbates@pdx.edu

Follow this and additional works at: https://pdxscholar.library.pdx.edu/usp_fac

Part of the Urban Studies Commons, and the Urban Studies and Planning Commons Let us know how access to this document benefits you.

\section{Citation Details}

Bates, Lisa K., "Gentrification and Displacement Study: Implementing an Equitable Inclusive Development Strategy in the Context of Gentrification" (2013). Urban Studies and Planning Faculty Publications and Presentations. https://doi.org/10.15760/report-01

This Working Paper is brought to you for free and open access. It has been accepted for inclusion in Urban Studies and Planning Faculty Publications and Presentations by an authorized administrator of PDXScholar. Please contact us if we can make this document more accessible: pdxscholar@pdx.edu. 
Gentrification and Displacement Study: implementing an equitable inclusive development strategy in the context of gentrification

Commissioned by City of Portland

Bureau of Planning and Sustainability

Authored by Lisa K. Bates, PhD

Updated: 05/18/13 


\section{Table of Contents}

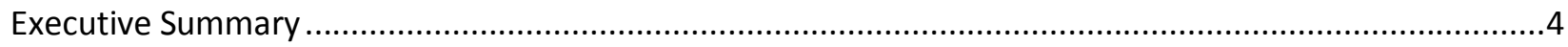

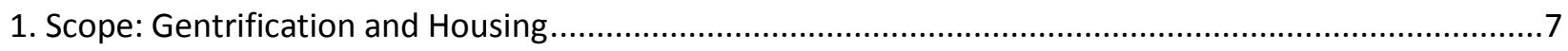

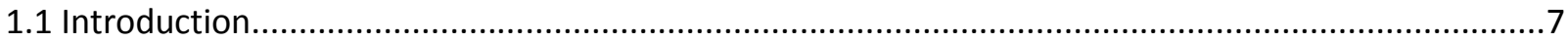

1.2 Gentrification and displacement risk assessment focus is on housing ......................................

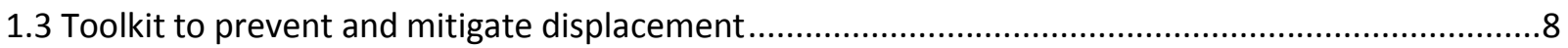

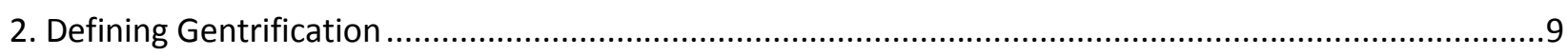



2.2 Housing displacement as the defining feature ........................................................................

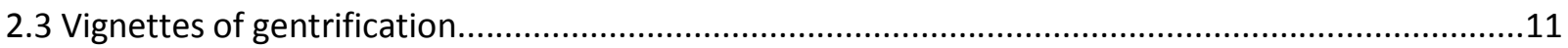

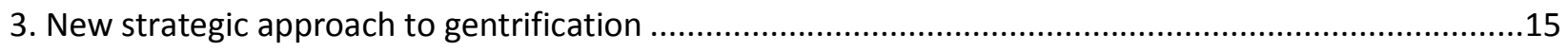

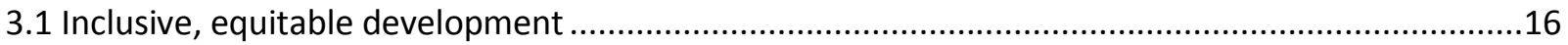

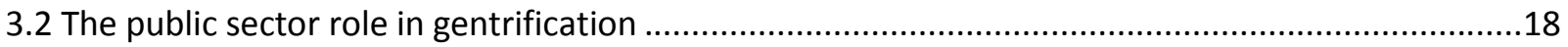

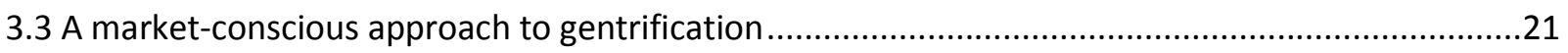

3.4 Conclusion: a coordinated approach for roles across institutions ................................................25

4. Neighborhood typology analysis for gentrification and displacement risk .......................................26

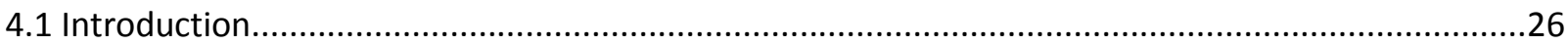

4.2 Purpose and concept for neighborhood change analysis .............................................................26

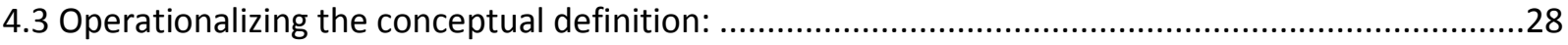

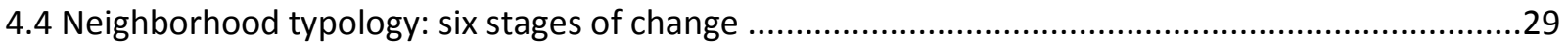

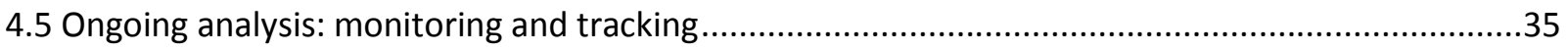

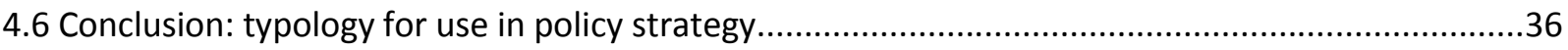

5. Policy strategy: operationalize inclusive and equitable development...............................................37

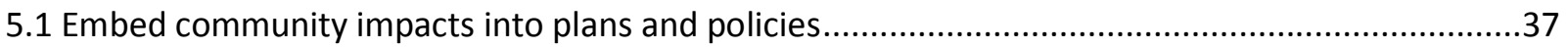

5.2 Coordinate policy strategy based on typology and level of public investment ..............................40

5.3 Gentrification data drilldown: focused equity analysis to set priorities .........................................42

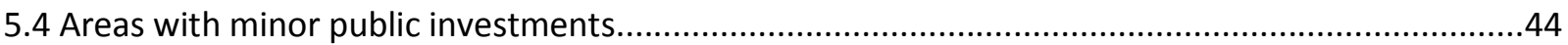

5.5 Major public investments/ new major investment areas ..........................................................45

5.6 Private development without subsidy in gentrifying neighborhoods........................................47

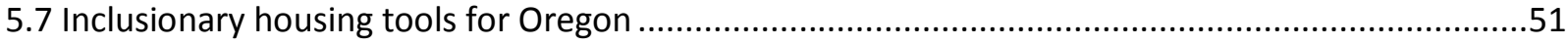

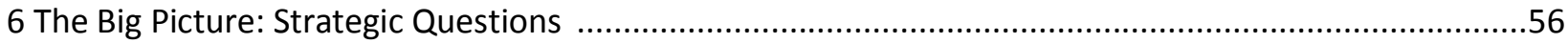




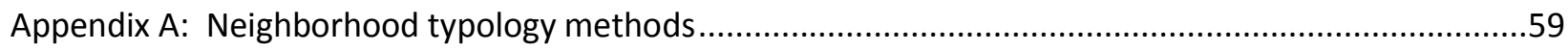

Appendix B: Data and methods for a neighborhood equity analysis "drilldown" .................................63

Appendix C: Cully Neighborhood: drilldown analysis example.................................................................66

Appendix D: Annotated Policy toolkit: best practices............................................................................76 


\section{Executive Summary}

\section{Background}

Gentrification and displacement have changed the character of urban neighborhoods in cities across America. Portland, with its growing acclaim for livability, has not escaped the challenges that growth and change bring forth. Among the challenging issues has been the gentrification of closer-in neighborhoods. In the last two decades, Portland's North and Northeast

neighborhoods have seen significant public and private investments, steep increases in housing prices, and changes in demographic and economic profile of residents that have resulted in displacement (voluntary and involuntary) of low-income residents and community serving small businesses. Making investments to improve a neighborhood, which can have many positive outcomes for current residents, can make the neighborhood more attractive and create upward pressure on rents and property values. The key distinction between revitalization and gentrification is the negative consequence of involuntary residential displacement.

As a strategic response, the Portland Plan made a commitment to better understand and minimize the effects of gentrification. This study can serve as the basis for understanding and developing a policy strategy to address gentrification. It provides strategic guidance for the City of Portland to better understand gentrification and its effects; to assess the susceptibility or risk of gentrification for different neighborhoods; and to identify best practices for addressing gentrification and displacement that may be appropriate for Portland.

\section{Key Findings}

This study focuses on the effects on the housing market, particularly the loss of affordable housing. It builds upon earlier studies to consider a broader interpretation of displacement that encompasses not just when a household is forced to move by conditions that affect the dwelling, but also to take into account changes in the neighborhood as a whole. These neighborhood changes can result in a neighborhood's inability to provide basic services that make it impossible to continue residency as a "voluntary" response.

Housing in Portland is almost exclusively produced by the private sector, with a limited public sector role through regulation, incentives, and some direct construction. The study recommends a market-conscious approach to gentrification embracing new principles that allow for:

- An inclusive development paradigm with a racial/ethnic equity lens.

- A recognition of how public investments affect the private market.

- Ways to anticipate housing demand and market changes.

- Options for utilizing the public sector to regulate and engage a range of private development and community actors to minimize the effects. 


\section{Risk Assessment}

The approach to assessing the susceptibility or risk of gentrification for different neighborhoods has two levels of analysis. The first level is to anticipate the potential market changes by focusing on a relatively small set of indicators based on resident's vulnerability to displacement, recent demographic changes, and housing market conditions. These indicators are used to identify and classify neighborhoods into a typology that represents different stages of gentrification. The second level is a focused equity analysis to understand the specific change dynamics of a particular neighborhood that can help focus a public response. Public agencies can use this assessment approach to better understand the risk of gentrification in the communities in which they are working. It also implies a commitment to ongoing monitoring and tracking to understand changing conditions and emerging at-risk neighborhoods.

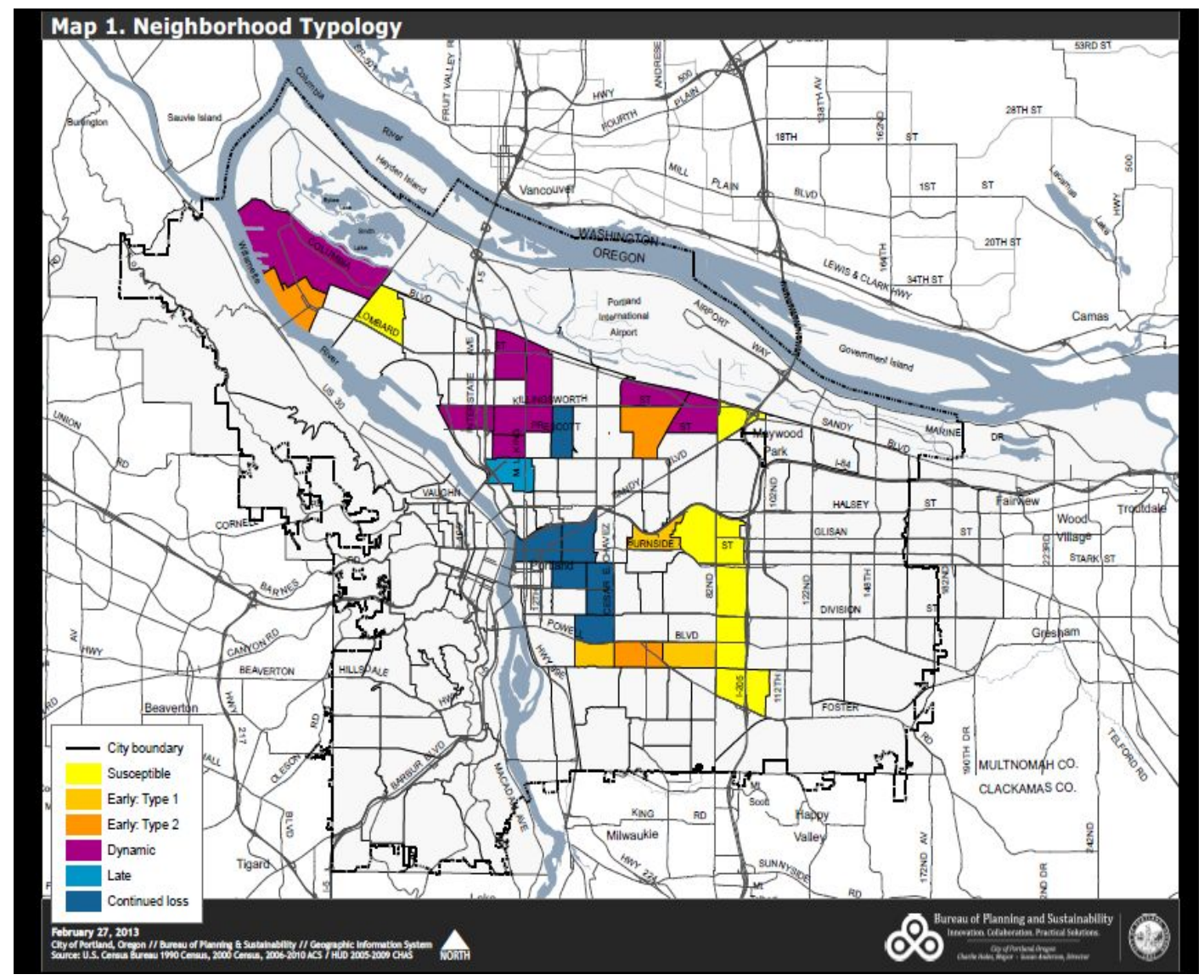

\section{Policy Strategy}

The concept of inclusive, equitable development is to improve neighborhood livability, while working to ensure that new development and neighborhood change does not disproportionately impact current residents. The approach is to match the tool(s) to specific stages of gentrification and the type of public investment that is being made. 
The report summarizes a "toolbox" of policies and programs that could be used in these different situations. The toolbox is based on a review of best practices from across the nation. Five key elements of the toolkit are:

1. A broad community impacts policy that sets clear expectations about promoting positive community impacts and mitigating harms.

2. Community Impact Reports for major projects, especially for projects with public funding, to define the potential impacts, costs and benefits and identify possible mitigation programs.

3. Community Benefits Agreements, primarily for private projects, that create a negotiated agreement between developer and the surrounding community to create a less adversarial review process and provide specific benefits related to the development.

4. Inclusionary Zoning through which developers provide affordable units or pay in lieu fees to ensure affordable housing is part of new development.

5. Education and Technical Assistance through which the City could do more to promote best development practices for mixed income and affordable/workforce housing, similar to Portland's effort to promote green building .

Given the pursuit of multiple important goals and limited resources, the study concludes with the following set of strategic questions for Portland:

1. Which changing neighborhoods should be addressed first and/or with the most resources?

2. Could an anti-displacement goal mean an entirely different set of priorities for the City?

3. Which policy tools or activities should be implemented, and how should they be prioritized?

4. How does gentrification policy fit into the broader set of goals, policies and identified needs for Portland's neighborhoods? 


\section{Scope: Gentrification and Housing}

\subsection{Introduction}

While gentrification has been discussed in Portland for some time, the Portland Plan provides new focus on the issue of balancing neighborhood revitalization with the ability of current residents to stay in place to enjoy new amenities. The City has committed to ensuring that all communities are prosperous, healthy, and accessible_-but with increasing numbers of newcomers to Portland, housing pressures rise. As some neighborhoods become more desirable, long-time residents with lower incomes, particularly in communities of color, find themselves priced out and moving out-often to areas of Portland and eastern Multnomah County with fewer services, amenities, and institutions.

Portland Plan: Gentrification and displacement, whether the result of large infrastructure investments or the cumulative effect of smaller investments, have disrupted communities and resulted in serious questions about the motivations behind government investments in Portland. Today's challenge is to figure out how to provide all Portlanders with quality of life and other improvements and programs without the negative consequences of gentrification and displacement, all while improving trust and confidence in local government (70).

As part of the recognition of the potential for gentrification to disrupt communities and create inequities, the Cully Main Street Plan resolution includes a provision to monitor and mitigate the displacement of residents. As an area that was historically underdeveloped and lacking in public investment, but now receiving infrastructure upgrades and economic development incentives, Cully is an area with the potential for transformation. The resolution guides the City to take care to revitalize while mitigating harms for lower-income households and people of color.

In light of these plans and priorities, this study provides analysis and strategic guidance for the City to better understand gentrification and its effects; to assess the status of neighborhoods' changing conditions; and to align policy tools with the challenges and opportunities present in different kinds of neighborhood change conditions.

This study includes the following sections:

1. Scope : gentrification and housing

2. Defining gentrification

3. A new approach to the housing market

4. Neighborhood typology of gentrification and displacement

5. Policy program for inclusive, equitable development 
6. Strategic policy questions

Appendices:
A. Housing Market Typology: Detailed methods and maps
B. Neighborhood Drilldown Analysis: data and variables
C. Cully drilldown analysis example
D. Annotated toolkit of best practices

\subsection{Gentrification and displacement risk assessment focus is on housing}

This gentrification strategy study focuses on the effects of gentrification in the housing market. Gentrification changes neighborhood character through housing market, economic status, and demographic changes. The gentrification and displacement risk assessment map tool focuses on the essential features of neighborhood housing market change. It highlights areas that are in the midst of gentrification and those where gentrification may be imminent. These maps focus on market and policy drivers of gentrification for those vulnerable to housing change-lowincome, renter, low educational attainment, and/or persons of color households.

Gentrification can also involve businesses and commercial space. The turnover of neighborhood-serving commercial areas from serving basic needs of lower-income residents to serving higher-income customers or offering luxury items is a problem for achieving neighborhood livability for all. Additionally, business ownership can be a way to build wealth and neighborhood businesses can offer family-wage jobs, both of which help residents become more resilient to neighborhood housing market appreciation. Commercial gentrification involves a different set of dynamics that are related to this work, but it is different enough that it is not addressed thoroughly in this paper.

The focus of concern about gentrification is displacement from changing neighborhoods, and strategies to prevent affordable housing loss in those neighborhoods. Therefore, this gentrification study focuses on neighborhoods where housing values are appreciating or likely to appreciate. It does not address areas with persistently low housing values and residents with low incomes. However, those areas are very much connected with the gentrification and displacement problem. When public investments in one neighborhood create displacement, it is important to understand how they affect other neighborhoods as well. Neighborhoods with low housing prices are destinations for displaced households. They may face problems of increased concentrations of poverty and racial segregation; in Portland these neighborhoods also tend to be more inaccessible, leaving households with limited opportunity. The neighborhoods that are determined to be persistently low market value and low-income require a different strategy for revitalization and providing opportunity for residents.

\subsection{Toolkit to prevent and mitigate displacement}

This study includes a compilation of policies, regulations, incentives, and other tools that could be utilized to address housing displacement. These tools are linked to the stage of gentrification to connect a tool to the particular challenges and opportunities in different kinds of markets. 
Many of the tools are directly housing-related, and the toolkit is compiled recognizing there are only very limited dedicated funds for subsidizing affordable housing production, and that Oregon is one of only two states (along with Texas) that pre-empts local governments' ability to utilize mandatory inclusionary zoning policies (ORS 197.309). Additional tools are programs and policies that can help residents to be more resilient to housing market changes so they can avoid being displaced; these include broader community economic development activities. Along with listing best practice tools and resources, the section provides an overview for incorporating a suite of policies to promote a community impacts approach to development. It also highlights community benefits agreements, incentive-based inclusionary zoning, and capacity building for resident engagement with land use planning.

\section{Defining Gentrification}

\subsection{Common definition for gentrification}

This study requires a conceptually rich framework for understanding gentrification in Portland, but also needs to be concise and actionable. The discussion about gentrification is fraught and conflicted, particularly as it relates to race and historical disinvestment. While there are intense debates in academic circles about how to describe gentrification as a process, the common characteristics for defining the effects are: housing market changes, economic status changes, and demographic changes in a neighborhood that alter its character. ${ }^{1}$

Gentrification occurs when a neighborhood has attractive qualities-for example, location or historic architecture - but remains relatively low value. This disconnect between potential value and current value (called "the rent gap") may occur due to historic disinvestment by public and private sectors. When the area becomes desirable to higher-income households and/or investors, there are changes in the housing market. As demand rises for the neighborhood, higher-income households are able to outbid low-income residents for housing, and new development and economic activity begins to cater to higher-income tastes. Lower-income households and/or households of color migrate out of the neighborhood and new in-migrants change the demographics of the neighborhood.

\footnotetext{
${ }^{1}$ Levy et al (2006) provide an overview of the variations on the gentrification definition that appear in literature since the phenomenon was first described: housing rehabilitation for middle-class residents; new capital flowing to areas of historical disinvestment; racial turnover caused by white in-migrants. Slater (2009) laments that many urbanists describe neighborhood change positively, using terms like revitalization, renaissance, and resurgence-rather than addressing "what happens when forces outside the household make living there impossible, hazardous, or unaffordable."(here he quotes Hartman's "Displacement: how to fight it"). Hamnett's "The Blind Man and the Elephant: the explanation of gentrification" (2009) lays out a combination of conditions for gentrification to occur: attractive locations with nevertheless undervalued properties (housing supply), along with sufficient populations of demographic groups who have a taste for urban living and have the financial means to outbid current residents (housing demand).
} 
Portland Plan: As cities grow and develop, they often experience a rise in property values and a change in demographic and economic conditions in neighborhoods. The term gentrification applies when these changes are part of a shift from lowerincome to higher-income households and often when there is a change in racial and ethnic make-up of a neighborhood's residents and businesses (70).

For some observers, neighborhood revitalization appears to be an unmitigated positive change. Revitalization is usually desired by current residents and can have many positive outcomes for cities, neighborhoods, and individuals. Here, we focus on the negative consequence of involuntary residential displacement as the distinction between revitalization and gentrification. Rather than debating the complex causality of neighborhood change or attempting to weigh all its possible benefits and costs, this approach places the emphasis on recognizing and avoiding the displacement of residents as their neighborhood receives new investments and upgrades. As Kennedy and Leonard (2001) note in "Dealing with Neighborhood Change":

"In cities hit by gentrification pressures, residents, city officials and other interests frequently descend into rhetoric and factional fighting. This often occurs because different parties define gentrification differently, see different parts of the issue, or otherwise talk past each other. Moreover, the political focus is often on gentrification's character and consequences without linking these more pragmatically to its "end game," its causes and solutions.(2)"

This approach intends to sidestep these debates and focus on the housing displacement problem.

\subsection{Housing displacement as the defining feature}

Housing displacement can occur directly due to housing market changes, or occur because of pressures and community changes. The literature on gentrification lists many dimensions of displacement. Low-income residents may be displaced by rising rents or evictions for tenure conversion; rising property taxes or homeowners' insurance rates; or a loss of subsidized housing units. As the housing market appreciates, the number of housing units available to a lower-income household shrinks, excluding any others who may have chosen the neighborhood. Residents also may experience a loss of community that leads them to moveas friends or family leave the neighborhood, commercial centers no longer serve their needs, or community and cultural institutions relocate, residents are displaced by dispossession (Marcuse 1985). 
Portland's previous study of displacement in 1981 adopted the definition first presented by George and Eunice Grier in their 1978 displacement reconnaissance report prepared for HUD. It is:

"Displacement occurs when any household is forced to move from its residence by conditions which affect the dwelling or its immediate surroundings, and which:

1. are beyond the household's reasonable ability to control or prevent;

2. occur despite the household's having met all previously imposed conditions of occupancy; and

3. make continued occupancy by that household impossible, hazardous or unaffordable."

In some ways the present understanding of displacement is a broader interpretation-including changes in the neighborhood as a whole as an impetus for moving ("its immediate surroundings") and considering a range of reasons for "impossible" continued occupancy—not only forced moves but "voluntary" responses to a change in a neighborhood's ability to serve basic needs.

The costs of displacement to a household or family are more than a loss of a sense of community or social supports. They are tangible and measurable: loss of access to 'high opportunity' locations and displacement to less accessible neighborhoods; and the loss of assets/wealth when home-owning families exit without realizing increased values, or when long time renter families cannot buy into increasing neighborhood value. Residential displacement also costs the entire community. The effects of concentrated poverty on schools, spatial mismatch between low-wage workers' homes and their jobs, and the social and economic costs of the health, educational, and employment impacts of housing instability all affect the city. When individuals have inadequate housing, limiting their opportunities and the development of human capital, there is an overall economic impact (Belfield, in Turner et al 2008).

Portland Plan: The harm of gentrification is tangible and measurable. This includes loss of access to desirable locations; displacement of individuals and businesses to less desirable locations; a loss of wealth when homeowners leave without realizing the increased property values; and, more generally, the loss of the ability for current residents to enjoy the benefits of revitalization. It is difficult to calculate the real costs and benefits to current residents from gentrification, but dearly, there are losses (70).

\subsection{Vignettes of gentrification}

Gentrification is a complex process with multiple causes and effects-some positive, some negative. The following vignettes, drawn from qualitative research on gentrifying neighborhoods, 
illustrate the range of experiences and reactions to these neighborhood changes. Many of these captured moments will resonate for Portlanders.

Who are gentrifiers and what are they seeking? Portland is a top destination city for the young and college educated (Jurjevich and Schrock 2012), a demographic group likely to contribute to gentrification pressures due to their taste for urban lifestyles. Portland also attracts a significant number of "empty-nester" households, also moving to central city neighborhoods. Portland's much-celebrated planning for livability, neighborhood amenities, and culture attracts more affluent and/or educated households to "20-minute neighborhoods."

New York City: "Young American Midwesterners responding to what the real estate editor of New York Magazine dubs the "Friends effect", thanks to NBC's decade-long primetime "infomercial for New York" (Pi Roma, 2003). (Now brokers speak of the "Sex in the City effect", for the HBO series that lives on through reruns.)"

Newman and Wyly, 2006, 30

Portland now has a national reputation not only for sustainability and livability, but for coolness, a food scene, indie music, and the "hipster" sensibilities of Portlandia (Portland's 'Sex in the City' for promoting a lifestyle). The UK paper The Guardian even named the Boise-Eliot and Overlook neighborhoods among the five best places to live in the world, writing in 2011 in a perfect encapsulation of how gentrification starts and intensifies:

Portland: "Do you like letterpress? Do you like vintage clothes? Do you play in a nu-folk band? Then get ye to Boise, Eliot and Overlook in Portland. The city has been the capital of liberal, hipster USA for decades.... Shockingly, it still remains relatively good value. ... When I first visited in the early 90 s, Boise, Eliot and Overlook were the kind of spots you sped through: always the first sign of a neighbourhood [sic] you should buy in." Dyckhoff, 2012.

While new in-migrants to urban neighborhoods are often appreciative of, and even seeking, cultural diversity, their arrival can have the unintended consequence of eliminating that diversity.

San Francisco: "Twenty-something workers at Silicon Valley firms are much more inclined to live in a dynamic city such as San Francisco than quiet and expensive suburbs near their jobs. Many young newcomers in the Mission District are attracted to the cultural diversity there... [but] Under great pressure are the same Latino groceries and religious stores that give the neighborhood character and attract twenty-something newcomers. The owners of El Herradero Restaurant face a 63 percent increase in rent after 12 years in business, while the Los Jarritos Restaurant and Mi Rancho Market were displaced as the buildings' owner put them up for sale." Kennedy and Leonard, 2001, 21

The change in the business district not only decreases diversity as a cultural asset, but makes it harder for long-time Latino residents to meet their daily needs. 
Neighborhood residents can gain a sense of place, community, and empowerment through cultural expression. Through festivals and celebrations, neighborhoods can attract new consumers of culturally-specific foods and goods, and cities may promote cultural diversity as a means of economic development. However, the use of these events as tourism promotions can lead to conflict.

Chicago: The Pilsen neighborhood's Fiesta Del Sol brings residents together for cultural preservation and also to deliver a State of the Neighborhood Address that includes a report card of City policies regarding the neighborhood. The city's tourism office, however, describes Fiesta as only a fair. Furthermore, it provides services for tourists to Fiesta that are not otherwise available. "The city has engaged in an intense process of promotion of Pilsen's unique Mexican culture including the neighborhood in its downtown tourist route [on the free trolley]... Alejandra Ibáñez, Executive Director of The Pilsen Alliance, a local activist organization, views these free trolley rides and overt attempts to boost tourism as a bit of a slap in the face to residents, in light of the fact that night and weekend public transportation service for the community was discontinued in 1997." Betancur, 2005, 26

Neighborhood change can be a mixed blessing for long-time residents, who enjoy public service upgrades and new commercial venues-for as long as they can afford to.

New York City: "A Harlem resident describes the changes on 125th Street in Central Harlem. "People love Starbucks. People who would buy 50-cent coffee now go in there and buy one for $\$ 3.00$ ". But residents fear that their new shopping venues come with a high price tag and may help to spur the revitalization that will ultimately displace them. One resident explained that he liked the new stores but feared displacement: "I don't want to have to take a train to go to the Magic Johnson theatre. I live on 126th. I should be able to walk to there and when I'm done, walk back."

Newman and Wyly, 2006, 45

When services remain in the neighborhoods, displaced community members may go to extraordinary lengths to access the institutions to which they belong.

Portland: "Every Sunday morning, the Lord's work for Bradford involves driving to the farthest reaches of Portland to pick up congregants who lack the means to get to the small, century-old building, with its rectangular steeple and fresh coat of cream paint, whether because of age, disability, or finances. He is part of a small fleet of van drivers dispatched from inner North and Northeast's predominantly African American churches to round up their scattered flocks....Four stops, one and a half hours, and 50 miles later, Bradford drives back up Alberta." Scott, Portland Monthly, February 2012

The return of residents to historical community gathering spaces can create conflict with new residents. In some cities, the reverse commute of African-Americans to attend their historic 
church homes leads to fights for parking space. These conflicts lead to questions about whose neighborhood it is-those with long historical roots, or those who own property today?

Washington, $D C$ : "In Shaw, neighbors frustrated with the influx of cars every Sunday requested new, resident-only parking restrictions that effectively ban churchgoers without permits. Lincoln Congregational Temple is fighting back with a letter-writing campaign to local leaders. 'Quite frankly, I'm angry,' the Rev. Rubin Tendai, Lincoln's interim pastor, said. 'Some of [our members] have been in this church for 30, 40, 50 years, and we are an elderly congregation. We're not going to take this sitting down." Essley, Washington Examiner, October 2012

Conflicts can arise when new improvements are viewed skeptically-are public agencies responding only to new, higher status residents? These conflicts can erupt in public processes when long-time residents address improvements that appear to be for "them."

Portland: "The racial demographics have almost completely flipped....For the city to publicly turn its eye toward helping the neighborhood now is insulting to some longtime residents. Safety-from guns, drugs, and, sure, cars-was as much an issue in 1990 as it is now. 'There's this sense that it's been a long time coming for funding in the neighborhood,' says Paige Coleman, director of the Northeast Coalition of Neighborhoods. 'The question we're hearing now is 'Why now?' and 'Where were you then?"' Mirk, 2012

Residents whose demands for improvements were not met view changes with cynicism, decreasing trust in local government. The often racialized nature of gentrification means this sense of disenfranchisement is most often felt by communities of color, who are already underrepresented in local process and government.

Washington, DC: "My homeboy's dad, who lived on the corner of 5th and L St. N.E., used to rant about how there needed to be a four way stop sign at the intersection. Oh, how he would wax about how someone was going to get hit by a car and how the city didn't care about the black folks that lived there. The city turned over and the first thing that showed up on the corner of 5 th and $L$ was a four way stop sign. I guess this is to say I am grateful for the stop signs but sad that it took us leaving to have it happen. That it didn't feel important to build until we were gone. "

Crockett, Washington Post, August 2012

Schools are a particular concern for residents who have observed how new facilities and programs appear when neighborhood incomes rise-particularly when the new programs do not accept all residents, but require qualification to enter.

Chicago: A resident decries of a newly renovated public school with an exclusive admissions policy, "Who were they developing King for? When four years ago you stopped accepting students and flushed them out, that's no success...All that's being 
done is not being done with the intent to serve the existing community. That's urban planning." Patillo, 2007, 99

Neighborhood conflict can also emerge when new residents seek remedies for what they view as problematic or nuisance properties in the planning/regulatory system. As new standards for the neighborhood's physical appearance evolve, existing lower-income owners may struggle to keep pace, or even face penalties or lose their property. More educated and affluent neighbors are more knowledgeable and better equipped to utilize the regulatory system to prevent uses they find incompatible, including economic and community activity.

Columbus, Ohio: The documentary Flag Wars, depicting conflict in Columbus Ohio, includes scenes in code enforcement hearings that depict long-time residents fighting complaints for problems they cannot afford to repair. One resident even faces arrest for failing to address code violations. The founder of a neighborhood art gallery, which predated the gentrification, spent three years fighting to keep the gallery's sign that did not meet new Historic District standards because of its African style. The historic designation was based on Victorian history-the time before it was a Black community.

Chicago: Instead of a space for forging consensus, the block club had conflict over residential and commercial activity compatibility. A newer resident explained "...in the block club "it's probably 50-50, new residents versus residents who have been here prior to the 'gentrification.' ... one of the residents wanted to get the block club behind him to allow him to run his own car wash down the street here. ...l'm like, I would have moved next to a car wash if that's what I was wanting to do. You know, we have zoning laws for a reason. And all of the older residents were on his bandwagon..." Pattillo, 2007, 91

Finally, the racial tension at the heart of many gentrifying neighborhoods is summarized, along with the reaction of an African-American resident to the implied de-valuing of communities of color:

Washington, DC: "This demographic reality creates a crude, ethically charged math, and everyone who owns a stake in Washington calculates with it. The presence of white faces is the most reliable sign of the quality of a school. The more white people move in, the higher the property values go. The city's population is growing, but each black family that leaves a school or neighborhood makes it richer. It was Donna who was in the way. 'When you hear people say, 'the good news is the neighborhood is being gentrified,' it just makes you feel worthless," Donna told me." Hopkinson, New York Times, June 2012

\section{New strategic approach to gentrification}

Fundamentally, the question about addressing gentrification is "what can the City of Portland do differently?" A new approach does not mean being resigned to changes that have already happened in Portland neighborhoods, nor to be mired in past decisions and consequences. It does include understanding how those changes have happened and how to make future 
decisions to mitigate costs-to move forward with a new approach. A new approach to gentrification should mean embracing new principles:

1. An inclusive development paradigm with a racial/ethnic equity lens.

2. A recognition of how public investments affect the market.

3. Ways to utilize the opportunities of the role of the public sector in the housing market by anticipating change, regulating appropriately, and engaging networks of development and community actors.

\subsection{Inclusive, equitable development}

Portland Plan: All Portlanders have access to a high-quality education, living wage jobs, safe neighborhoods, basic services, a healthy natural environment, efficient public transit, parks and greens paces, decent housing and healthy food....

The benefits of growth and change are equitably shared across our communities. No one community is overly burdened by the region's growth (18).



The Portland Plan, among other guiding documents, sets forth a vision for the city of livability and equity. The vision of "complete neighborhoods" includes not only economic prosperity and a healthy built environment, but access to opportunity through affordable housing.

This vision should be an overarching guide for policy-making across planning, housing, economic development, and infrastructure. A paradigm of inclusive, equitable development is a critical concept for moving forward this vision while addressing how neighborhood change can negatively impact some communities. The definition developed by Kennedy and Leonard (2001) is useful:

We define equitable development as the creation and maintenance of economically and socially diverse communities that are stable over the long term, through means that generate a minimum of transition costs that fall unfairly on lower income residents

This vision recognizes that the city is healthier with mixed-income and racially/ethnically diverse neighborhoods than neighborhoods with growing status gaps, with concentrated poverty and racial segregation in some parts of the city. Economic development aims to revitalize neighborhoods that need more activity, but with a vision of a prosperous neighborhood economy that includes diversity in businesses, owners, and customers. 
In order to realize this vision, neighborhood change needs to be addressed to ensure that benefits are shared and burdens are not disproportionate, particularly for disadvantaged and underrepresented groups. The vision asks that private development provide positive and equitable community impacts, especially when occurs in neighborhoods susceptible to gentrification, and/or it uses public resources, requires infrastructure services, or seeks special permissions in the land use regulatory system.

\subsubsection{Racial/ethnic equity lens supports the approach}

The Portland Plan also activates a racial/ethnic justice initiative for the City that is relevant to the gentrification and displacement policy strategy. A racial/ethnic justice lens helps analysis both at the strategic scale and in program development.

The racial/ethnic equity lens justifies a focus on gentrification and displacement as critical to achieving equity, including the goals of fair housing, because of the historic and current impact of neighborhood change for communities of color. Housing and commercial displacement can affect lower-income residents of any race, but there are particular concerns in addressing gentrification with respect to communities of color.

Historically, racial segregation and disinvestment have been coupled, leaving neighborhoods of communities of color more vulnerable to market pressures. When residents of color are displaced, they have fewer choices in the housing market due to lower incomes, more limited access to mortgage credit, and discrimination. Similar barriers to minority business ownership and development -limited access to credit to start and expand businesses, lack of intergenerational history of business ownership_affect the ability to avoid commercial displacement. Recognizing these specific challenges can help to craft policies that improve racial equity.

Portland Plan: We will....

- Initiate a racial and ethnic focus, using well-documented disparities.

- Build the skills, capacity, and technical expertise to address institutionalized racism and practice and intercultural competencies.

- Engage diverse constituencies to discuss race, disparities and public services.

- Actively work to eliminate racial and ethnic disparities in public agency hiring, retention and contracting (22).

The racial/ethnic equity lens also helps to develop anti-displacement policy and programs that reduce disparities. It is important to use a racial/ethnic lens with policies and programs for revitalization, even those attempting to be equitable in terms of benefits and burdens. It is important to utilize data disaggregated by race/ethnicity to target programs: for example, if 
communities of color have lower incomes than whites, housing affordability at a "workforce" income level may not assist families of color. There would need to be additional set-asides for very and extremely low income families.

Even well-intentioned policies can exacerbate inequities without a racial/ethnic justice lens. For example, ending mortgage redlining in a predominantly black neighborhood can result in new homebuyers, but without specific supports for African-Americans, the residents who experienced deprivation of access may not benefit. Given the racial wealth and credit gap, the infusion of capital goes to those immediately prepared to purchase a home -predominantly white households - and has the effect of substantially increasing white homeownership and increasing the racial homeownership gap.

\subsection{The public sector role in gentrification}

\subsubsection{Public sector planners as market actors}

Housing is almost exclusively produced by the private sector, with only limited direct production/management by the public sector. The monetary resources available to the public sector for subsidizing housing for low-income households are very limited. However, planners and policy-makers are part of the housing market. Although the public sector has only limited direct contribution to the housing stock, it does affect the housing market through the creation of general and specialized plans; through regulation of development; and with incentives. ${ }^{2}$ In order to understand how gentrification relates to public policy and investments, it is important to understand the market ramifications of public sector actions. Neighborhood change and community displacement aren't due to "just the market" acting on its own, but occur within a context set in part by plans and policies-especially within areas designated for special public investment, such as urban renewal areas.

Understanding the role in the market also opens new opportunities for actively engaging with the problem of gentrification by anticipating and mitigating its effects. When planners and policymakers use this role, they can make plans and regulations that work towards the goal of inclusive, equitable development. Incentives and subsidies can be aligned to meet antidisplacement goals. Planners can also work to build the capacity of other market actorsnamely, developers and community members - to participate together in creating places that meet the vision of inclusive, equitable development.

\footnotetext{
${ }^{2}$ Tiesdell and Allmendinger $(2005,63)$ describe four functions of planning in the housing market: market shaping, through plans that communicate information about future development; regulating with land use and environmental controls; stimulating some kinds of development activity with subsidies and incentives; and building capacity by developing public-private partnerships or creating networks among actors.
} 


\subsubsection{Gentrification and displacement as a consequence of public sector activity}

Understanding how public investments can cause or deepen gentrification pressures is important. Public investments are often made in order to improve living conditions for residents through housing rehab/restoration, economic development, and improvements to infrastructure services-but there can be unintended effects for vulnerable groups. The intention of policies and investments is as important as understanding the potential consequences; these consequences include losing the trust of communities negatively affected by housing market changes.

Public investments - sometimes even just the announcement of a planned investmentincrease the investment potential of a neighborhood. When a City signals its commitment to place-making in a particular neighborhood through improvements to the built environment and development incentives, it decreases the risk of investment. The private market will respond by making capital available and increasing development activities. Additionally, as the public sector improves neighborhood access, infrastructure, and amenities, the neighborhood becomes more desirable and demand to live there by higher-income households increases. When public investments are made in neighborhoods where markets are already heating up, it can increase the intensity of the change and exacerbate displacement.

Some public investments are not large-scale enough to "tip" a neighborhood into gentrification or reduce affordable housing, but nonetheless create conflicts and potentially inequitable outcomes. In these cases, decision processes and public input are made more complicated by the context of gentrification. If public investment decisions respond to new residents' needs, but not long-time residents' needs, it can reinforce inequities. For instance, as new bicycle lane infrastructure was considered on the North Williams corridor in the historic Albina District, longtime residents argued that their requests for safer pedestrian crossings had been ignored. With choices to be made about promoting active transportation, given the racial demographics of walkers and cyclists, a bicycle-only improvement would disproportionately benefit white residents. The scenario was described in the Partnership for Racial Equity (PRE) Racial Equity Strategy Guide $^{3}$ as a missed opportunity for understanding the differential racial impact of a planned upgrade to infrastructure.

As neighborhoods change, different priorities may emerge from new residents-and in typical public input processes, higher-income, home owning residents are more likely to make their voices heard. This may be particularly the case when new demands align with other agency goals and/or with dominant culture lifestyles familiar to staff and voiced by new residents, while long-term residents' demands have been unheard or do not easily align with existing programs and goals. Conflicts can arise among neighbors.

\footnotetext{
${ }^{3}$ The Partnership for Racial Equity, convened by the Urban League of Portland, worked with City staff to develop a strategy guide for implementing a racial equity lens on policymaking. This guide describes how to develop an equity lens for policymaking, provides examples of model equity work, and refers to available technical assistance within the City of Portland.
} 
Furthermore, as neighborhoods become more attractive to higher-income households' lifestyles (due to amenities, economic activities, cultural shifts), there may be further population turnover. Considering gentrification pressures by using neighborhood change analysis tools (i.e. the typology in section 3) along with using equity analysis tools such as the PRE Racial Equity Strategy Guide can help to avoid conflict in public processes. This strategy can actively work to identify and prioritize the needs of historically underserved communities, promote the participation in decision-making by vulnerable residents of a neighborhood, and to mitigate unintended consequences for those people who may be vulnerable to displacement.

Finally, the revitalization and investment activities that change one neighborhood have broader impacts throughout the housing market. When planners act in one area, they are not only affecting that neighborhood, but other nearby and similar areas as well. Watkins $(2008,168)$ writes, "clearly, it is difficult to effectively and strategically target resources at neighborhood or sub-regional levels without a sound understanding of spatial linkages between localities and likely spillover effects." In the case of understanding the history of gentrification in Portland, we could point to the concomitant increase in housing prices and exodus of lower-income AfricanAmericans from inner Northeast Portland and the more concentrated poverty and racial isolation in outer East Portland. Failing to mitigate displacement from the Albina District has created a range of issues in mid-County neighborhoods, including crowding in schools and overburdened infrastructure. Understanding how neighborhoods might be linked in conditions of market change is useful for considering a broader strategy for neighborhood stabilization.

By actively taking on board a sense of itself as a market actor, the City of Portland does take some responsibility for the changes that have negatively affected communities. It says that a lack of planning for gentrification and limited responsiveness to market changes have been part of how displacement happened. In the Portland Plan, it is acknowledged that neighborhood changes have multiple negative impacts:

The critique of our past policies indicates that actions for neighborhood improvement were not paired with actions to address the likelihood of economic and racial displacement. Gentrification and displacement, whether the result of large infrastructure investments or the cumulative effect of smaller investments, have disrupted communities and resulted in serious questions about the motivations behind government investments in Portland. Portland Plan,70

But, embracing the role of a market actor also means the City of Portland can develop strategies that allow it to shape and guide change for more equitable outcomes. This approach helps to meet Portland Plan action item.

Portland Plan action:

Equity in neighborhood change: Use neighborhood planning and development programs to help minority and low-income people stay in their homes and neighborhoods (63). 


\subsection{A market-conscious approach to gentrification}

Gentrification and displacement can come about as unintended consequences. It requires intentional action to avoid these kinds of changes and implement a strategy for equitable development of livable, complete neighborhoods. This strategy includes:

1. Careful planning including anticipating market change, setting goals, and monitoring.

2. The creation of incentives that leverage public subsidy to achieve goals.

3. Capacity building among partners for participation in anti-displacement work.

This section provides an overview of these functions. Subsequent sections of this report detail the analysis that could be used for planning and monitoring and lay out a set of policies, including incentives and capacity-building programs, that could be employed in a gentrification strategy.

\subsubsection{Anticipating housing demand and market change}

The state of housing in the city is easy to assess and map relative to other activities. The housing stock is mostly durable, with only a fraction of housing provided by new construction. Data are available on the kinds of households served by the current housing stock and monitor housing across different types, tenures, sizes, and prices. The City has taken these analyses further to employ an opportunity mapping concept that considers the location of housing (especially affordable housing) with respect to economic opportunities, accessibility, healthy environment, and other public services.

The basic housing demand that arises from shelter needs is fairly predictable. Planners can provide demographic projections of household growth, which predict future needs for housing, especially if combined with preference studies as in Myers and Gearin (2001) and Myers and Ryu (2007), who anticipate changes over twenty years. Projections are useful indicators of how current trends may play out in the future. Portland Metroscope provides market segments analysis (although not analyzed for racial/ethnic population differences) that can help with considering needs for housing at different income levels, tenures, and unit types/sizes. These kinds of analyses are found in the City of Portland's background report Housing: Updates on Key Housing Supply and Affordability Trends.

Neighborhood housing markets change. When neighborhoods are targeted for revitalization, upgrading, and investments, it is not surprising that the private market responds. The changes to neighborhood housing markets that lead to the displacement of lower-income residents are not and should not be unpredictable (particularly not when increased market activity by higherincome households and consumers is an express goal of the development/redevelopment). Public sector actors must anticipate the speed and intensity with which the private market can turn-private market actors can act quickly to acquire and develop, to buy and sell properties, 
and to respond to new demand. Failing to anticipate these changes means missing opportunities to prevent the harms of displacement. It is far easier to avoid the harmful effects of these changes than to mitigate them once they are underway; and far easier to mitigate them at an early stage than to shoehorn in solutions later in the process.

Understanding change and dynamics can help to match appropriate tools with neighborhood conditions-whether gentrification is anticipated, or whether population and market changes show it is already well underway. When neighborhoods are understood to be potential areas of revitalization or new investment, there should be analysis of the potential impacts on the housing market. The City could include areas experiencing gentrification as a variable in growth scenarios models. If population growth and development are focused on areas already experiencing housing market pressures, planners could consider how these might create further displacement and population shifts in order to develop responses.

Portland Plan

Housing strategy: Develop and implement a Citywide Housing Strategy for all levels of housing. This should include an estimate of housing needs, strategies to create new rental and home ownership opportunities in "high opportunity" areas - those that already have infrastructure to support household success, such as quality active transportation, high-performing schools, commercial centers and recreation facilities. Address resource development, equity initiatives such as increased use of minority contractors, and alignment with other community services for low- and moderate-income residents (63).

\subsubsection{Plan: Set goals and monitor continuously}

Demographic projections can tell what population changes are likely to occur given current trends. However, projections do not and should not set policy. The continuation of a trend may result in further inequity, shortages of some types of housing, jobs-housing spatial mismatch, or other undesirable outcomes. Planners and other decision-makers need to consider goals for providing housing of different types, prices, and in different locations in response to projected demand and likely unmet needs. For this reason, planners need to think strategically about how current changes will accumulate along with the current housing stock to reach the goals for housing availability.

Housing strategies can recognize market and population changes by monitoring and continuously updating analysis on the status of neighborhoods, the need to deploy different policy tools and practices, and to build new partnerships with community-based organizations or development sector actors. If a neighborhood begins to experience accelerated housing displacement, additional programs could be directed that match with the new stage of 
gentrification. For instance, the priorities for development proposals in an RFP for public funds or land could be updated to match with housing needs for particular unit types, sizes, affordable level, and tenure. In order to make these strategic shifts, it is necessary to assess housing market activity fairly frequently by analyzing patterns of sales, development permits, and commercial activity.

Portland Plan:

Tracking and Program Evaluation

- Develop approaches to track neighborhood change including race, ethnicity, age, disability, ownership and other factors.

- Develop analysis methods to help anticipate potential gentrification impacts of new policies and programs.

- Evaluate City investments and actions using the Framework for Equity (19).

\subsubsection{Regulate and incentivize}

Regulation is the traditional tool of planning to intervene in the housing market. Strategic use of regulations and incentives can help to leverage limited housing resources. In many cities, a lack of affordable housing is related to land use regulation; but many of the most common regulatory barriers to lower cost housing development have already been eliminated in Portland. Oregon is also nearly unique in prohibiting the use of mandatory inclusionary zoning, a common best practice for requiring the construction of new affordable units. However, the City could explore ways to more effectively incentivize not only affordable housing development, but a broader set of anti-displacement tools like workforce agreements. Rather than being stymied by the loss of one tool (IZ), the broader approach of community benefits in development policy can include many practices linked to the regulatory system.

The kinds of planning and policy tools that are available and most effective depend on the neighborhood market context and the stage of gentrification, as well as the focus of the effort. Therefore, the best practices toolkit is organized into the key stages identified here as well as to specific policy areas. Anti-displacement practices can be implemented alongside of public investments in all areas-from comprehensive neighborhood economic development programs to infrastructure upgrades to planting trees. Development that includes public subsidy should be linked to community benefits appropriate to the neighborhood.

\subsubsection{Capacity building among partners}

As the City works to develop appropriate strategies and policies for addressing gentrification, it must recognize its fellow actors in the market: community residents and private sector 
development entities. Public agencies may need to develop the capacity of both residents and developers to participate in the inclusive, equitable development framework.

Community member capacity. Residents of changing neighborhoods-particularly those from traditionally underserved and underrepresented groups-may find it very difficult to participate in planning processes. Part of an anti-displacement strategy is to empower residents and enables them to stay in place if they so choose. The principles espoused in the City's Public Involvement Advisory Committee's work include "increasing public understanding of and support for public policies and programs" and a focus on engaging the diversity of the community. There may need to be additional programming for residents to learn about the development and planning process and how to participate to put forth community priorities. The City already has a number of community leadership capacity programs that could attend to these issues. As the City asks communities to participate in equity discussions about planning and infrastructure investment, as well as community and economic development, there may be a need for additional technical assistance.

\section{Portland Plan:}

- Build capacity for people to participate. Ensure broad inclusion in decision-making and service level negotiations.

- Leadership training. Expand community-based leadership training programs to build community organizing capacity and the capacity for people to engage in shared governance, focusing on under-represented and underserved communities (20).

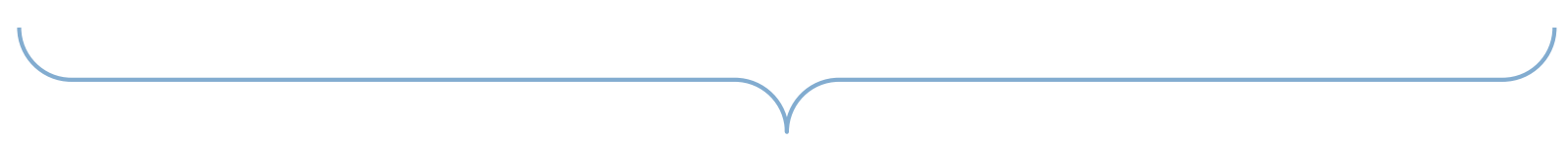

Development sector capacity. In discussing how gentrification happens, this analysis focuses on market activity and quantitative data showing trends. However, the development sector is not only driven by pure economics-developing land and property is also a social and political process. Private sector actors - developers, financers, agents, and builders, among othersproduce a culture with norms, and standard operating procedures; they share information and consider ideas within a network of relationships. ${ }^{4}$ The development industry sometimes moves slowly to work with new models and requires "proof of concept" before adopting a new practice. An example with immediate local resonance is the construction of apartment buildings without

\footnotetext{
${ }^{4}$ Patsy Healey's work (Healey 1991, Healey and Barrett 1990) tries to describe these cultures, detailing the interactions, reactions, and relationships in the redevelopment industry, and how the public sector could influence their thinking. Guy and Henneberry conclude that we can come to understand a housing market that is "dynamic, deeply contextual and contingent on the particular aims and objectives of development actors" $(2000,2413)$.
} 
providing parking, which was difficult to finance (even when allowed by-right in zoning code) until a project was successful.

As planners try to influence private market actors, it is important to understand these cultures: What prompts developers to adopt new models or technologies? What incentives might be meaningful for getting developers to serve particular public aims? Some development actors are interested in moving into new niches, such as green building or mixed-use development, both of which are now relatively common in Portland; are there also developers who are ready to take on mixed-income or affordable housing? The networking and capacity building function of planners could incorporate activities like design fairs, demonstration projects, and competitions to provoke interest in affordable and mixed-income housing. It may also be that local development actors need technical assistance with programs like the Low-Income Housing Tax Credit and layered financing for affordable housing, which could be supported through partnerships and education. As the City attempts to influence the development sector towards meeting public goals, it needs to understand how private market actors are making decisions and how best to build new practices through a mix of regulation, incentive, and cultural shift.

\subsection{Conclusion: a coordinated approach for roles across institutions}

Extending upon the definition of gentrification as a process of neighborhood housing market change, this section suggests an approach that is market-conscious. With a vision for inclusive, equitable development, and the use of a racial/ethnic equity lens, the City can better plan, regulate, and engage with community members and development actors to mitigate gentrification. Specific functions might be distributed in different ways as determined by bureaus to best match their spheres of activity. In order to address the range of factors related to gentrification and the policies and investments that respond to it, it would be most effective to:

- Coordinate bureau roles,

- Analyze how land use and growth relate in a housing strategy,

- Monitor neighborhood change, and

- Create subsidy and incentive programs that maximize public resources.

The PDC's work on the Neighborhood Prosperity Initiative could connect to neighborhood change and resident economic empowerment; the agency also could contribute to monitoring neighborhoods for shifts in the market. Infrastructure bureaus need also be aware of the potential for projects and investments to cause or react to neighborhood demographic change. 


\section{Neighborhood typology analysis for gentrification and displacement risk}

\subsection{Introduction}

One goal in developing a gentrification policy is to analyze how neighborhoods in Portland are changing, and to anticipate potential changes that may lead to displacement. Of course, this analysis is not absolutely predictive, but by assessing past neighborhood changes and current conditions, we can develop a metric for starting the policy analysis.

The gentrification and displacement risk assessment map focuses on a first pass look at a relatively small set of data to assess housing market and demographic changes to understand if a neighborhood is currently undergoing or is susceptible to gentrification. It results in a fairly clear typology of neighborhoods: long-term high-income/high-cost, dynamic areas that are gentrified or gentrifying, at-risk for gentrification, and long-term low-income/low-cost. Public sector actors can use this map to understand the context of the neighborhoods in which they are working. This analysis does not attempt to track household moves from neighborhood to neighborhood. Rather, neighborhoods are assessed based on aggregate status shifts: housing tenure and price changes; and income level, educational attainment, and racial/ethnic population changes. Therefore, this typology should be monitored with data sources that are more frequently updated, in order to assess market conditions that may 'heat up' rapidly.

\subsection{Purpose and concept for neighborhood change analysis}

Changes in neighborhood character associated with gentrification include demographic and socioeconomic changes as well as changes to the housing market. The neighborhood typology map identifies census tracts currently experiencing or at-risk for gentrification based on residents' vulnerability to displacement, recent demographic change, and housing market conditions. Public agencies may use this tool to understand gentrification and displacement risk for communities in which they are working.

The map assigns each tract one of six typologies referring to a stage of neighborhood change. Appropriate strategies to mitigate displacement and other adverse impacts of gentrification will depend on the stage as well as other neighborhood-specific considerations, which can be identified through a more detailed data drilldown. The vulnerability, demographic change, and housing market designations used to create the neighborhood typologies attempt to capture the complex array of conditions that both fuel and are a product of gentrification.

This assessment follows the method developed by Lance Freeman in his 2005 Urban Affairs Review paper, "Displacement or Succession? Residential Mobility in Gentrifying Neighborhoods," and has been used in several analyses since then, proving to be robust. Gentrified neighborhoods are defined by Freeman as those with a greater than average increase in educational attainment and house prices from a starting point of below average incomes and housing stock, and a change in racial demography due to white homebuyers, measured using Home Mortgage Disclosure Act (HMDA) data. Additional approaches include the Urban Institute's analysis of Washington, DC, which incorporates architecture, high capacity 
transit access, and adjacency to high-priced areas ${ }^{5}$; and the Center for Community Innovation's reporting of gentrification related to BART expansion in the Bay Area, which focused on amenities and transit ${ }^{6}$. This typology does not incorporate location and accessibility features into the initial analysis, but recommends using those features as part of a drilldown analysis to understand additional dimensions of gentrification for a specific area.

The neighborhood typology criteria incorporates a conceptual definition of gentrification through a set of robust yet select indicators. The typology establishes appropriate distinctions between neighborhood stages that may elicit different actions. The indicators and typology have been reviewed by staff from BPS, PDC, and PHB and participants in Policy Expert Groups for Portland's Comprehensive Plan Update

The typology uses relatively few indicators to create meaningful distinctions among susceptibility to and experience of gentrification. In acting in these neighborhoods, it is important to develop more detailed profiles to consider process and tools for promoting positive developments and mitigating harms. The drill-down look at neighborhoods would include as relevant: demographic profile to account for underrepresentation in planning processes; more detailed assessment of housing vulnerability; and analysis of commercial activity and ownership.

It is also important to develop a process of updating the typology by tracking market and population data to anticipate and respond to neighborhood changes. Gentrification is not a static condition. In an analysis like the "pattern areas" urban form typology that is based on the built environment, neighborhoods are unlikely to change their status. ${ }^{7}$ In the case of gentrification analysis, neighborhood housing markets and demographics are continually changing. The definition of the typology as six stages of gentrification and displacement is fixed in terms of the concepts and variables measured, but it is dynamic in two ways. First, it is based on a neighborhood's status relative to citywide conditions, and as the city changes as a whole, the thresholds for "high" or "low" changes will change. Second, and more importantly, the labeling of a given neighborhood within the typology may change as its conditions evolve.

Due to the nature of the data sources used in the typology, this baseline map can only be updated as significant data emerge from the Census Bureau. With an assessment based on market changes reported in Census/ACS data, this is likely a five-year exercise. However, for the implementation of policy, it will be important to know if, for example, a neighborhood has shifted to a more intense stage of displacement due to market pressures; the timeline for such a change is likely to be much less than five years. In addition, frequently updated data should be tracked to indicate neighborhood changes for ongoing policy evaluation and to assess whether

\footnotetext{
${ }^{5}$ In their presentation Leading Indicators of Gentrification in D.C. Neighborhoods, Margery Austin Turner and Christopher Snow identify areas where rapid reinvestment is most likely.

${ }^{6}$ Mapping Susceptibility to Gentrification: The Early Warning Toolkit identifies 19 factors associated with gentrification in the 1990s and considers how these factors can be used to predict future gentrification.

${ }^{7}$ The pattern areas analysis of urban form considers natural and built features to describe five types of development patterns. The analysis allows for policy development that "respects the differences in culture, history, and the environment" among the distinct neighborhood types.
} 
any new neighborhoods are emerging as high risk for displacement, needing new kinds of policy attention.

\subsection{Operationalizing the conceptual definition:}

Gentrification occurs when a neighborhood has been under-valued in the market relative to its potential, and market actors and higher-income households recognize its desirability. Increased potential can be signaled by public sector investment and development incentives. As new households enter the neighborhood housing market, vulnerable lower-income residents are displaced due to the loss of affordable housing. An operational definition should capture both market trends and population changes. Areas are compared to citywide average levels and designated into types based on high levels of different combinations of market and population conditions.

\subsubsection{Vulnerability to housing displacement}

Tracts designated as vulnerable have higher-than-average populations with characteristics that make resisting displacement more difficult: they are renters rather than homeowners, belong to communities of color, lack college degrees, and have lower incomes. These socioeconomic factors suggest displacement risk largely because they signal a reduced ability to withstand housing price increases caused by gentrification. Additionally, neighborhoods with large populations of at-risk residents are more likely to be areas of long-term disinvestmentprecisely the places that are often targeted by young people on the leading edge of gentrification.

\subsubsection{Demographic changes}

Gentrification-related demographic change includes increases in white residents, homeowners, college-educated residents, and household incomes over the last decade. These factors indicate that gentrification and displacement have occurred or are occurring by signaling an influx of more affluent, better educated residents that increases demand for housing, particularly owner-occupied homes. The result is an increase in housing prices that often displaces existing residents, leading to even more changes in neighborhood character. In short, these demographic change indicators likely capture both the in-migration of "gentrifiers" and the outmigration of longtime residents.

\subsubsection{Housing market appreciation}

Lastly, longitudinal housing market indicators can identify housing price changes that accompany gentrification and displacement. The housing market designations used to create the neighborhood typology map take into account both median home values (relative to the citywide median) and appreciation rates for owner-occupied units. While increasing values in already high-value neighborhoods may be considered a type of neighborhood change, it is not the type generally associated with gentrification. As such, the housing market designations are based on the assumption that gentrifying neighborhoods experience high appreciation starting from low or moderate home values at the beginning of the period under consideration. The categorization of low, moderate, or high is based on how an individual tract compares to the 
citywide average for that characteristic. We identified three gentrification related housing market typologies:

Adjacent tracts:

- Had a low or moderate 2010 value

- Experienced low or moderate 2000-2010 appreciation

- Touch the boundary of at least one tract with a high 2010 value and/or high 2000-2010 appreciation

Accelerating tracts:

- Had a low or moderate 2010 value

- Experienced high 2000-2010 appreciation

Appreciated tracts:

- Had a low or moderate 1990 value

- Had a high 2010 value

- Experienced high 1990-2010 appreciation

The adjacent typology attempts to capture the spillover effects of gentrification, whereby neighborhoods next to gentrifying areas are at-risk of gentrifying as housing pressures and commercial investment expand outward. The accelerating and accelerated typologies capture housing market changes associated with gentrifying and gentrified neighborhoods, respectively.

\subsection{Neighborhood typology: six stages of change}

Using ArcGIS and publicly available data, we assigned six neighborhood types—representing different stages of gentrification-using various combinations of vulnerability, demographic change, and housing market designations. (see Table 1 and Appendix A for details) Additional components are added as an overlay: accessibility (measured in the 20-minute neighborhood analysis to include sidewalks, street connectivity, and transit service) and public investment areas (geographically designated such as URAs, EcoDistricts, transit station areas, and Main Street/NPI zones). The typology uses six categories to capture dimensions of gentrification; but these can be collapsed into three major categories for the purpose of policy implementation: Early, Mid, and Late.

Three neighborhood types are Early: tracts that are at-risk or showing early signs of gentrification.

Susceptible tracts are near high-value and/or high-appreciation tracts, but still have low or moderate home values and appreciation rates. They have vulnerable populations and are not yet experiencing demographic change indicative of gentrification.

Early: Type 1 tracts experienced high appreciation rates over the last decade, but still have low or moderate home values. Their populations are vulnerable but no gentrification-related demographic change has occurred. 
Early: Type 2 tracts are near high-value and/or high-appreciation tracts but still have low or moderate home values and appreciation rates. They have vulnerable populations and have experienced demographic change indicative of gentrification.

These neighborhoods represent the best opportunities for an early and comprehensive antidisplacement strategy that includes planning for inclusive development, including affordable housing preservation and development opportunities.

The risk of displacement in these areas may be increased by a desirable location with respect to accessibility and amenities_for example, near a planned light rail extension or another "hot" neighborhood destination. Risk is also increased by designation as a public investment area, such as an Urban Renewal Area, EcoDistrict, Neighborhood Prosperity Initiative or Main Street-but these designations also can provide resources and capacity for planning and antidisplacement tools.

In these types of neighborhoods, it is important to track the housing market to observe whether market pressures are building quickly or "tipping" is occurring (rapid changes to neighborhood housing market). These areas require a balance between revitalization aims and antidisplacement tools, and processes for neighborhood planning may involve some conflict between these goals and groups in the neighborhood.

The fourth type represents Mid- current and ongoing significant gentrification pressures.

Dynamic tracts experienced high appreciation rates over the last decade but still have low or moderate home values. They exhibit demographic change indicative of displacement but still have vulnerable populations.

In dynamic areas, there is the opportunity for mitigating displacement, even though the loss of affordable housing may be acute, through targeted housing and economic development.

The typology finally identifies two neighborhood types that are in Late stages of gentrification, when the housing market is currently high value, but there is still potential for further loss of affordable housing.

Late tracts had low or moderate median home values in 1990, but experienced high appreciation over the last two decades and are now high-value tracts. They have experienced gentrification-related demographic change, but still have populations that are vulnerable.

Continued loss tracts are also high-value areas that experienced high appreciation over the last two decades starting from low or moderate 1990 values. They no longer have above-average levels of vulnerable populations, but exhibited high levels of demographic change over the previous period, and remaining vulnerable households may be in a precarious situation.

In these neighborhoods, strategies for creating new affordable housing and preserving any existing affordable housing are important to maintain access to opportunity. 
Table 1 summarizes the different combinations of tract-level vulnerability, demographic change, and housing market designations represented by the six neighborhood typologies. Map 1:

Neighborhood Typology shows these neighborhoods.

Table 1: Tract-level neighborhood typology representing different stages of gentrification

\begin{tabular}{|l|l|l|l|}
\hline $\begin{array}{l}\text { Neighborhood } \\
\text { Type }\end{array}$ & $\begin{array}{l}\text { Vulnerable } \\
\text { population? }\end{array}$ & $\begin{array}{l}\text { Demographic } \\
\text { change? }\end{array}$ & $\begin{array}{l}\text { Housing market } \\
\text { condition }\end{array}$ \\
\hline Susceptible & Yes & No & Adjacent \\
\hline Early: Type 1 & Yes & No & Accelerating \\
\hline Early: Type 2 & Yes & Yes & Adjacent \\
\hline Dynamic & Yes & Yes & Accelerating \\
\hline Late & Yes & Yes & Appreciated \\
\hline Continued Loss & No & $\begin{array}{l}\text { Has \% white and \% } \\
\text { with BA increasing }\end{array}$ & Appreciated \\
\hline
\end{tabular}

In Map 1: Neighborhood Typology, the neighborhood typology method is applied to Portland Census tracts. The map highlights the early, mid, and late stages of change in neighborhood demographics and housing markets. 


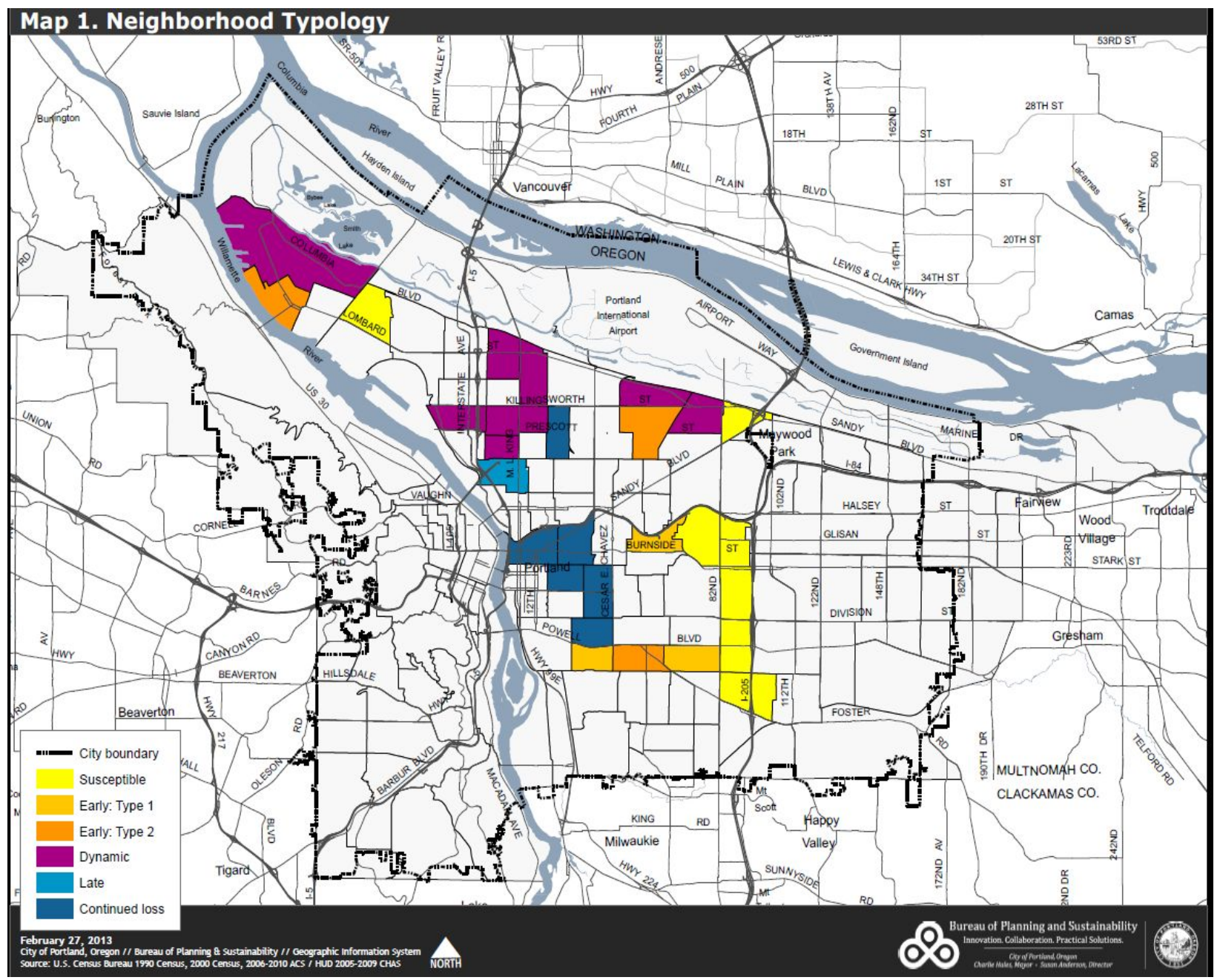

When assessing the likelihood for further neighborhood changes, there are two additional dimensions that add to the analysis, corresponding with the supply and demand side drivers of gentrification. Neighborhoods with upward trending housing markets that are part of current or planned public investment areas are likely to face additional market pressures.

Map 2: Neighborhood Typology with Public Investment Areas adds an overlay of current and planned public investment areas: planned and under construction light rail and streetcar stops, Main Streets, Neighborhood Prosperity Initiative districts, Urban Renewal Areas, and EcoDistricts. Neighborhoods that are at-risk for gentrification that are in these zones should be monitored carefully, as the signaling of public investment and the investments themselves can cause upswings in the housing market. 


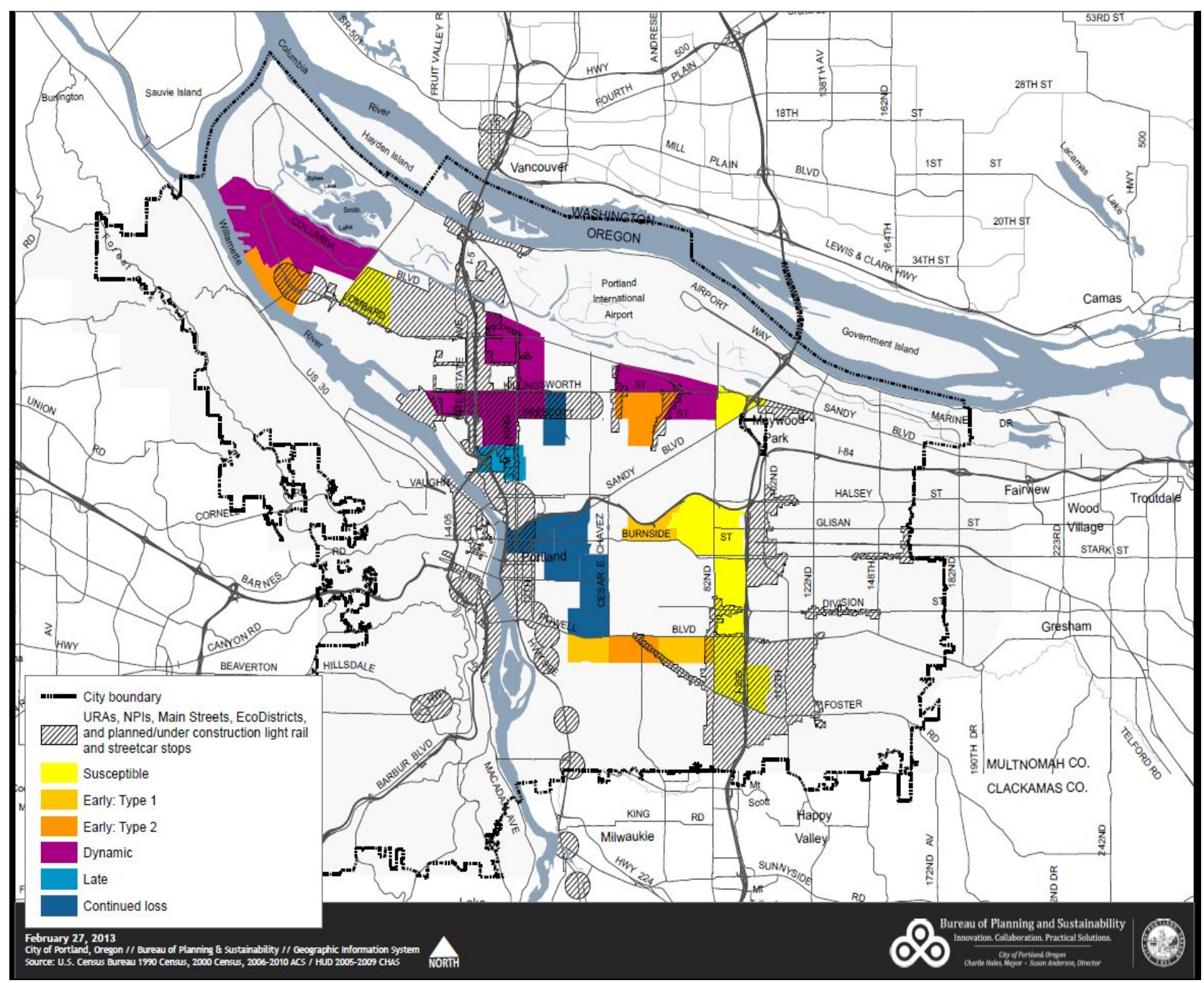

Housing demand is likely to be greater in neighborhoods that are already highly accessible and near to amenities. The existing "20-minute neighborhood" analysis conducted by BPS is used to depict neighborhood walkability and access to destinations that meet daily needs. ${ }^{8}$ Map 3: 20Minute Neighborhood Map with Neighborhood Typology combines the current "20-Minute Neighborhood" accessibility scores with areas identified by the gentrification typology depicted in cross-hatch. The neighborhoods with higher "20-minute" scores are more likely to be desirable to households with the resources to out-bid vulnerable residents in the housing market.

\footnotetext{
${ }^{8}$ The "20-minute neighborhood" considers street connectivity and transit as well as the availability of destinations including grocery stores, dining/beverage establishments, parks, and elementary schools to develop a score for nonauto access to daily needs.
} 
Map 3. 20-Minute Neighborhood Map with Neighborhood Typology

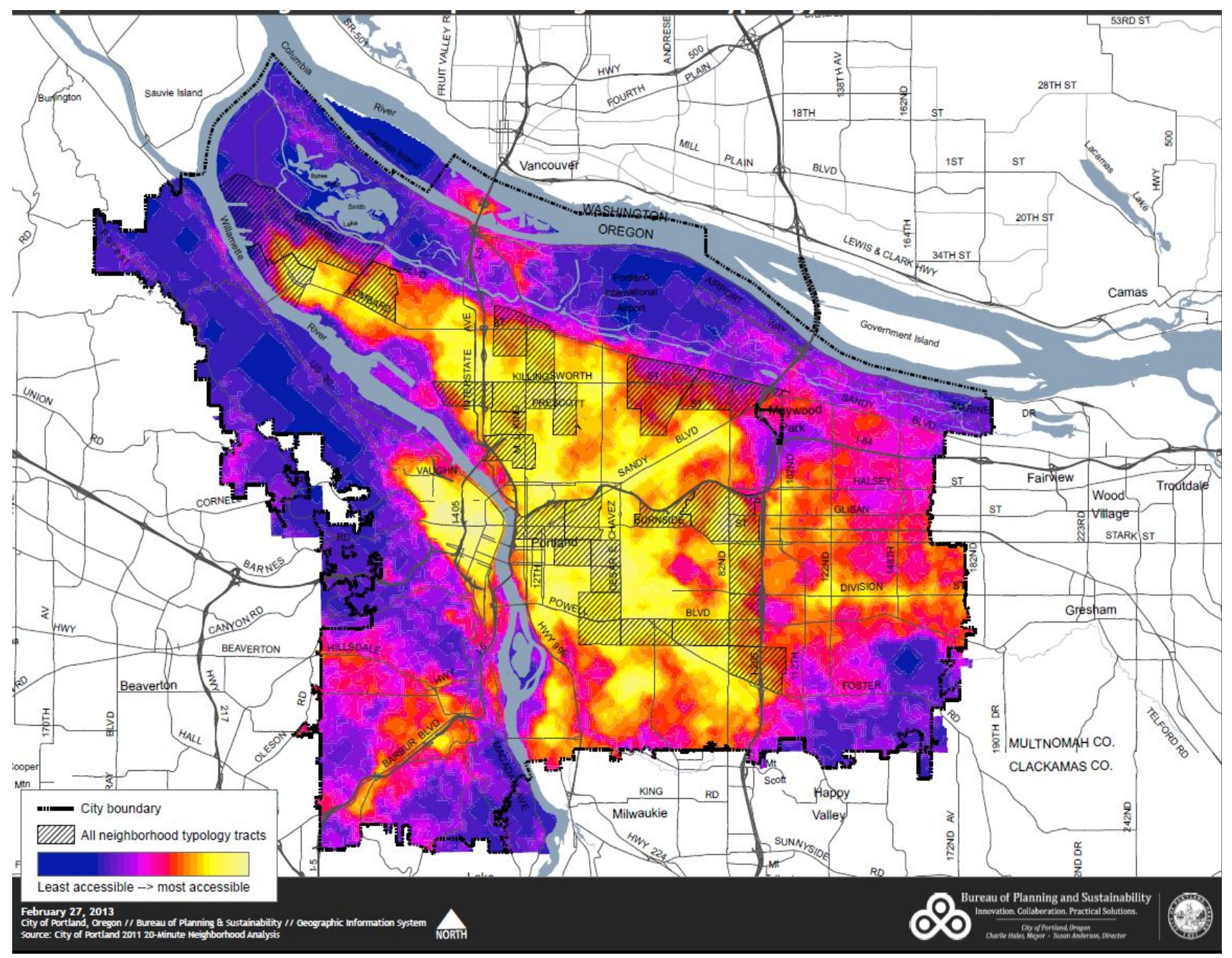

Neighborhoods that do not appear in the gentrification/displacement risk map are those that do not meet the thresholds for "high" incidence of each factor. Many of these neighborhoods are persistently high income and high housing value areas or persistently low income and low housing value areas. Persistently high income and high housing value areas (along with Continuing loss areas) are areas where it may be desirable, although financially difficult, to increase affordable housing availability. These areas are incorporated in the larger policy conversation about opportunity neighborhoods and the location of affordable housing investments. The neighborhoods with persistently low income and low housing value over this time period are not at-risk for gentrification, but are affected by displacement as likely destinations for low-income households. Care is needed to ensure that these areas receive adequate services and infrastructure, and neighborhood revitalization can proceed with less concern about rapid neighborhood change. Other neighborhoods may be just beyond the citywide threshold cutoff points for appearing—but still need some attention through tracking 
market and demographic changes, particularly in areas where the housing market is on the rise. $^{9}$

\subsection{Ongoing analysis: monitoring and tracking}

The baseline typology map is somewhat static due to data availability limitations; there should be ongoing assessment to track market and demographic changes. Implementation of an antidisplacement or gentrification management strategy has to be keyed to the stage of gentrification in a neighborhood, and requires frequent data tracking to evaluate the situation and notice if market changes are occurring more quickly or intensively than anticipated. General market monitoring is important for understanding the citywide picture of neighborhood change.

As the typology data can only be updated infrequently, the gentrification policy strategy needs additional data sources for ongoing monitoring of housing market conditions. In areas where gentrification is likely or ongoing (and particularly if there are significant public investment strategies ongoing), there should be frequent updates to gauge market responses. Sales data, Home Mortgage Disclosure Act (HMDA) data, and permitting data are more frequently updated than Census/ACS and can also reveal housing market activity that is indicative of changing demographics.

Citywide housing market trends can be updated quarterly using data aggregated from available sources. Quarterly updating is focused on City bureau sources and free/public information already tracked by industry groups. Homebuyer data (HMDA) are available annually at no cost and can be added to a year-end reporting. Investing in this kind of ongoing analysis of the housing market will help planners and housing policy-makers to better understand the context in which they work; and to consider market repercussions of investment decisions.

The following set of indicators should be tracked to serve as warning signals of neighborhood change to light up 'hot spots' (including those not anticipated by this analysis). New market activity such as higher-priced sales and conversions of rental to owner-occupancy, homebuyers of higher income or who are white, and new commercial activities are signals of a change in demand for the neighborhood. These signs of gentrification and housing displacement should be monitored especially closely in high-risk areas.

Home sales: County assessor's data on recorded home sales (address, updated continuously)

- Velocity of sales is increasing - percentage of single family homes selling per quarter

- Value increasing- price per square foot and total sales price compared to previous periods

New development and rehabilitation: BDS permits (address, ongoing)

- New construction of residential or commercial properties indicate private market investment interest

\footnotetext{
${ }^{9}$ Through dialogue with PDC and PHB and presentations at comprehensive plan PEGs, some neighborhoods identified as potentially of concern, but not in the typology were Woodlawn, Piedmont, and some parts of broader Foster-Powell.
} 
- Permits for remodeling/rehabilitation indicate homeowner or investor upgrades

Code violations: BDS enforcement (address, ongoing)

- Increased code complaints may indicate conflict over property use as new residents with different standards for conditions engage the City to enforce codes. ${ }^{10}$

Multifamily rents and vacancies Center for Real Estate (PSU) Multifamily report (geographic submarket, quarterly)

- Increased pressure on the rental market indicated by decreasing vacancies and increasing rents in a neighborhood

Homebuyer demographics: HMDA data (Census tract, annual)

- Home loan/home purchase data by race indicate whether the new buyer population moving to a neighborhood is of a different racial/ethnic group than current occupants

- Loan denial data by race demonstrate whether applicants of color are less likely to be able to purchase in the neighborhood

Emerging concept: Realtor panel. Home sales data sources that include information such as list vs. sales price and time on the market are expensive. However, realtors often have a sense of this information as well as knowing how many bids properties are receiving (i.e. how competitive a market is), what neighborhoods buyers are asking to be shown, and what areas are considered "hot" or "on the verge" among the professional community. Realtors are also actively engaged in marketing neighborhoods and so are involved in making places "happen" through naming, describing, and encouraging attention.

It could be fruitful to occasionally poll realtors, perhaps through a focus group setting, about their sense of the market in neighborhoods of interest. A carefully selected panel of realtors could represent those whose business includes significant numbers of first-time homebuyers, who offer multi-lingual services to immigrant communities, who specialize in historic "fixerupper" homes or other styles identified in neighborhoods of interest, and/or who specialize in the eastside neighborhoods that are "on the verge." These professionals would offer another view of market change from the private sector.

\subsection{Conclusion: typology for use in policy strategy}

The typology analysis presents a way to categorize neighborhoods' changing housing market and demographics. This analysis started by assessing citywide neighborhood housing market changes over the period 1990 to 2010, focusing on 2000 to 2012 as a predictor for risk of gentrification and displacement. The neighborhood typology identifies six stages of

\footnotetext{
${ }^{10}$ Again, this conflict was depicted extensively in the documentary Flag Wars, in which new residents entered complaints about the conditions of property of lower income long-term residents. Observing upticks in code violation complaints has also been noted in gentrifying neighborhoods in Chicago, where the cost of repairs or fines can cause displacement (Betancur 2010).
} 
neighborhood change as the focus of this study. These stages represent early, mid, and late stages of neighborhood change that may cause displacement. In keeping with the recommendation for a more market-sensitive approach to planning, this analysis also includes an outline of data sources for ongoing monitoring of housing market conditions updated for relevant changes.

The typology of stages of gentrification/displacement is a high-level, citywide look at trends. It can be used to develop a policy strategy in which policies are related to the stages of neighborhood change for maximum impact. In the next section, a policy concept is outlined.

\section{Policy strategy: operationalize inclusive and equitable development}

The concept of inclusive, equitable development is to set neighborhood livability and vitality goals, while working towards ensuring that new development and neighborhood change does not disproportionately impact current residents negatively. From a policy standpoint, this could mean using the gentrification/displacement risk typology to set standards for considering community impacts in new development where public investment occurs. This section lays out strategies based on best practices for addressing gentrification and inclusive, equitable neighborhood development and revitalization.

In the context of growth and hot housing markets, having a clear community benefits strategy captures the potential of new developments, as more residents can participate in the growth and new prosperity. The strategy begins with embedding the concept of community benefits and mitigation of displacement into key policies and plans.

When a neighborhood is identified in the gentrification typology as being at-risk for gentrification, care should be taken with public investments. In order to assess what kinds of public benefits would be prioritized in a particular neighborhood identified in the gentrification typology, and to build a community impacts statement, there is a need for additional information on the dimensions of gentrification present. The neighborhood gentrification impacts drilldown is a focused equity analysis for that purpose; it provides the data foundation for choosing and focusing tools to particular neighborhood conditions. An overarching strategy addresses minor public investments with a focus on outreach and partnerships; and major public investments with a wider range of tools and practices.

\subsection{Embed community impacts into plans and policies}

\subsubsection{Portland Plan}

In a strategy for equitable, inclusive development, it is important to set expectations that development and revitalization will have positive community impacts and mitigate harms. This goal is already embedded in the Portland Plan through the Equity strategy and the focus on healthy, connected neighborhoods. The response to the challenge of displacement is also part 
of strategies for prosperity and neighborhood business development. In the Portland Plan section on gentrification and displacement, it states the importance clearly:

The Portland Plan strives to make government explicitly consider how projects and spending reduce disparities and improve equity.

\subsubsection{Comprehensive plans and area plans}

Having a broad community impacts policy starts with such a statement and should be carried into additional plan and policy documents, setting high level goals for equitable development and the consideration of negative impacts of new activity. The City of San Diego, for example, embeds community impacts into its comprehensive plan element for economic development (see below).

The City has already incorporated anti-displacement and equity goals into its area planning for the Cully Commercial Corridor. The language included in the local street plan can serve as a model for future neighborhood planning. The plan includes an overview of the history of Cully's development and signs that it may be susceptible to rapid gentrification pressures. The resolution includes a brief assessment of neighborhood resiliency and challenges that may arise with neighborhood change, which could lead to a prioritization of community benefits. It also specifically calls on the City to "proactively address the potential issue of gentrification and displacement" as part of community economic development. These activities derive from the Portland Plan's attention to equity and to considering consequences of revitalization. In particular, the resolution calls for coordinated plans and programs by directing:

"the Bureau of Planning and Sustainability, Portland Housing Bureau, and Portland Development Commission to work together and with interested Cully community organization representatives to implement Portland Plan Action 97 [Mitigate negative social impacts] and align existing policies, strategies and investments, and where needed develop policies that anticipate and address the displacement impacts of gentrification."

\section{Comprehensive Plan goals as an underpinning for community impacts priority:}

\section{San Diego General Plan Economic Development Element}

San Diego's comp plan includes goals and policies that address industrial lands, commercial areas, and redevelopment activity so as to support inclusive and equitable economic development through setting expectations and providing for monitoring of community plan priorities.

Intro to element: The Economic Prosperity Element also expands the traditional focus of a general plan to include a variety of economic development policies that have a less direct effect 
on land use, but are designed to achieve a rising standard of living. These include policies aimed at supporting existing and new businesses that reflect the changing nature of industry, creating the types of jobs most beneficial to the local economy, and preparing our workforce to compete for these jobs in the global marketplace. Despite the economic growth that has occurred over the last several years, economic prosperity has not been evenly distributed in San Diego.

Some key policies:

EP-E.1. Encourage the retention and creation of middle-income employment by:

- Preserving employment land and capacity for base sector export industries that generate opportunities for middle-income wage earners as discussed in Section A.

- Investing in infrastructure, educational and skill development, and quality of life assets that support middle-income employment development.

- Encouraging the development of measures that facilitate expansion of high technology business facilities that have the potential to create middle-income jobs likely to be filled by local residents.

EP-K.8. Minimize displacement of existing residents businesses, and uses in redevelopment projects. Those displaced should have adequate access to institutions, employment and services.

EP-K.9. Extend involvement opportunities to existing property owners in the redevelopment process by encouraging the use of owner participation agreements.

Economic information, monitoring, and strategic initiatives: Major development projects can have a significant effect on a community's economic environment, especially those projects that were not envisioned as part of the community in the planning process. A formal method of providing information on the fiscal and economic impacts of revisions to community plans can assist decision-makers, community planning groups and other community members that review planning projects. The assessment should serve as an informational tool only; it should not create criteria or standards for project approval. Indicators have been developed for the purpose of monitoring community economic performance. Traditionally, economic indicators have focused on the profits and losses of community businesses. However, the vision outlined in the City's Economic Prosperity Element requires a more comprehensive view by adding indicators to address housing, smart growth, and equity-all facets of San Diego's economic prosperity. The indicators, in combination with the existing conditions database, will provide decision-makers and community groups with frequently updated information about their communities.

EP-L.2. Prepare a Community and Economic Benefit Assessment (CEBA) process focusing on economic and fiscal impact information for significant community plan amendments involving land use or intensity revisions. A determination of whether a CEBA is required for community plan amendments will be made when the community plan amendment is initiated.

\subsubsection{Development Review}

Expectations for equitable development should also be part of the development review approval process. As part of a community impacts policy, the City could set clear expectations that developers will demonstrate that their projects have community support from the full range of stakeholders. The City could require as part of the development review process that a developer address plan priorities and demonstrate community support. This would mean developers would need to engage with community groups and address their concerns in a robust community 
review process. These expectations could be made clear from political leadership through bureaus and commissions. The Community Benefits Law Center sets forward roles for various elected officials in urging community impacts to be addressed:

...it is plainly legitimate for an elected official to make clear to a developer that he or she will consider the degree of community support for a project in deciding whether to grant discretionary project approvals; to encourage governmental staff to require certain developer commitments through the accepted land use approval process; to inform the developer, governmental staffers, and the public of factors that the elected official will consider relevant in voting on discretionary approvals for the project...

More specific tools for incorporating plan goals and broad community impacts expectations are discussed with respect to public investment in the next section.

\subsection{Coordinate policy strategy based on typology and level of public investment}

A strategic approach will utilize policy tools appropriate to neighborhoods based on the stages identified in the gentrification typology. The combination of tools also depends on what kind of public investment is being made. In the following sections, the approach is developed to include a drilldown on the features of neighborhood change in an area identified in the gentrification typology, and a set of activities that are appropriate for a minor public investment and for major public investments. The stages of gentrification provide opportunities for different kinds of action.

The table suggests how the neighborhood change stage and level of investment should be considered jointly. As a new public project is identified, staff would consider whether the location is in a neighborhood experiencing change (position in typology) and how significant the investment will be/has been. A coordinated approach may require multiple bureaus to address issues across policy sectors. 


\begin{tabular}{|c|c|c|c|c|}
\hline $\begin{array}{c}\text { My project is } \\
\text { a.... }\end{array}$ & Minor investment & $\begin{array}{c}\text { Major investment/ } \\
\text { infrastructure } \\
\text { upgrade }\end{array}$ & $\begin{array}{l}\text { New URA or NPI } \\
\text { area designated }\end{array}$ & $\begin{array}{l}\text { Existing URA or NPI } \\
\text { area }\end{array}$ \\
\hline \multicolumn{5}{|l|}{$\begin{array}{c}\text { In a } \\
\text { neighborhood } \\
\text { that is... }\end{array}$} \\
\hline $\begin{array}{c}\text { Early/ } \\
\text { Susceptible }\end{array}$ & $\begin{array}{l}\text { Opportunity for } \\
\text { community } \\
\text { engagement, build trust } \\
\text { and relationships; } \\
\text { understanding of } \\
\text { potential for change } \\
\text { and needs for equity } \\
\text { impact assessment }\end{array}$ & $\begin{array}{l}\text { Anti-displacement } \\
\text { planning opportunity } \\
\text { - address drilldown } \\
\text { and community } \\
\text { impacts approach } \\
\text { for all relevant policy } \\
\text { sectors }\end{array}$ & $\begin{array}{l}\text { Anti-displacement } \\
\text { planning opportunity } \\
\text { - address drilldown } \\
\text { and community } \\
\text { impacts approach } \\
\text { for all relevant policy } \\
\text { sectors }\end{array}$ & $\begin{array}{l}\text { Keep monitoring for } \\
\text { market 'heat' } \\
\text { Engagement on } \\
\text { effects } \\
\text { Balance market } \\
\text { revitalization vs. } \\
\text { potential future } \\
\text { displacement- } \\
\text { engage with } \\
\text { developers }\end{array}$ \\
\hline $\begin{array}{c}\text { Mid/ } \\
\text { Dynamic }\end{array}$ & $\begin{array}{l}\text { Public process is } \\
\text { important - address } \\
\text { conflict over } \\
\text { prioritization, } \\
\text { engagement important } \\
\text { and possible re- } \\
\text { consideration based on } \\
\text { impacts }\end{array}$ & $\begin{array}{l}\text { Housing } \\
\text { displacement is } \\
\text { critical- Prioritize } \\
\text { preservation and } \\
\text { building new } \\
\text { affordable housing }\end{array}$ & $\begin{array}{l}\text { Assess whether } \\
\text { benefits are going to } \\
\text { vulnerable } \\
\text { populations, target } \\
\text { programs and } \\
\text { benefits }\end{array}$ & $\begin{array}{l}\text { Process/engagement } \\
\text { to maintain trust; } \\
\text { equity analysis and } \\
\text { specific benefits } \\
\text { related to drilldown } \\
\text { required for projects } \\
\text { with subsidy; } \\
\text { Encourage CBAs for } \\
\text { residents/developers } \\
\text { as subsidy } \\
\text { declines/no longer } \\
\text { used }\end{array}$ \\
\hline Late & $\begin{array}{l}\text { Assess impacts of new } \\
\text { investment for groups } \\
\text { of concern- are they } \\
\text { receiving any benefit? } \\
\text { Other possible projects } \\
\text { that would benefit }\end{array}$ & $\begin{array}{l}\text { Prioritize } \\
\text { preservation and } \\
\text { building new } \\
\text { affordable housing }\end{array}$ & $\begin{array}{l}\text { Assess whether } \\
\text { benefits are going to } \\
\text { vulnerable } \\
\text { populations, target } \\
\text { programs and } \\
\text { benefits }\end{array}$ & $\begin{array}{l}\text { Unlikely? But focus } \\
\text { remaining funds on } \\
\text { affordable housing } \\
\text { and workforce } \\
\text { development }\end{array}$ \\
\hline
\end{tabular}

them?

Early or susceptible: Approaches can be more balanced towards attention to boosting revitalization activity. With careful coordinated planning that engages the public and uses enabling tools for asset building, residents can enjoy benefits of economic development and home value appreciation. There should be a focus on participation and equity in the vision statements of plans. These stages provide the best opportunities for monitoring and updating priorities as the neighborhood evolves.

Mid/Dynamic: Using the drilldown analysis, planners will be able to identify problem areas that can be related to specific tools. There is a need to support evaluation to ensure measured outcomes for the benefits linked to public investment. In this stage, there may be projects that do not have public investment and need a different approach (see Community Benefits Agreements section) 
Late: Affordable housing creation/preservation is a greater priority for public investment in order to maintain a stock of affordable housing in opportunity areas. Development without public investment requires a different approach (see Community Benefits Agreements section)

Policy development under these different conditions would begin with a focused equity analysis drilling down on data about vulnerable groups and housing conditions.

\subsection{Gentrification data drilldown: focused equity analysis to set priorities}

Having a neighborhood typology to understand the big picture of neighborhood changes throughout Portland can help to focus public investments and how they are managed. Turning to a focus on gentrification and displacement may mean new or additional priorities. When policy strategies are being developed or investment decisions are being made in a specific neighborhood, the next step would be to drill down and analyze additional neighborhood characteristics and information on housing and vulnerable populations. This more detailed look can help to prioritize resources and investments.

When acting in a particular neighborhood, a drilldown analysis with available data on additional characteristics is important to understand the particulars of housing vulnerability, commercial activity, and demographic issues that may affect public decision processes within a particular neighborhood. The gentrification drilldown is an equity analysis that addresses the specific questions about how neighborhood change can affect communities. The City is already working to assess equity more consistently in its policymaking, The BPS equity tool asks the broad questions at the heart of an inclusive, equitable development paradigm for addressing gentrification:

- What are the positive effects, the negative effects, and the missed opportunities to affect communities?

- Have racial/ethnic groups been inequitably impacted or denied access by this policy or plan, or similar projects in the past?

- Is income (ability to afford/pay) a determining factor in the ability to benefit from this policy or plan?

- Are there known disparities? Possible disparities?

- Who are the stakeholder groups? Do they include populations historically underrepresented or marginalized groups? Have mainstream educated, middle and upper class persons historically benefited from or 'had ownership' or the topic and is participation reliant on comfort interacting with such persons, OR City employees?

The equity analysis further asks about the collection of demographic data to determine whether inequity is occurring, whether a program is targeted to address inequity, and how to develop measures of success.

Gentrification is a process with multiple stages and dimensions of population migration, development and redevelopment of housing, changes to neighborhood commercial activities, and shifts in demands on the public sector. Drilling down on dimensions of vulnerability and 
change can illuminate which particular aspects of gentrification-related change are occurring and can help analyze specific options in different policy areas.-results lead to particular toolsets. The drilldown relates to questions that should be asked when considering neighborhood-specific interventions:

- Which populations are most vulnerable to housing displacement and in what form?

- What impacts may result from economic development changes?

- Is there a process in place for inclusive community participation?

In the context of gentrification, there are a set of questions based on 'best practices' that are specific to vulnerability with respect to housing displacement, economic status and activity, and community participation. These questions can help guide the analysis.

Housing:

- Which populations are or are not served by housing stock in the neighborhood? What types of households in terms of ages, incomes, tenure?

- What housing options are missing?

- Is new housing being developed in the neighborhood affordable/otherwise match these needs?

- Which populations are vulnerable to displacement, based on current housing conditions-in what specific way does housing vulnerability manifest?

- Is the housing market heating up?

Demographic changes:

- Is there a diversity of household income and how has it changed?

- What are the racial/ethnic groups and limited English proficiency populations?

Opportunities:

- What opportunities exist for housing preservation (undercapitalized or expiring subsidized housing)?

- Are there development opportunities on vacant land? Is any land publicly owned?

- Are there underdeveloped sites like parking lots, unused commercial/industrial buildings, surplus school property/vacant schools?

The drilldown, by clarifying the dimensions of possible displacement, could direct the kinds of community benefits that would be prioritized in developments receiving public subsidy and/or windfall benefits from discretionary public action (e.g. upzoning, infrastructure changes to accommodate development). Appendix $B$ lists publicly available data sources and variables for assessing population and housing vulnerability and housing market changes for the development of policies. Appendix $\mathrm{C}$ provides an example analysis for the Cully neighborhood, demonstrating analysis of the area that could be used as part of the Neighborhood Prosperity Initiative/Main Streets economic development program. 


\subsection{Areas with minor public investments}

With minor public investments, there may not be sufficient resources to address a broad spectrum of issues arising from gentrification pressures. However, processes for making investments in a neighborhood may be delayed by community distress and conflict over priorities and resource allocations. The neighborhood drilldown analysis will point to potential areas of concern and can guide public outreach and engagement strategies to address vulnerable populations.

- Priority setting and resource allocation analysis. Consider equity impacts of proposed investments and whether alternative plans/programs/options may be included to provide more benefit to underserved populations.

- Public engagement. Using the demographic drilldown, consider public outreach and engagement strategies that are open and inclusive. Language considerations include not only translation/interpretation services, but also taking care to avoid jargon and traditional 'public involvement' language that is not familiar for under-represented groups. Reach out to community organizations that can connect the public sector with these communities, as well as the 'usual suspects' of neighborhood associations and organized interest groups.

- Coordination with other Bureaus. Conflict may be pre-empted or redirected into more productive venues for addressing the issues of concern to the community by including other bureaus that are also at work in a neighborhood. If in a major investment zone such as a URA, there may be additional programming occurring or available that is important to know about. Even if not, there may be support for anticipating and discussing issues around gentrification that are outside the scope of the investing bureau's usual work.

When community benefits and anti-displacement activities are generally incorporated into the planning and economic development policies of a city, there may be less conflict over minor public investments and infrastructure upgrades. Residents may view those improvements as beneficial to them, rather than as triggering displacement. The example of Chicago's Paseo Boricua is one in which having a community economic development strategy with a practice of resident engagement prevented conflict over new bicycling infrastructure desired by new residents (see example below).

\section{Economic Development with Cultural Preservation \\ Lays foundation for bike lanes Paseo Boricua, Chicago}

\footnotetext{
Paseo Boricua, which stretches along Division Street from Western Avenue to Mozart, represents a microcosm of the Puerto Rican historical and cultural experience. The 50 light poles adorned with laser-etched wrought iron banners, representing images of the three cultural experiences that define the Puerto Rican people (the Taino, Spanish and West African,) the 16 placitas along the walkway; and the variety of businesses with a Puerto Rican accent, all testify to this reality. - Paseo Boricua business directory site
} 
Amidst commercial gentrification pressure, the Division Street Business Development Association supports an area with a distinct cultural identity-Paseo Boricua, or the Puerto Rican way-boosting local entrepreneurship and a sense of place for residents. The Paseo Boricua area is marked with culturally specific public art, including large gateway sculptures of the Puerto Rican flag. Along with the Puerto Rican Cultural Center, businesses on Division Street "between the flags" include restaurants; La Cosecha ("the harvest"), a fresh market; and small businesses located in the Paseo Boricua incubator building. The PRCC and neighborhood sponsor several festivals celebrating Puerto Rican culture throughout the year. According to surveys, most businesses are owned by first-time entrepreneurs and community residents shop on the street daily, supporting the businesses and feeling a strong sense of Puerto Rican identity is present in the area. The cultural identification and festivals are not just a superficial neighborhood marketing device; Latinos have ownership in the neighborhood and community economic development is a priority.

With the strong identification of the area with the Puerto Rican community, a precedent was set for engaging with Puerto Rican leaders on issues of public investment. As bicycle lanes were installed in nearby neighborhoods, community members feared it was a sign of gentrification and served only privileged new residents. Local bike shop West Town Bikes worked with the community, creating CicloUrbano, which engages with youth and the Chicago Cruisers, a Latino club that parades classic Schwinn bicycles. With new community support, bicycle facilities have now been added to Division Street. While the neighborhood continues to change and redevelopment pressures are real, community leaders now see bike lanes as part of health and safety for neighborhood residents, rather than a threat. With stable businesses and support from the DSBA, fears of economic displacement as the neighborhood becomes more attractive are mitigated. Puerto Rican residents retain a strong voice in neighborhood development. While there continue to be market pressures on housing, these factors mitigate the harms of gentrification.

\subsection{Major public investments/ new major investment areas}

When major public investments are made, many neighborhood changes may be triggered. Public investments are often bounded-as in URAs—or could be defined with an impact arealike a station area for a light rail stop. Best practices research suggests that having clearly articulated criteria for considering development's community impacts within a bounded area makes the environment for the private sector more predictable than having to negotiate on a project by project basis. This approach suggests that along with the designation of public investments, there should be a "community impacts zone" that defines an area for displacement mitigation planning; within the 'zone' a broad set of community impacts mitigation tools would be applied. A 'zone' for anti-gentrification would set expectations that development consider impacts and attempt to mitigate negative consequences; tie public subsidy to public benefits; and utilize tools that are most appropriate for the stage of neighborhood change observed.

\subsubsection{Create a "community impacts zone"}

The community impacts zone incorporates best practice tools for all types of developments, not only those receiving direct public investment or subsidy. Urban Renewal Areas, NPI, EcoDistricts, and station areas could all be examples of boundaries for these 'zones.' 
The Atlanta Beltline Ordinance. A TOD zone was created within which projects receiving bond funding were required to use first-source hiring systems that targeted low-income residents of neighborhoods inside the TOD area. It also created a community advisory system to continue to discuss how community benefits could be targeted and implemented in affected neighborhoods as development continues

Develop area plans for these 'zones' using the neighborhood drilldown analysis as a basis for setting goals for specific community benefits and the mitigation of potential harms as desired by the community. Set priorities that include diversity and equitable access to benefits of revitalizing neighborhood. Engage residents in developing a vision of inclusive development. Establish early partnerships with key community based organizations [neighborhood and policy sector] that can work in tandem, recognizing that the public sector cannot address all goals/activities.

\subsubsection{Establish a practice of Community Impacts Reports}

Community Impacts Reports (CIR) are analogous to environmental impact reports, asking developers to spell out costs and benefits of impacts on housing, jobs/employment, neighborhood services, or other major goals (e.g. how does a project address "healthy, connected neighborhoods" priorities?).

A CIR request could be targeted to address the vulnerabilities revealed in the neighborhood drilldown analysis and how the development will benefit community residents based on goals/priorities. A CIR includes analysis of how a project may affect vulnerable populations, how any negative impacts might be mitigated, and whether it offers benefits to identified resident groups. A CIR should be available for public review and comment to be considered in the development approval process.

Strong encouragement and institutionalizing a practice is important. In some cases, CIRs might be required. Projects that receive direct public subsidy could be required to provide community review of CIRs that demonstrate how a the project addresses identified goals. CIRs might also be required if there are infrastructure upgrades or zoning changes to accommodate a new development. In some cities, CIR requirements have been formalized by ordinance for some kinds of development, particularly for commercial development over a certain size threshold (socalled "big box" stores).

Petaluma, California requires a Fiscal and Economic Impact Analysis report for large scale commercial development projects. These FEIA reports are community impacts reports covering the effects on local retailers and employment in particular. Examples include an assessment of impacts of a new hotel; and of a shopping plaza that included a Target, an FEIA that drew a response from the Sonoma Living Wage Coalition. ${ }^{11}$

\footnotetext{
${ }^{11}$ The text of these and other Petaluma FEIAs can be found at Living Wage Sonoma's website for CIRs http://www.livingwagesonoma.org/community_impact_reports.htm
} 


\subsubsection{Use public subsidy and incentives with specific, plan-based benefits.}

With clearly defined criteria for receipt of subsidy or public contracts, the approval of a project application should be based on specific benefits with measurable outcomes that are evaluated for continued compliance. Priorities for these benefits could be determined by the drilldown analysis of particular vulnerabilities.

Housing. For instance, the City has a set-aside of urban renewal tax increment funds for affordable housing. The drilldown analysis can be used to determine specific priorities for the following policies:

- Utilize proposed mitigation efforts as selection criteria, prioritizing development proposals that address the most vulnerable or highest priority harms

- Include mitigation of specific potential negative impacts (identified by drilldown and community input) as priority decision criteria for developers responding to RFPs for public land or subsidy;

- Adjust existing incentives (e.g. SDC or tax exemptions) and subsidy (e.g. TIF setaside) to match particular neighborhood housing conditions

Workforce agreements. Create robust workforce and hiring policies for development (contractors/subcontractors and ongoing employment) using public land or direct investment. Using careful definitions for first source hiring can target neighborhood residents and disadvantaged workers. Partnering with community-based organizations that provide workforce development for particular populations is effective. "Good faith agreements" on hiring would not necessarily have the intended outcomes-workforce agreements should include evaluation of performance and penalties for not meeting goals.

- The City of Los Angeles Community Workforce Agreements (CWA) requires of contractors that $30-40 \%$ of construction jobs are filled by residents of neighborhoods where a project is located; with 10-15\% of hours filled by "at-risk" or "disadvantaged" workers. Because of laws disallowing racial/ethnic targets in hiring, the City uses "at-risk" or "disadvantaged" definitions to address equity concerns. At-risk /disadvantaged may include: poverty, history of incarceration, receipt of public assistance, living in high-unemployment zip codes, being homeless, or being an unemployed custodial single parent among other criteria. Non-compliant contractors may receive assistance in finding workers, but ultimately face financial penalties or the possibility of being designated ineligible for future public work $^{12}$. LAANE-sample language

\subsection{Private development without subsidy in gentrifying neighborhoods}

Public policy can directly address community impacts when there are public investments. However, development in neighborhoods in later stages of gentrification may be no longer supported by public funds-meaning the private sector is investing on its own without the

\footnotetext{
${ }^{12}$ Specific examples of policy language for community workforce agreements with Los Angeles public agencies can be found at http://www.forworkingfamilies.org/page/policy-tools-community-workforce-agreement-examples
} 
possibility for public "hooks" on development. Therefore it is also important for the community to be empowered and knowledgeable enough to seek and negotiate community benefits agreements (CBAs) with private sector actors.

\subsubsection{Negotiated Community Benefits Agreements (CBAs)}

It is important to make a distinction between a broad community impacts policy and negotiated private Community Benefits Agreements (CBAs). A community impacts policy approach from the public sector means addressing the negative impacts of new development through processes where private developers and the public sector interact. A CBA occurs between communities and developers, not as a requirement by a public agency, but in a negotiation between the parties to create a legally enforceable set of conditions.

Community Benefits Agreements (CBAs) are complex, multi-party contracts executed by several community-based organizations and one or more developers, including developers' commitments to provide a range of community benefits related to a proposed development project, and usually containing the community-based organizations' commitment to support approval of the project.

- Community Benefits Law Center

Essentially, the organized community lays out the conditions under which it will support (or not oppose) a new development. The private sector actors agree to meet goals for benefits that might range from environmental hazard mitigation to affordable housing to hiring. These agreements are enforceable, and as agreements between private entities, are not problematic in terms of Takings law. Negotiating a binding CBA requires that a community be well organized with clear goals and the ability to muster sufficient power to generate a response from a developer. Negotiated CBAs also may require legal assistance for community groups.

Negotiated CBAs include the ability of a community group to enforce a developer's commitments to provide community benefits, even without local government involvement (although, if a project includes public subsidy, it is a good practice for commitments to be included in the public agreements as well). Community benefits should be clearly spelled out, with a timeframe for their provision, a monitoring and reporting plan, and consequences for nonfulfillment. Some benefits are immediate and/or one-time, like a developers' providing an in-lieu fund for affordable housing, which are easier to monitor and enforce immediately. Others, like hiring agreements, are ongoing and may involve tenants; these require more legalities to create enforcement through the developer. Reporting on benefits provided should be regular, verifiable by the community groups, and include a procedure for notification of not meeting the agreement and for correcting the deficits.

Where the goal is inclusivity and accountability, the participation of the community should be authentic, not "astroturfed" or cherry-picked participation that ends in agreements that skirt real issues. Meaningful CBAs emerge from community-defined priorities and demands. The Partnership for Working Families, a leading technical assistance provider for CBAs, strongly warns against governments' requiring CBAs: Formal attempts by local government to structure 
or facilitate CBA negotiations generally lead to governmental efforts to control who can participate, and/or predetermine results of negotiations.

The Partnership's document Community Benefits: Practical Tools for Proactive Development, includes developer-oriented encouragements, such as making the case that negotiating a CBA is a less contentious and adversarial process that is fundamentally pro-growth. Rather than community groups saying "no" they would be saying "yes, with these conditions...." leading to more and more beneficial development. ${ }^{13}$

\section{Negotiated Community Benefits Agreement for redevelopment:}

\section{One Hill CBA, the Hill District, Pittsburgh}

The Hill District comprises several historic African-American neighborhoods located between downtown and the university district in Pittsburgh. The district, featured in the plays of August Wilson, served as the center of black cultural life, but it was also redlined and deteriorating. Urban renewal projects of the 50s and 60s demolished thousands of homes and the black business district to build a Civic Arena in the Lower Hill and in anticipation of wider redevelopment that never happened-devastating neighborhood residents. As market pressures began to mount in the 2000s with public housing redevelopment, a planned new hockey arena, arts-oriented development downtown, and burgeoning interest in the well-located neighborhoods with views - the community organized to ensure that new development would benefit long-term residents by negotiating community benefits agreements. The One Hill CBA includes the Pittsburgh Penguins, the Sports and Exhibition Authority, the Pittsburgh Urban Redevelopment Authority, the City and the County governments. Key features of the One Hill CBA relating to gentrification: Organized communities can negotiate CBAs. In order to bring a CBA to fruition, Hill residents had to overcome internal division and a painful history. Residents used the process to turn from past disenfranchisement and fear of any changes to empowerment about the neighborhood's future. They also were successful in incorporating a "right to return" for the Lower Hill that gives preference to displaced people in new affordable housing.

Key features of the One Hill CBA:

Hill District Community Master Plan guides development. The Plan was created with substantial community input; a paid planning professional was provided to support technical assistance for the community. This plan guides project selection, funding, and property disposition in the district. The Penguins agreed not to submit their development plans for the sites around the arena until the completion of the Master Plan.

\footnotetext{
${ }^{13}$ The Partnership for Working Families collects examples of CBAs with contract language and links to community organization partners. http://www.forworkingfamilies.org/page/policy-tools-communitybenefits-agreements-and-policies-effect
} 
Continued monitoring and reporting. Development entities must regularly, publicly report their progress on contracting/hiring and other goals. Future development, particularly around the arena and civic center, must include notification to the community and potentially further negotiation of community benefits.

The One Hill CBA includes a spectrum of community impacts-while affordable housing and workforce impacts are critical, the CBA also includes preferring LEED certified buildings, minimizing diesel fuel emissions, and supporting parks/green infrastructure.

Continued community monitoring and accountability through organizing and partnerships among CBOs is necessary along with City/PURA action on development.

\subsubsection{Public sector role: building and supporting community capacity}

In the overall approach of seeking community benefits-whether via public sector or community action - the City can play a very important role in ensuring that under-represented, under-served communities are engaged and empowered to voice their needs and priorities. In order to respond to a CIR or to negotiate a CBA, a community has to understand the development process and the stages at which their input will be effective.

The City can communicate that having a development proposal come forward with community support and a lack of major opposition is a viewed favorably. Without capacity building support, the residents most vulnerable to neighborhood changes may not be able to enter these processes. The City might support the capacity to engage in development processes and create CBAs through programs like those at the Office of Neighborhood Involvement that help community members and groups to understand and engage in City processes. Present practices like Good Neighbor Agreements could serve as a model for some kinds of impacts mitigation that residents demand of new development. The present utilization of GNAs to address potential harms of alcohol sales might be very relevant for gentrifying neighborhoods with new nightlife activity —as restaurants, bars, and other entertainment venues are often part of a "hot" new neighborhood.

- The Tracking Toolbox is a guide for community groups to understand how development happens from proposal to groundbreaking. ${ }^{14}$ It provides an outline of a typical development approval process and a framework for community groups to track priorities and projects by suggestion key questions for each stage of development process. This guide helps build capacity around the land use/regulatory process and opportunities for communities to engage on specific development proposals.

\footnotetext{
${ }^{14}$ The Partnership for Working Families. The Tracking Toolbox. Available at http://www.forworkingfamilies.org/sites/pwf/files/publications/2010.05_tracking_toolbox.pdf
} 


\subsection{Inclusionary housing tools for Oregon}

Inclusionary zoning (IZ) is a best practice tool for ensuring that affordable housing units are part of new residential development. With IZ policies, developers provide affordable units or pay inlieu fees towards housing, in exchange for development incentives. Recent research of the national performance of $\mathrm{IZ}$ policies finds that this tool is effective at incorporating affordable housing into higher opportunity neighborhoods, mitigating the concentration of poverty. ${ }^{15}$ Although reviews find that mandatory $\mathrm{IZ}$ is the most effective approach to inclusionary housing, mandatory $\mathrm{IZ}$ is not available as a tool for the City of Portland due to Oregon's nearly unique pre-emption law (ORS 197.309). However, incentive-based voluntary inclusionary housing policy can be developed and could be especially useful in gentrifying neighborhoods where there is significant development of new housing.

\subsubsection{Developing an inclusionary housing policy}

Inclusionary zoning varies widely in different jurisdictions, offering a range of implementation tools that can be matched to the local context (one recent article referred to "31 flavors of IZ"and actually compared 150 regulations!). There are several fundamental issues to consider in developing an inclusionary housing policy's requirements and incentives, which must be discussed in the local market context.

Inclusionary housing policies depend on developers' willingness to produce affordable housing in return for these kinds of benefits. It is important to carefully consider developers' market realities to develop the right set of tools The City could begin to address an inclusionary housing approach with developers who are interested in this kind of niche-mixed-income development-bringing together for and non-profit developers both to consider policies and to build networks. Developers eager to take advantage of regulatory incentives, especially in hot markets, may be ready to participate in considering the adaptation of an inclusionary housing policy to the Portland context.

To create effective inclusionary policies, planners would need to engage with a spectrum of interested developers to learn about their businesses in the Portland market context. This kind of dialogue would be sensitive to the feasibility of projects here and now, but also should recognize that the market has/continues to change. In California, for and nonprofit homebuilders came together to develop "Common Ground" principles for IZ-laying out the opportunities and constraints of their market and how IZ policies can provide the flexibility they seek. ${ }^{16}$

In developing an incentive-based inclusionary housing policy that will generate new affordable housing, there are a number of dimensions to consider: which developers are eligible, what

\footnotetext{
15 In "Is Inclusionary Zoning Inclusionary?: A Guide for Practitioners" (2012), authors Heather L. Schwartz, Liisa Ecola, Kristen J. Leuscher, and Aaron Kofner of RAND conclude that IZ policies do promote access to mixed-income neighborhoods. http://www.rand.org/pubs/technical_reports/TR1231.html

${ }^{16}$ The Nonprofit Housing Association of Northern California, along with the Home Builders Association of Northern California, jointly issued a set of concepts for inclusionary zoning policies that work for non-and for-profit developers. http://www.nonprofithousing.org/pdf_pubs/Inclusionary_Principles.pdf
} 
housing affordability levels are appropriate, and whether there are options for developers' fulfilling the obligation of affordable units. For the program to be utilized, the incentives must be valuable to developers. The following considerations should be made in developing a policy:

- Threshold triggers for inclusionary tools:

- Size of development: How many units trigger an inclusionary tool? Existing policies include some requiring inclusion at 2 to 5 units (with the smallest paying in-lieu fees), other common figures are 10 or 20 units.

- Some jurisdictions only use inclusionary tools when rezoning, subdivision, or variances are requested; or only in special districts.

- Affordability:

- What is the share of affordable units, and at what income levels? Most are in the range of $5-15 \%$ of units; but income ranges vary widely.

- Is there a trade off between number of units and income targets (ie deeper affordability requires fewer units)?

- How long are units required to remain affordable? Many jurisdictions require 20-30 years of affordability; although there are also many $I Z$ requirements for permanent affordability (may be combined with a community land trust model or nonprofit ownership/management).

- Incentives and options:

- Can developers fulfill affordable housing provision via in-lieu fees into an affordable housing fund or through off-site units?

- What incentives are valuable enough to developers to induce voluntary compliance with inclusionary housing?

- Density, unit size and building envelop bonuses

- Set percentages; one-for-one bonuses

- Unit size reduction

- Height/bulk bonuses to add floor area where unit numbers are set

- Relaxed parking requirements

- Design flexibility (setbacks, lot size)

- Process and fee incentives

- Impact/permitting fee waivers, reductions, or deferrals

- Streamlined permitting process

- Waivers of design or community review

- Market stop-gaps

- Prequalification/screening by nonprofits for buyers

- providing option to sell affordable owner-occupied unit at market rate if it doesn't sell within certain period of time

- Sales to nonprofits or public sector

PolicyLink: Effective inclusionary zoning programs usually offer developers a range of cost offsets to achieve a double bottom line: affordable housing for residents and a reasonable, overall return for developers. Minimum profitability is important to ensuring private developers and their investors actually build. To determine the need for cost offsets, in relation to other program parameters, jurisdictions typically conduct an economic feasibility analysis that takes 
into account various aspects of development (e.g., cost of land, normal profit margins, construction costs, fees, etc.) and the jurisdiction's housing needs and goals.

Sample inclusionary housing policies: There are many variations in inclusionary zoning policies' approach to affordability standards and compliance. Incentives also vary widely.

Montgomery County, Maryland Moderately Priced Dwelling Units program (MPDU): Montgomery County's program is the best-known of mandatory IZ programs. It has been in effect since 1973 and has resulted in the production of over 12,000 affordable housing units.

- Threshold: MPDUs are required in any new development of 20 or more housing units, even if phased over time.

- Developers may not break up land into separate developments of fewer than 19 units and must report all land holdings.

- Affordable requirements:

○ Number of units-From 12.5 to $15 \%$ of total units must be affordable, depending on the density bonus received. Affordable units must be built alongside market rate units.

- Unit types- Single family units must have $3+$ bedrooms. Multifamily units may be efficiency and one-bedroom only in proportion to market rate units.

- Affordability levels-For-sale unit price is based on MPDU sales program pricing. Rental units are targeted at $65 \%$ AMI with no more than $25 \%$ of monthly income paid towards rent.

- Restrictive covenants-govern occupancy and disposition

- Alternative compliance:

- Includes alternative location for MPDUs; land transfer; alternative payment into housing investment fund

- Incentives:

- Density bonus upon request up to $22 \%$ above normal density permitted in zone

- Fee waivers for systems development charges and development impact tax, upon request.

- Expedited "green tape" processing status for permits

Workforce Housing Policy in Seattle: an incentive zoning policy for unsubsidized development. Developments seeking density bonus under this program may not receive subsidy for the construction of affordable units, including Low-Income Housing tax Credits..

- Affordability requirements:

- Number of units-Set aside $10-17.5 \%$ of living space in the bonus height area

○ Affordability levels- households earning $80 \%$ of AMI (17.5\% requirement); households earning $50 \%$ of $\mathrm{AMI}$ ( $10 \%$ requirement)

- Units remain affordable for 50 years

- Alternative compliance:

- Contribution to affordable housing fund based on $\$ 18.94$ per square foot of new development

- By request units can be produced offsite if they are within the neighborhood or within $0.5 \mathrm{mi}$ of a light rail/rapid transit station 
- Incentives:

- Floor area/height bonus

Sacramento Mixed Income Housing is part of the zoning code as an incentive-based inclusionary policy. It was adopted into the General Plan in 2000.

- Threshold: Residential development in new growth areas, including "major redevelopment opportunity areas" that have more than 9 units.

- Affordable requirements:

- Number of units- $15 \%$ of all units in the development

- Unit types- Single family, multifamily, for-sale, and/or rental units

- Affordability levels- $5 \%$ of units are affordable to low-income households ( $80 \%$ of $\mathrm{AMI}) ; 10 \%$ are affordable to very-low income households (50\% AMI)

- Affordability period- 30 years for rental; income-restrictive covenant on for-sale units

- Alternative compliance with approval:

- Dedicate land to the Sacramento Housing and Redevelopment Agency

- Off-site development for single-family development, if site is in a "superior" location

- Incentives:

- Fee reductions per unit, reimbursements for school facility fees and systems development charges

- Priority processing for building and planning approvals

- Unit size reductions

- Density bonuses

- Eligible for public subsidy financing

\subsubsection{Public sector role: building and supporting development sector capacity}

Some developers may simply be hesitant to take on a new kind of project if they are unsure of the market demand or if the financing is complicated (as it is with mixed-income and/or affordable projects). The City could work in partnership to develop this market niche and the capacity to take advantage of opportunities present in producing mixed-income housing. Through capacity-building, the development community could begin to form new 'rules of thumb' for calculating the riskiness or worth of a potential development-specifically, a greater willingness to produce affordable and mixed-income housing.

The City's Green Building Program is a model in how to help the private development community adopt new development practices. These programs address developer and finance sector concerns: they promote a new feature to the public broadly, increasing demand for new technologies/materials/designs. They also provide technical assistance and demonstrate the feasibility of new approaches. The kinds of activities in the program-information fairs with demonstrations, technical education, building tours, making available case studies-all build the development sectors' knowledge and comfort with new methods. The program also serves as a clearinghouse for connecting to other resources on green building, and a way to promote local success stories-further marketing and building demand. Currently there is not a similar 
program for affordable or mixed-income housing. The City could create a housing technical assistance program, similar to the Green Building Program. Providing additional "proof of concept" could be valuable in building the sector for mixed-income and affordable housing.

- $\quad$ There are national community development intermediary organizations, like NeighborWorks, LISC (Local Initiatives Support Corporation) and Enterprise Community Partners, that could be tapped to bring expertise in financing tools like the Low Income Housing Tax Credit and development in TODs and infill housing, bringing best practices and speaking the language of developers.

- LISC in Seattle focuses on mixed-income development around light rail TOD areas.

- NeighborWorks offers major training institutes several times a year (as well as elearning), including sequences on affordable housing finance tools, construction/production management, and asset management.

- Nationally known architect Michael Pyatok specializes in affordable housing design and processes that reduce community opposition to new multifamily development; his work is used as demonstration of concept and he participates in design competitions as a juror.

Building networks between for-profit and non-profit developers can also be useful. Non-profit partners can share knowledge about financing and development in this niche. Non-profit community development corporations (CDCs) can also serve as partners for mixed-income development. A non-profit homeownership organization could provide homebuyer counseling, pre-qualification or mortgages for income-qualified buyers. Other CDCs might actually partner with a private developer to own/manage affordable rental units-which also provides access to different sources of funding for the project. 


\section{The Big Picture: Strategic Questions}

The suite of policies outlined above is one way to address gentrification. However, the City has limited resources and a number of important goals to achieve. There are some significant strategic questions that should be considered in putting together a program to address gentrification in the context of healthy, connected neighborhoods and equity goals. These questions cannot be answered by a research study; they are eminently political and should be considered with input from stakeholders. This set of questions is not exhaustive and others may arise as these policies tools are considered.

Which changing neighborhoods should be addressed first and/or with the most resources?

The typology of early/susceptible, dynamic, and late gentrifying neighborhoods describes neighborhood change and the possible avenues for addressing different stages of residential displacement. The potential for impacts varies among these stages; and the resources required to implement policy tools varies. The typology does give a sense of the different policy packages needed in each stage, but does not imply any prioritization.

Given limited resources, should the City act first in neighborhoods already experiencing change (mid-dynamic), prevent/mitigate gentrification before it happens (early-susceptible), or pursue opportunity neighborhood housing (late-continued loss)? If the City develops policy tools that include subsidy/incentive, which kinds of areas should receive the most resources?

Balancing equity concerns is complicated: are historic harms to long-standing communities 'worse' than newly emerging problems? If working in neighborhoods that are not as far along the gentrification continuum is more efficient in terms of using public resources-does such a 'bang for the buck' approach to leveraging resources help some communities more than others; but could that approach be ultimately helpful in conserving scarce resources to be used elsewhere?

Further questions may arise if additional neighborhoods not currently identified as gentrifying begin to experience housing market and demographic changes. If upon updating the typology map, there are new neighborhoods identified as potentially gentrifying, how could/should the City incorporate these into a policy program?

Could an anti-displacement goal mean an entirely different set of priorities for the City?

The City currently operates with a set of priorities for the use of public resources, especially within the very limited funding available for housing. The strategy developed above suggests that the City would apply anti-displacement, community impacts tools when public investments, especially at the large scale, are planned. In such a strategy, anti-displacement is proactive work, but only for some neighborhoods.

However, an anti-displacement strategy could be initiated more broadly-which would mean a substantial shifting of City resources. A community benefits program could apply not only when public investment zones are created, but for any neighborhood identified in the typology as 
gentrifying, for neighborhoods identified as 'opportunity areas' (long term high value areas), or for all neighborhoods.

Does the City use the typology map to create a broad anti-gentrification strategy for housing, economic development, and community development and planning (shifting priorities of bureaus altogether)—where all areas identified as gentrifying have a new set of policies/tools? Or do Bureaus use the map when planning a direct public investment/project/etc in a particular neighborhood, to assess a need for tools to be used piecemeal?

Which policy tools or activities should be implemented, and how should they be prioritized?

If there is a mix of approaches, where some areas are designated to receive anti-displacement policies - the question arises of which tools would be implemented. How to prioritize among the kinds of policies and tools to implement? Should the drilldown and area plan process determine which actions are the highest priority for a community or for public benefit broadly? The choice of tools also is made in a particular neighborhood or investment zone and at a particular stage of gentrification-further complicating the decisions.

Some 'best practice' tools are resource-intensive; some require code changes; others may involve rather extensive negotiation over implementation. In other words, some practices could be activated quickly and/or easily while others cannot. Some practices are more effective at particular stages or with particular kinds of partners. When all possible best practices cannot be activated simultaneously, which should be pursued?

How does gentrification policy fit into the broader set of goals, policies and identified needs for Portland's neighborhoods?

The scope of this study is to address the neighborhoods experiencing changes associated with gentrification, and particularly to consider housing displacement as a primary harm. The study does not prioritize among the stages of gentrification, but it also does not address neighborhoods that are not experiencing housing pressures because they are in persistently low-value markets. The neighborhoods that are persistently low income and low housing value are also in need of policies and resources towards equitable development. How should the needs of these neighborhoods be balanced against the needs in gentrifying areas?

There is a relationship between gentrifying and low-income areas: the latter are the most likely destinations for low-income, vulnerable residents displaced from newly 'hot' markets. The pattern of mobility to neighborhoods in mid-county/East Portland has already been observed to cause deepening poverty and disparities, as these neighborhoods also have serious challenges with overburdened infrastructure, limited accessibility, and schools that are over capacity with assisting families experiencing issues related to low income, limited English proficiency, and instability-including residential instability (and even hypermobility). The connection from gentrification in close-in neighborhoods and East Portland is clear; with fewer affordable units close-in, low income households have to locate in low-priced areas. However, it is not clear whether the City's priority should be to stem displacement and address gentrification in the 'hot' 
markets or to create economic opportunities, infrastructure upgrades, and provide more healthy environments in areas where there are no upward housing market pressures.

Focusing attention on persistently low-income/low value neighborhoods would require a different set of policy tools than those considered here. Some of the approaches for community benefits, like workforce agreements and creating community economic development and wealth building opportunities, are similar to those used in gentrifying areas. However, it is far more difficult to require or negotiate community benefits in places where the private market is not as eager to develop because of limited profit opportunities. It also is easier to create vibrant, mixedincome environments in the context of gentrification, where higher income households are already moving in and bringing more economic activity, than where an area has more concentrated poverty. The vulnerable populations and neighborhoods identified here as persistently low income/low value need attention; but how much/what kind? 


\section{Appendix A: Neighborhood typology methods}

Detailed methodologies for creating the vulnerability, demographic change, and housing market designations and the overall neighborhood typology map are presented here.

The typology assessment began with a retrospective look at neighborhood change in Portland to assess whether a small number of measured indicators could represent the changes observed today. These analyses were "ground-truthed" with planning staff, building a common sense of gentrification as it is seen in neighborhoods. Measured indicators were chosen to represent the "robust, yet parsimonious" approach, and to align with policy-relevant metrics (such as the HUD income standards for housing assistance). Several iterations of maps were produced with assessment and comment from BPS, PHB, and PDC staff.

For each dimension of neighborhood change, tracts are assigned as "high" or "low" on the measure based on the relative level of the citywide variable. The dimensions are vulnerability to housing displacement; population changes indicative of potential displacement; and housing market changes.

\section{2010 Vulnerability}

Census tracts were assigned a "vulnerability score" between 0 and 4 , with a weight of 1 for each of the following that is true:

- Greater than $44.2 \%$ of households are renters

- Greater than $26.7 \%$ of the population are communities of color

- Greater than $58.2 \%$ of the population 25 years and older do not have a bachelor's degree

- Greater than $47.0 \%$ of households have incomes at or below at or below $80 \%$ of the HUDadjusted median family income (MFI) [Note: The FY 2009 HUD-adjusted MFI for the Portland-Vancouver-Beaverton area was $\$ 70,000$.]

We defined vulnerable tracts as those with a vulnerability score of at least 3 out of 4 .

\section{Data sources}

Data for the first three variables was drawn from tract-level 2006-2010 American Community Survey (ACS) estimates. We defined communities of color as all residents except for nonHispanic whites.

The percentage of households with incomes at or below $80 \%$ of the HUD-adjusted MFI was calculated from 2005-2009 HUD Comprehensive Housing Affordability Strategy (CHAS) data. At this time, the CHAS tract-level data is available only as a very large raw data file containing values for all U.S. census tracts. The values relevant to this calculation come from Table 8 of the census tracts dataset. Tracts with boundaries in more than one local jurisdiction are split into 
multiple rows; values for each portion were summed before calculating percentages for the overall tract.

\section{Calculation of thresholds}

For the three variables drawn from ACS data, the threshold was defined as the citywide percentage adjusted by the margin of error (MOE) to the lower bound for a more sensitive cutoff. For example, the 2006-2010 ACS estimate for the percentage of renter-occupied units in Portland was $44.8 \%+/-0.6 \%$, resulting in a threshold of $44.2 \%$.

No MOEs are available for the 2005-2009 CHAS data. The threshold for the last variable was defined as the citywide percentage of households with incomes at or below $80 \%$ of the HUDadjusted MFI (calculated from values in Table 8 of the CHAS census places dataset).

\section{2000-2010 Demographic Change}

We defined census tracts with gentrification-related demographic change from 2000 to 2010 as those that experienced either at least 3 of the following 4:

- The share of homeowners either increased or it decreased less than $1.2 \%$

- The white population share either increased or it decreased less than $3.0 \%$

- The share of the population 25 years and older with a bachelor's degree increased more than $7.9 \%$

- The median household income either increased or it decreased less than $8.5 \%$

or experienced only 2 out of 4 , which were:

- The white population share either increased or it decreased less than $3.0 \%$

- The share of the population 25 years and older with a bachelor's degree increased more than $7.9 \%$

\section{Data sources}

Data for 2000 and 2010 was drawn from the 2000 Decennial Census and 2006-2010 ACS estimates, respectively. We converted 2000 median household income values to 2010 dollars before calculating the percent change.

\section{Calculation of thresholds}

MOEs are available for 2006-2010 ACS data but not 2000 Census data. Thresholds were determined by calculating the citywide percentage-point difference from 2000 to 2010 (for white population, homeowners, and bachelor's degree-holders) or percent change (for median household income), determining the new MOE (we used this calculator: http://pad.human.cornell.edu/acscalc/index.cfm), and adjusting by the calculated MOE to the lower bound for a more sensitive cutoff.

Portland experienced declining values for three of the four variables (white population, homeowners, and median household income). In these cases, we considered gentrificationrelated demographic change to have occurred if tract-level values increased, or decreased less than citywide (e.g., "the share of homeowners either increased or it decreased less than 1.2\%"). 


\section{Census tract boundary changes}

There were a few instances where tract boundaries changed between 2000 and 2010; one tract was split into two, or two tracts were combined into one. In either case, we averaged the values for the two resulting tracts or the two original tracts before calculating the percentage-point difference or percent change.

Some tract boundary lines were redrawn slightly without significantly changing the tract geography; we did not alter our calculation method for these cases.

\section{Housing Market Conditions}

All census tracts were assigned a home value for 1990, 2000, and 2010 equal to the ratio of the tract median home value to the citywide median home value. We defined tracts with low or moderate values as those with ratios in the bottom three quintiles; tracts with high values were defined as those with ratios in the top two quintiles.

Home value appreciation rates (i.e., the percent change in median home value) from 1990 to 2000, 2000 to 2010, and 1990 to 2010 were also calculated for each tract. We defined tracts that experienced low or moderate appreciation as those with appreciation values in the bottom three quintiles; tracts with high appreciation were defined as those with appreciation values in the top two quintiles.

Using this data, we identified three gentrification related housing market typologies:

Adjacent tracts:

- Had a low or moderate 2010 value

- Experienced low or moderate 2000-2010 appreciation

- Touch the boundary of at least one tract with a high 2010 value and/or high 2000-2010 appreciation

Accelerating tracts:

- Had a low or moderate 2010 value

- Experienced high 2000-2010 appreciation

Appreciated tracts:

- Had a low or moderate 1990 value

- Had a high 2010 value

- Experienced high 1990-2010 appreciation

The adjacent typology attempts to capture the spillover effects of gentrification, whereby neighborhoods next to gentrifying areas are at-risk of gentrifying as housing pressures and commercial investment expand outward. The accelerating and accelerated typologies capture housing market changes associated with gentrifying and gentrified neighborhoods, respectively. 
Tract median and citywide median home values for 1990, 2000, and 2010 were drawn from the 1990 Decennial Census, the 2000 Decennial Census, and 2006-2010 ACS estimates, respectively. Median home values for 1990 and 2000 were converted to 2010 dollars prior to calculating appreciation rates.

Census tract boundary changes

Boundary changes from 1990 to 2000 and 2000 to 2010 were dealt with as described above of this document. 


\section{Appendix B: Data and methods for a neighborhood equity analysis "drilldown"}

Available Variables and data for the drilldown

The focus is on readily available public data sources, and suggestions for additional data collection and analysis.

Housing displacement. A more detailed look at housing displacement should assess the potential form that displacement in a particular neighborhood could take. Both homeowners and renters may be vulnerable to gentrification-related displacement. Affordability and availability of housing can be described using the tabulations for Consolidated Planning: CHAS data (available from HUD) includes cost-burdened renters and owners at different income levels, and units available at an affordable price for different income levels (as well as their occupancy by low-income households).

Household types: focus on additional specific vulnerable populations

- Households with disabilities [CHAS]. Reports housing problems, including costs and substandard units, for households with a member who has a mobility or self-care limitation. Finding accessible housing or supportive services may be even more difficult in an appreciating market.

- Elderly households [CHAS]. Elderly households may be more vulnerable to scams; they are also more likely to leave the neighborhood due to life cycle, making opportunities for new homebuyers. Elderly households may need additional unit modifications or services as they attempt to age in place.

- Large families [CHAS]. Family units are difficult to obtain when incomes are restricted.(for example, Housing Choice Voucher lease success rates are significantly lower for families with several children)

Homeowners: can be displaced by rising taxes, homeowners' insurance (due to increased valuation of homes), foreclosure (often related to subprime refinance loans, or to lending scams), or being pressured to sell without realizing the full increased value of the home.

- Cost-burdened homeowners [CHAS]. Owners paying more than 30\% (cost-burdened) or $50 \%$ (severely cost burdened) of their income on housing are at-risk when taxes or insurance rise; they may also be subject to predatory lending or flipping scams if they are cash-poor.

- New buyers [HMDA] - income and race. Indications that potential buyers of color are not or cannot purchase in the neighborhood may be of concern and could point to opportunities for homebuyer services.

- Foreclosure filings [county- aggregator?]- We did not find a simple solution for these data; but it would be useful to track foreclosures to assess vulnerability to home loss for current owners. Foreclosures are not likely due to gentrification market pressures, but indicate vulnerable homeowners with economic problems. 
Renters: can be displaced by rising rents, expiring subsidies, the turnover of rental units into owner-occupied.

- Subsidized inventory.[Metro Affordable Housing inventory]. number of units and targets; date for expiring units

- Available units at affordable rents [CHAS]. The CHAS data set includes analysis of rental units available at rent levels affordable to households at different income levels, and how many of those affordable units are inhabited by a household of that income level. In other words, it provides availability and actual occupancy data.

Development: Housing exclusion occurs when new development does not include affordable units. Forward tracking should include developments in the pipeline, particularly those with public subsidy (including tax incentives) to ascertain their market niche (unit size and price) relative to housing needs. Exclusion might also occur via code complaints that make it difficult or impossible for owners or landlords to maintain properties as affordable housing. ${ }^{17}$

- Permits for new construction, rehabilitation, teardown-BDS

- Code violations-BDS

- Land purchase/PDC disposition

- Land and buildings underutilized

Community economic development Data should be collected to focus on commercial activity. Decreased vacancies and increased commercial rents can signal reinvestment. A shift in occupancy from resident needs-serving to new kinds of businesses may signal gentrification.

- Commercial data to be tracked by PDC includes:

- Commercial vacancies [USPS quarterly report]

- Commercial rents [Co-Star data]

- Emerging: neighborhood-serving business analysis. Using NAICS code data, analysis could be conducted to assess business type turnover, focusing on neighborhood-serving businesses (e.g. basic grocery, Laundromat) to new in-migrant/destination businesses (e.g. gourmet grocery, wine bar) ${ }^{18}$

Infrastructure investment Geographically disaggregated data on levels of service can indicate whether investments are needed to create more equitable infrastructure - these analyses are already underway for many infrastructure services in the City. Environmental justice-compliance analysis is also important for focusing on impacts on low-income and communities of color. In combination with housing market analysis, infrastructure upgrading may signal potential gentrification pressures.

- Accessibility data [20-minute neighborhood] include street intersections and sidewalks (measuring "walkability"), and frequent service transit availability.

\footnotetext{
${ }^{17}$ This is not to imply that living in substandard housing is acceptable for lower-income households.

${ }^{18}$ This concept was proposed by Tyler Bump of BPS with ideas on how to conduct this analysis through a retrospective of agreed-upon gentrified business districts such as Mississippi Avenue. This proposes to get at the change in neighborhood commercial area character-the shift from everyday corner market to gourmet salt and "urban taxidermy"- -via more detailed data available via NAICS codes for business type and share of employment for different kinds of businesses.
} 
- Access to parks in neighborhood; park improvements

Racial/ethnic demographics. Along with housing vulnerability, racial/ethnic demographics can affect public processes, specifically resident awareness and participation. Public agencies should pay careful attention to whether populations are traditionally underrepresented in planning processes, whether there are some community groups that are substantially better organized and have a greater presence while others are marginalized, and whether there is a need for language interpretation for documents and meetings.

- Specific racial/ethnic population breakdowns [ACS]. There may be existing communitybased organizations that are aware of the needs of smaller populations and can be used to assist in outreach.

- English language proficiency [ACS]. Indicates a need for interpretation services in outreach and participation.

\section{Community institutions.}

- Public school enrollment data-Public schools are of concern as they relate to neighborhood housing markets. School demographics can show neighborhood racial/ethnic demographics and changes. There are concerns when schools are highpoverty. The attraction of higher-income families to neighborhoods may depend on highperforming schools or the ability to exit the catchment area for other education options (other public schools, charters, or private schools). It may be of concern, for example, if there is a significant in-migration of higher income households with children, but a decreasing school enrollment within district (i.e. families not choosing the home school). It would also be of concern if a school were to revamp its curriculum/focus and see a dramatic shift in demographics away from the demographics of resident young people (i.e. resident children unable to qualify for new offerings). These issues are represented by tracking school demographics (race and poverty based on free/reduced lunch status) and the proportion of schoolchildren exiting the neighborhood catchment area to attend other schools. These data are freely available from the public school system.

- Additional data would need to be collected to assess the status of community-based organizations and culturally specific institutions. For example, there is reporting about the movement of historically African-American churches from Northeast to East Portland. Nonprofit organizations could be surveyed to ascertain whether they are incurring additional transportation costs to serve low-income households who have been displaced, are opening satellite offices or considering moves, or have additional insights about growing spatial mismatch between populations they serve and their location. These data could be qualitative and collected from key community-based organizations as identified. 


\section{Appendix C: Cully Neighborhood: drilldown analysis example}

In order to demonstrate some of the information that could be gathered for a drilldown, this section presents some analysis for the Cully neighborhood (defined roughly as Census tracts 74,75 , and 76 and falling into the Susceptible/Early categories in the typology). The information about Cully is not exhaustive and additional data are suggested for further assessment, but this gives a sense of how a drilldown could be produced. Using drilldown data can fill in the picture of the Cully neighborhood. As Cully is a current focus for infrastructure and economic development investments, From the City's initial work on the Cully project, it is apparent that there are a number of community-based organizations prepared to participate in dialogue about development in the neighborhood. These data suggest there are some ethnic/language groups that may be easily marginalized; ensuring that all racial/ethnic groups receive targeted attention and language support may mean engaging with additional CBOs.

Cully is not a high rentership neighborhood and has a number of nonprofit-owned rental developments that will help to stabilize renter households. If public subsidy is directed towards rental development, it could be productive to prioritize units for larger families along with affordability targets. Homeowners in Cully may be at-risk due to age and housing cost burden, so homeownership stability programming may be appropriate. It would also be appropriate to support targeted homebuying support for communities of color, who are underrepresented in new buyers in Cully.

\section{Typology assessment:}

- Vulnerable populations:

- The tracts that make up the Cully neighborhood range from 40 to $50 \%$ communities of color, compared to $27 \%$ in Portland.

- Cully's rate of rentership is about equivalent to Portland's, except in tract 75.

- Cully residents are less likely to have a college degree (between $67 \%$ and $80 \%$ do not have a degree in the three tracts)

- Incomes are lower; over half of residents are at or below $80 \%$ of median family income

- Demographic changes (00-10):

$\circ$ Tract 76 has seen a significant increase in white population (4.3\%), while Portland as a whole became less white $(-3 \%)$

- Two tracts have increased homeownership rates at around $3 \%$ over 2000 , compared to Portland's falling homeownership

- The increase in college-educated residents is higher than Portland's average

- Median income has fallen less than in the city as a whole in two tracts; but tract 74 has substantially declining incomes

- Housing market conditions:

- Cully median home values remain below the citywide median for 1990-2010 
- Appreciation has been increasing in the 2000-2010 period and the neighborhood is adjacent to high appreciation/high value tracts

Housing drilldown highlights:

- Vulnerable populations:

○ Among elderly non-family households ( $11 \%$ of pop), over two-thirds are cost burdened, with most severely cost burdened.

$\circ \quad$ Of large family households (9\%), half are cost burdened.

- Affordability:

○ Of homeowners: $28 \%$ are cost burdened; $13 \%$ are severely cost burdened

- Of renters, over $40 \%$ are severely cost burdened.

- New buyers:

- Two-thirds of new buyers were white in 2011, compared to white households making up half of Cully's population. Loans from white buyers were denied less frequently than those from Latinos and Asians.

- There are 624 units of affordable housing listed as subsidized/income restricted in the Affordable Housing inventory. Only two developments (totally 124 units) have incomerestriction expiration dates within the foreseeable future; as both are owned/managed by nonprofits it is likely they will remain in the affordable inventory.

\section{CED drilldown highlights:}

- Cully is currently the focus of a Main Street partnership that will bring new investment to its commercial corridors

- PLACEHOLDER FOR VACANCY/RENT DATA

Infrastructure drilldown highlights:

- Rated "moderate accessibility" to "room for improvement"

- Recent investment in Cully Boulevard bike/ped infrastructure

- New investments in Cully Commercial Corridor and Local Streets Plan

- Cully Park has ongoing improvements and requested for additional

Racial/ethnic drilldown highlights:

- Communities of color are primarily comprised of Latino/Hispanic (22\%) and AfricanAmerican (19\%); Asian/Asian-American are also present (5\%)

- Over one-quarter of Cully residents speak a language other than English at home.

- About half of the Spanish-speaking population does not speak English very well.

- Vietnamese and African populations, while small, have a majority of households who do not speak English well

Community institution highlights: 
- Cully schools demographics appear to be changing rather substantially; though this may be due to enrollment balancing/redistricting, there are flags raised by high poverty levels and high transfer rates.

- Cully is home to several active community-based organizations working on community development, such as Hacienda CDC and Verde.

\section{Cully - Neighborhood Typology Inputs}

2010 Vulnerability

$\begin{array}{llll}\text { Tract } 74 & \text { Tract } 75 & \text { Tract } 76 & \text { Portland }\end{array}$

\begin{tabular}{|l|c|c|c|c|}
\hline Risk factor \\
\hline Communities of color & $52.4 \%$ & $51.0 \%$ & $41.3 \%$ & $26.7 \%$ \\
\hline Renters & $42.1 \%$ & $33.6 \%$ & $40.2 \%$ & $44.2 \%$ \\
\hline Population 25+ without bachelor's degree & $72.5 \%$ & $67.2 \%$ & $81.6 \%$ & $58.2 \%$ \\
\hline At or below 80\% MFI & $70.9 \%$ & $53.5 \%$ & $59.1 \%$ & $47.0 \%$ \\
\hline Total vulnerability score & 3 & 3 & 3 & - \\
\hline
\end{tabular}

Source: U.S. Census Bureau - 2006-2010 ACS; HUD - 2005-2009 CHAS

2000-2010 Demographic Change

Tract 74 Tract $75 \quad$ Tract $76 \quad$ Portland

Change factor

\begin{tabular}{|l|c|c|c|c|}
\hline Percent white & $-1.3 \%$ & $-7.5 \%$ & $4.3 \%$ & $-3.0 \%$ \\
\hline Percent homeowners & $2.6 \%$ & $3.2 \%$ & $-2.7 \%$ & $-1.2 \%$ \\
\hline Percent pop. 25+ with bachelor's degree & $10.0 \%$ & $16.0 \%$ & $8.8 \%$ & $7.9 \%$ \\
\hline Median household income & $-30.1 \%$ & $-4.5 \%$ & $-4.8 \%$ & $-8.5 \%$ \\
\hline Demographic change score & 3 & 3 & 3 & - \\
\hline
\end{tabular}

Source: U.S. Census Bureau - 2000 Census and 2006-2010 ACS

Housing Market Conditions

Median home value

\begin{tabular}{|l|c|c|c|}
\hline Median home value & $\begin{array}{c}\$ 88,065 \\
(0.89)\end{array}$ & $\begin{array}{c}\$ 83,961 \\
(0.84)\end{array}$ & $\begin{array}{c}\$ 79,173 \\
(0.80)\end{array}$ \\
\hline $\begin{array}{l}1990 \\
\text { (tract:city ratio) }\end{array}$ & $\begin{array}{c}\$ 171,069 \\
(0.87)\end{array}$ & $\begin{array}{c}\$ 164,973 \\
(0.84)\end{array}$ & $\begin{array}{c}\$ 152,908 \\
(0.78)\end{array}$ \\
\hline $\begin{array}{l}2000 \\
\text { tract:city ratio) }\end{array}$ & $\begin{array}{c}\$ 270,400 \\
(0.93)\end{array}$ & $\begin{array}{c}\$ 243,800 \\
(0.83)\end{array}$ & $\begin{array}{c}\$ 234,600 \\
(0.80)\end{array}$ \\
\hline $\begin{array}{l}2010 \\
\text { (tract:city ratio) }\end{array}$ & $94.3 \%$ & $96.5 \%$ & $93.1 \%$ \\
\hline Appreciation & $58.1 \%$ & $47.8 \%$ & $53.4 \%$ \\
\hline $1990-2000$ & $207.0 \%$ & $190.4 \%$ & $196.3 \%$ \\
\hline $2000-2010$ & accelerating & accelerating & adjacent \\
\hline $1990-2010$ &
\end{tabular}

Source: U.S. Census Bureau - 1990, 2000, 2010 Census

Tract $74 \quad$ Tract $75 \quad$ Tract 76 


\section{Cully - Neighborhood Typology Inputs}

\begin{tabular}{|l|c|c|c|c|} 
Population & \multicolumn{1}{c}{ Tract 74 } & Tract 75 & Tract 76 & \multicolumn{1}{c|}{ Combined } \\
\hline 1990 & 2,765 & 4,193 & 3,176 & 10,134 \\
\hline 2000 & 3,247 & 4,937 & 3,760 & 11,944 \\
\hline 2010 & 3,654 & 5,080 & 3,562 & 12,296 \\
\hline
\end{tabular}

Source: U.S. Census Bureau - 1990, 2000, 2010 Census

Age

Under 5 Years

5 to 9 Years

10 to 14 Years

15 to 17 Years

18 to 24 Years

25 to 34 Years

35 to 44 Years

45 to 54 Years

55 to 64 Years

65 to 74 Years

75 to 84 Years

85 Years and over

Source: U.S. Census Bureau - 2006-2010 ACS

Race/Ethnicity

Not Hispanic or Latino

White alone

Black or African American alone

American Indian and Alaska Native alone

Asian alone

Native Hawaiian and other Pacific Islander alone

Some other race alone

Two or more races

Hispanic or Latino

White alone

Black or African American alone

American Indian and Alaska Native alone

Asian Alone

Native Hawaiian and Other Pacific Islander alone

Some other race alone

Two or more races

All communities of color

Source: U.S. Census Bureau - 2006-2010 ACS

Tract 74 $\quad$ Tract 75 $\quad$ Tract 76 $\quad$ Combined

\begin{tabular}{|l|l|l|l|}
\hline $5.7 \%$ & $8.7 \%$ & $6.3 \%$ & $7.2 \%$ \\
\hline
\end{tabular}

$5.8 \%$

$6.7 \%$

$10.3 \%$

$7.4 \%$

$4.7 \%$

$5.6 \%$

$5.3 \%$

$10.1 \%$

$17.9 \%$

$15.0 \%$

$14.1 \%$

$9.9 \%$

$3.8 \%$

$2.1 \%$

$5.7 \%$

$3.2 \%$

$6.0 \%$

$19.1 \%$

$14.7 \%$

$11.7 \%$

$5.0 \%$

$8.3 \%$

$7.1 \%$

$3.8 \%$

$7.2 \%$

$2.4 \%$

$9.8 \%$

\begin{tabular}{l|l}
$14.7 \%$ & $15.4 \%$ \\
\hline $14.8 \%$ & $15.7 \%$
\end{tabular}

$14.8 \%$

$15.7 \%$

$17.5 \%$

\begin{tabular}{l|l}
$8.0 \%$ & $8.4 \%$
\end{tabular}

$3.8 \%$

$2.9 \%$

$7.6 \%$

$5.1 \%$

$3.0 \%$

$2.4 \%$

\begin{tabular}{|l|l|l|l}
\hline Tract 74 & Tract 75 & Tract 76 & Combined \\
\hline 76.5\% & $78.9 \%$ & $76.8 \%$ & $77.7 \%$ \\
\hline
\end{tabular}

\begin{tabular}{|c|c|c|c|}
\hline $76.5 \%$ & $78.9 \%$ & $76.8 \%$ & $77.7 \%$ \\
\hline $47.6 \%$ & $49.0 \%$ & $58.7 \%$ & $51.2 \%$ \\
\hline $0.0 \%$ & $0.0 \%$ & $0.0 \%$ & $0.0 \%$ \\
\hline $4.2 \%$ & $4.8 \%$ & $6.2 \%$ & $5.0 \%$ \\
\hline $0.0 \%$ & $0.0 \%$ & $0.0 \%$ & $0.0 \%$ \\
\hline $0.4 \%$ & $0.2 \%$ & $0.0 \%$ & $0.2 \%$ \\
\hline $4.3 \%$ & $1.7 \%$ & $0.4 \%$ & $2.1 \%$ \\
\hline $23.5 \%$ & $21.1 \%$ & $23.2 \%$ & $22.3 \%$ \\
\hline $11.7 \%$ & $9.9 \%$ & $11.3 \%$ & $10.8 \%$ \\
\hline $0.0 \%$ & $2.6 \%$ & $0.0 \%$ & $1.2 \%$ \\
\hline $1.9 \%$ & $0.0 \%$ & $0.0 \%$ & $0.5 \%$ \\
\hline $0.0 \%$ & $0.3 \%$ & $0.0 \%$ & $0.1 \%$ \\
\hline $0.0 \%$ & $0.0 \%$ & $0.0 \%$ & $0.0 \%$ \\
\hline $10.0 \%$ & $8.3 \%$ & $12.0 \%$ & $9.7 \%$ \\
\hline $0.0 \%$ & $0.0 \%$ & $0.0 \%$ & $0.0 \%$ \\
\hline $52.4 \%$ & $51.0 \%$ & $41.3 \%$ & $48.8 \%$ \\
\hline
\end{tabular}




\begin{tabular}{|l|c|c|c|c|}
\hline Foreign-Born Population & \multicolumn{1}{c}{ Tract 74 } & Tract 75 & Tract 76 & \multicolumn{1}{c|}{ Combined } \\
\hline Native & $80.4 \%$ & $86.8 \%$ & $76.7 \%$ & $82.4 \%$ \\
\hline Foreign-born & $19.6 \%$ & $13.2 \%$ & $23.3 \%$ & $17.7 \%$ \\
\hline
\end{tabular}

Source: U.S. Census Bureau - 2006-2010 ACS

Language Spoken at Home for Population

5 Years and Over

$\begin{array}{llll}\text { Tract 74 } & \text { Tract 75 } & \text { Tract 76 } & \text { Combined }\end{array}$

Speak only English

Spanish

Speak English "very well"

Speak English less than "very well"

Vietnamese

Speak English "very well"

Speak English less than "very well"

African languages

Speak English "very well"

Speak English less than "very well"

Other

Speak English "very well"

Speak English less than "very well"

Source: U.S. Census Bureau - 2006-2010 ACS

Income

Tract 74

Median household income

$\$ 34,390$

Tract 75

Tract 76

Combined

Source: U.S. Census Bureau - 2006-2010 ACS

\begin{tabular}{|l|c|c|c|c|}
\hline Educational Attainment & \multicolumn{1}{c}{ Tract 74 } & Tract 75 & Tract 76 & \multicolumn{1}{c|}{ Combined } \\
\hline Total population 25+ & 2,433 & 3,830 & 2,003 & 8,266 \\
\hline Less than high school graduate & $25.0 \%$ & $14.1 \%$ & $20.7 \%$ & $18.9 \%$ \\
\hline High school graduate & $22.5 \%$ & $26.4 \%$ & $29.6 \%$ & $26.0 \%$ \\
\hline Some college & $20.6 \%$ & $21.2 \%$ & $25.1 \%$ & $22.0 \%$ \\
\hline Associate's degree & $4.4 \%$ & $5.4 \%$ & $6.2 \%$ & $5.3 \%$ \\
\hline Bachelor's degree & $14.6 \%$ & $21.0 \%$ & $12.6 \%$ & $17.1 \%$ \\
\hline Graduate or professional degree & $12.9 \%$ & $11.9 \%$ & $5.7 \%$ & $10.7 \%$ \\
\hline
\end{tabular}

Source: U.S. Census Bureau - 2006-2010 ACS

\begin{tabular}{|c|c|c|c|c|}
\hline Tenure & Tract 74 & Tract 75 & Tract 76 & Combined \\
\hline Total \# households & 1,383 & 1,930 & 1,190 & 4,503 \\
\hline Renters & $42.1 \%$ & $33.6 \%$ & $40.2 \%$ & $37.9 \%$ \\
\hline Homeowners & $57.9 \%$ & $66.4 \%$ & $59.8 \%$ & $62.1 \%$ \\
\hline
\end{tabular}

Source: U.S. Census Bureau - 2006-2010 ACS 


Housing Cost Burden by Tenure
\begin{tabular}{|l|c|c|c|c|}
\hline Renters & Tract 74 & Tract 75 & Tract 76 & Combined \\
\hline Less than/equal to 30\% of income & $33.1 \%$ & $49.4 \%$ & $31.9 \%$ & $38.9 \%$ \\
\hline $\begin{array}{l}\text { Greater than 30\% but less than/equal to 50\% } \\
\text { of income }\end{array}$ & $16.6 \%$ & $20.7 \%$ & $23.1 \%$ & $19.6 \%$ \\
\hline Greater than 50\% of income & $49.0 \%$ & $29.9 \%$ & $45.0 \%$ & $41.0 \%$ \\
\hline Not calculated (no income/negative income) & $1.3 \%$ & $0.0 \%$ & $0.0 \%$ & $0.5 \%$ \\
\hline \begin{tabular}{l|l|l|} 
Homeowners \\
\hline Less than/equal to 30\% of income
\end{tabular} & $52.7 \%$ & $60.2 \%$ & $57.1 \%$ & $57.5 \%$ \\
\hline $\begin{array}{l}\text { Greater than 30\% but less than/equal to 50\% } \\
\text { of income }\end{array}$ & $30.2 \%$ & $27.4 \%$ & $27.9 \%$ & $28.2 \%$ \\
\hline Greater than 50\% of income & $17.1 \%$ & $11.1 \%$ & $13.6 \%$ & $13.3 \%$ \\
\hline Not calculated (no income/negative income) & $0.0 \%$ & $1.2 \%$ & $1.4 \%$ & $1.0 \%$ \\
\hline
\end{tabular}

Source: HUD - 2005-2009 CHAS Data

Household Type

\begin{tabular}{|l|l|l|l}
\hline Tract 74 & Tract 75 & Tract 76 & Combined \\
\hline
\end{tabular}

Small family (3 or 4 persons, or 2 persons with neither age 62 or over)

Large family (5 or more persons)

Elderly family (2 persons, either or both age 62 or over)

Elderly non-family

Other (non-elderly non-family)

Tract 74 Tract $75 \quad$ Tract 76 Combined

Source: HUD - 2005-2009 CHAS Data

Housing Cost Burden by Household Type

Tract $74 \quad$ Tract 75

Tract 76 Combined

Small family (3 or 4 persons, or 2 persons with neither age 62 or over)

\begin{tabular}{|c|c|c|c|c|}
\hline Less than/equal to $30 \%$ of income & $53.1 \%$ & $54.9 \%$ & $61.7 \%$ & $55.8 \%$ \\
\hline $\begin{array}{l}\text { Greater than } 30 \% \text { but less than/equal to } 50 \% \\
\text { of income }\end{array}$ & $19.5 \%$ & $20.9 \%$ & $22.3 \%$ & $20.7 \%$ \\
\hline Greater than $50 \%$ of income & $14.7 \%$ & $19.9 \%$ & $6.4 \%$ & $15.1 \%$ \\
\hline Not calculated (no income/negative income) & $12.8 \%$ & $4.3 \%$ & $9.6 \%$ & $8.4 \%$ \\
\hline \multicolumn{5}{|l|}{ Large family (5 or more persons) } \\
\hline Less than/equal to $30 \%$ of income & $66.7 \%$ & $67.7 \%$ & $23.5 \%$ & $51.3 \%$ \\
\hline $\begin{array}{l}\text { Greater than } 30 \% \text { but less than/equal to } 50 \% \\
\text { of income }\end{array}$ & $33.3 \%$ & $25.8 \%$ & $2.7 \%$ & $19.3 \%$ \\
\hline Greater than $50 \%$ of income & $0.0 \%$ & $6.5 \%$ & $73.8 \%$ & $29.3 \%$ \\
\hline Not calculated (no income/negative income) & $0.0 \%$ & $0.0 \%$ & $0.0 \%$ & $0.0 \%$ \\
\hline \multicolumn{5}{|c|}{ Elderly family (2 persons, either or both age 62 or over) } \\
\hline Less than/equal to $30 \%$ of income & $85.1 \%$ & $76.2 \%$ & $61.9 \%$ & $76.0 \%$ \\
\hline $\begin{array}{l}\text { Greater than } 30 \% \text { but less than/equal to } 50 \% \\
\text { of income }\end{array}$ & $14.9 \%$ & $17.7 \%$ & $22.2 \%$ & $17.8 \%$ \\
\hline Greater than $50 \%$ of income & $0.0 \%$ & $6.1 \%$ & $15.9 \%$ & $6.2 \%$ \\
\hline Not calculated (no income/negative income) & $0.0 \%$ & $0.0 \%$ & $0.0 \%$ & $0.0 \%$ \\
\hline
\end{tabular}




\begin{tabular}{|c|c|c|c|c|}
\hline \multicolumn{5}{|l|}{ Elderly non-family } \\
\hline Less than/equal to $30 \%$ of income & $14.5 \%$ & $58.1 \%$ & $43.5 \%$ & $32.2 \%$ \\
\hline $\begin{array}{l}\text { Greater than } 30 \% \text { but less than/equal to } 50 \% \\
\text { of income }\end{array}$ & $22.5 \%$ & $15.5 \%$ & $43.5 \%$ & $25.5 \%$ \\
\hline Greater than $50 \%$ of income & $63.0 \%$ & $26.4 \%$ & $13.0 \%$ & $42.3 \%$ \\
\hline Not calculated (no income/negative income) & $0.0 \%$ & $0.0 \%$ & $0.0 \%$ & $0.0 \%$ \\
\hline \multicolumn{5}{|l|}{ Other (non-elderly non-family) } \\
\hline Less than/equal to $30 \%$ of income & $37.1 \%$ & $55.9 \%$ & $40.8 \%$ & $47.2 \%$ \\
\hline $\begin{array}{l}\text { Greater than } 30 \% \text { but less than/equal to } 50 \% \\
\text { of income }\end{array}$ & $19.4 \%$ & $25.2 \%$ & $32.9 \%$ & $26.0 \%$ \\
\hline Greater than $50 \%$ of income & $40.3 \%$ & $16.5 \%$ & $26.3 \%$ & $24.9 \%$ \\
\hline Not calculated (no income/negative income) & $3.2 \%$ & $2.4 \%$ & $0.0 \%$ & $1.9 \%$ \\
\hline
\end{tabular}

Source: HUD - 2005-2009 CHAS Data

\begin{tabular}{|c|c|c|c|}
\hline School Enrollment & 2005-2006 & 2011-2012 & Change \\
\hline \multicolumn{4}{|l|}{ Rigler K-5 } \\
\hline Total enrollment & 442 & 524 & $18.6 \%$ \\
\hline Percent communities of color & $83.5 \%$ & $78.8 \%$ & $-4.7 \%$ \\
\hline Percent receiving free/reduced lunch & $84.3 \%$ & $84.5 \%$ & $0.2 \%$ \\
\hline Neighborhood PPS student population & 639 & 656 & $2.7 \%$ \\
\hline Percent of neighborhood students enrolled & $59.0 \%$ & $69.0 \%$ & $10.0 \%$ \\
\hline \multicolumn{4}{|l|}{ Scott K-8 } \\
\hline Total enrollment & 369 & 521 & $41.2 \%$ \\
\hline Percent communities of color & $60.7 \%$ & $79.7 \%$ & $19.0 \%$ \\
\hline Percent receiving free/reduced lunch & $68.4 \%$ & $88.5 \%$ & $20.1 \%$ \\
\hline Neighborhood PPS student population & 437 & 723 & $65.4 \%$ \\
\hline Percent of neighborhood students enrolled & $65.0 \%$ & $63.0 \%$ & $-2.0 \%$ \\
\hline \multicolumn{4}{|l|}{ Vernon PK-8 } \\
\hline Total enrollment & 384 & 500 & $30.2 \%$ \\
\hline Percent communities of color & $90.4 \%$ & $72.2 \%$ & $-18.2 \%$ \\
\hline Percent receiving free/reduced lunch & $87.8 \%$ & $72.8 \%$ & $-15.0 \%$ \\
\hline Neighborhood PPS student population & 667 & 818 & $22.6 \%$ \\
\hline Percent of neighborhood students enrolled & $43.0 \%$ & $47.0 \%$ & $4.0 \%$ \\
\hline \multicolumn{4}{|l|}{ Beaumont 6-8 } \\
\hline Total enrollment & 536 & 481 & $-10.3 \%$ \\
\hline Percent communities of color & $55.0 \%$ & $40.1 \%$ & $-14.9 \%$ \\
\hline Percent receiving free/reduced lunch & $43.0 \%$ & $31.8 \%$ & $-11.2 \%$ \\
\hline Neighborhood PPS student population & 503 & 327 & $35.0 \%$ \\
\hline Percent of neighborhood students enrolled & $59.0 \%$ & $65.0 \%$ & $6.0 \%$ \\
\hline
\end{tabular}

Source: Portland Public Schools Enrollment 2005-2006 and 2011-2012 Profiles

Note: Reduced-price and free meals are available to households with annual incomes at/below $185 \%$ and $130 \%$ of the federal poverty guideline, respectively. Poverty guidelines are based on household size; for a four-person household in 2011-2012, the federal poverty guideline was an annual income of $\$ 22,350$. 


\begin{tabular}{|l|c|c|}
$\begin{array}{l}\text { School Performance } \\
\text { Attendance, Participation) }\end{array}$ & $\begin{array}{c}\text { Math/Reading } \\
\text { Achievement }\end{array}$ \\
\hline Rigler K-5 & In need of improvement & Satisfactory \\
\hline Scott K-8 & Satisfactory & Satisfactory \\
\hline Vernon PK-8 & Satisfactory & Satisfactory \\
\hline Beaumont 6-8 & Outstanding & Outstanding \\
\hline
\end{tabular}

Source: Oregon Department of Education 2011-2012 School Report Cards

\begin{tabular}{|c|c|c|c|c|}
\hline $\begin{array}{l}\text { Home Purchase Loan Applicants } \\
\text { by Race/Ethnicity }\end{array}$ & Tract 74 & Tract 75 & Tract 76 & Combined \\
\hline White (non-Hispanic) & $80.4 \%$ & $73.2 \%$ & $43.1 \%$ & $63.0 \%$ \\
\hline Black or African American (non-Hispanic) & $0.0 \%$ & $3.7 \%$ & $2.0 \%$ & $2.1 \%$ \\
\hline $\begin{array}{l}\text { American Indian and Alaska Native (non- } \\
\text { Hispanic) }\end{array}$ & $0.0 \%$ & $0.0 \%$ & $0 \%$ & $0 \%$ \\
\hline Asian (non-Hispanic) & $0.0 \%$ & $0.0 \%$ & $11.8 \%$ & $3.2 \%$ \\
\hline $\begin{array}{l}\text { Native Hawaiian and other Pacific Islander } \\
\text { (non-Hispanic) }\end{array}$ & $0.0 \%$ & $0.0 \%$ & $2.0 \%$ & $0.5 \%$ \\
\hline Hispanic (of an race) & $0.0 \%$ & $2.4 \%$ & $3.9 \%$ & $2.1 \%$ \\
\hline Race/ethnicity unknown & $19.6 \%$ & $20.7 \%$ & $37.3 \%$ & $29.1 \%$ \\
\hline
\end{tabular}

Source: FFIEC - 2011 HMDA Data

Home Purchase Loan Denial Rates

$\begin{array}{lllll}\text { by Race/Ethnicity of Applicant } & \text { Tract } 74 & \text { Tract } 75 & \text { Tract } 76 & \text { Combined }\end{array}$

White (non-Hispanic)

\begin{tabular}{|l|c|c|c|c|}
\hline Total \# applicants & 37 & 60 & 22 & 119 \\
\hline Denial rate & $5.4 \%$ & $0.0 \%$ & $4.5 \%$ & $2.5 \%$ \\
\hline
\end{tabular}

Black or African American (non-Hispanic)

\begin{tabular}{|l|c|c|c|c|}
\hline Total \# applicants & 0 & 3 & 1 & 4 \\
\hline Denial rate & - & $0.0 \%$ & $0.0 \%$ & $0.0 \%$ \\
\hline
\end{tabular}

American Indian and Alaska Native (non-Hispanic)

\begin{tabular}{|l|c|c|c|c|}
\hline Total \# applicants & 0 & 0 & 0 & 0 \\
\hline Denial rate & - & - & - & - \\
\hline Asian (non-Hispanic) & 0 & 0 & 6 & 6 \\
\hline Total \# applicants & - & - & $33.3 \%$ & $33.3 \%$ \\
\hline Denial rate &
\end{tabular}

Native Hawaiian and other Pacific Islander (non-Hispanic)

\begin{tabular}{|l|c|c|c|c|}
\hline Total \# applicants & 0 & 0 & 1 & 1 \\
\hline Denial rate & - & - & $0.0 \%$ & $0.0 \%$ \\
\hline Hispanic (of any race) & 0 & 2 & 2 & 4 \\
\hline Total \# applicants
\end{tabular}




\begin{tabular}{|c|c|c|c|c|}
\hline Denial rate & - & $0.0 \%$ & $50.0 \%$ & $25.0 \%$ \\
\hline \multicolumn{5}{|c|}{ Race/ethnicity unknown } \\
\hline Total \# applicants & 9 & 17 & 19 & 45 \\
\hline Denial rate & $0.0 \%$ & $5.9 \%$ & $0.0 \%$ & $2.2 \%$ \\
\hline
\end{tabular}

Source: FFIEC - 2011 HMDA Data

\begin{tabular}{|c|c|c|c|c|}
\hline $\begin{array}{l}\text { Affordable Housing } \\
\text { Project Name }\end{array}$ & Sponsor Name & $\begin{array}{l}\text { Year } \\
\text { Built }\end{array}$ & $\begin{array}{c}\text { Year } \\
\text { Rehab. }\end{array}$ & $\begin{array}{l}\text { Regulated } \\
\text { Units }\end{array}$ \\
\hline 5195 NE Killingsworth St. & Cascadian Terrace Apartments & unavail. & - & 37 \\
\hline 5310 NE Cully Blvd. & Sabin CDC & 1970 & - & 20 \\
\hline 6936 NE Killingsworth St. & Jubilee Fellowship Ministries & 1978 & - & 25 \\
\hline 6766 NE Killingsworth St. & Albina Corner LP & 1999 & - & 12 \\
\hline 6480 NE Killingsworth St. & Sabin CDC & 1999 & - & 16 \\
\hline 6840 NE Killingsworth St. & Reach CDC, Inc. & 2006 & - & 27 \\
\hline 5000 NE Killingsworth St. & PCRI, Inc. & unavail. & - & 34 \\
\hline 5323 NE Cully Blvd. & Sabin CDC & 2006 & - & 18 \\
\hline 5731 NE Simpson St. & PCRI, Inc. & 1942 & - & 1 \\
\hline Villa de Suenos & Hacienda CDC & 1999 & - & 28 \\
\hline Elderplace at Cully & Sisters of Providence & 1996 & - & 6 \\
\hline Villa de Clara Vista & Hacienda CDC & 2004 & - & 118 \\
\hline $\begin{array}{l}\text { Barbra Roberts } \\
\text { East/West }\end{array}$ & Cascadia Behavioral Healthcare Inc. & 1995 & - & 5 \\
\hline Roselyn Villa & Charles Iheanacho & 2007 & - & 4 \\
\hline Clara Vista Townhomes & Hacienda CDC & 2006 & - & 44 \\
\hline Prescott Terrace & Cascadia Behavioral Healthcare Inc. & 1972 & 2005 & 48 \\
\hline Villas de Mariposas & Hacienda CDC & 2004 & - & 70 \\
\hline Los Jardines & Hacienda CDC & 2002 & - & 42 \\
\hline 7011 NE Emerson St. & PCRI, Inc. & 1941 & 2001 & 2 \\
\hline Good Shepherd II & Good Shepherd Corporation of Oregon & 1988 & - & 5 \\
\hline Prescott Place & Reach CDC, Inc. & 1990 & - & 19 \\
\hline Sunrise Place & PCRI, Inc. & 1996 & - & 10 \\
\hline $\begin{array}{l}\text { Large Family Rental } \\
\text { Housing }\end{array}$ & Hacienda CDC & 1999 & - & 4 \\
\hline NE Simpson & Good Shepherd Corporation of Oregon & 1989 & - & 5 \\
\hline Carlton Court & Government-owned with PBA subsidy & 1974 & - & 24 \\
\hline Total & - & - & - & 624 \\
\hline
\end{tabular}

Source: Metro - 2011 Affordable Housing Inventory 
20-Minute Neighborhood Analysis

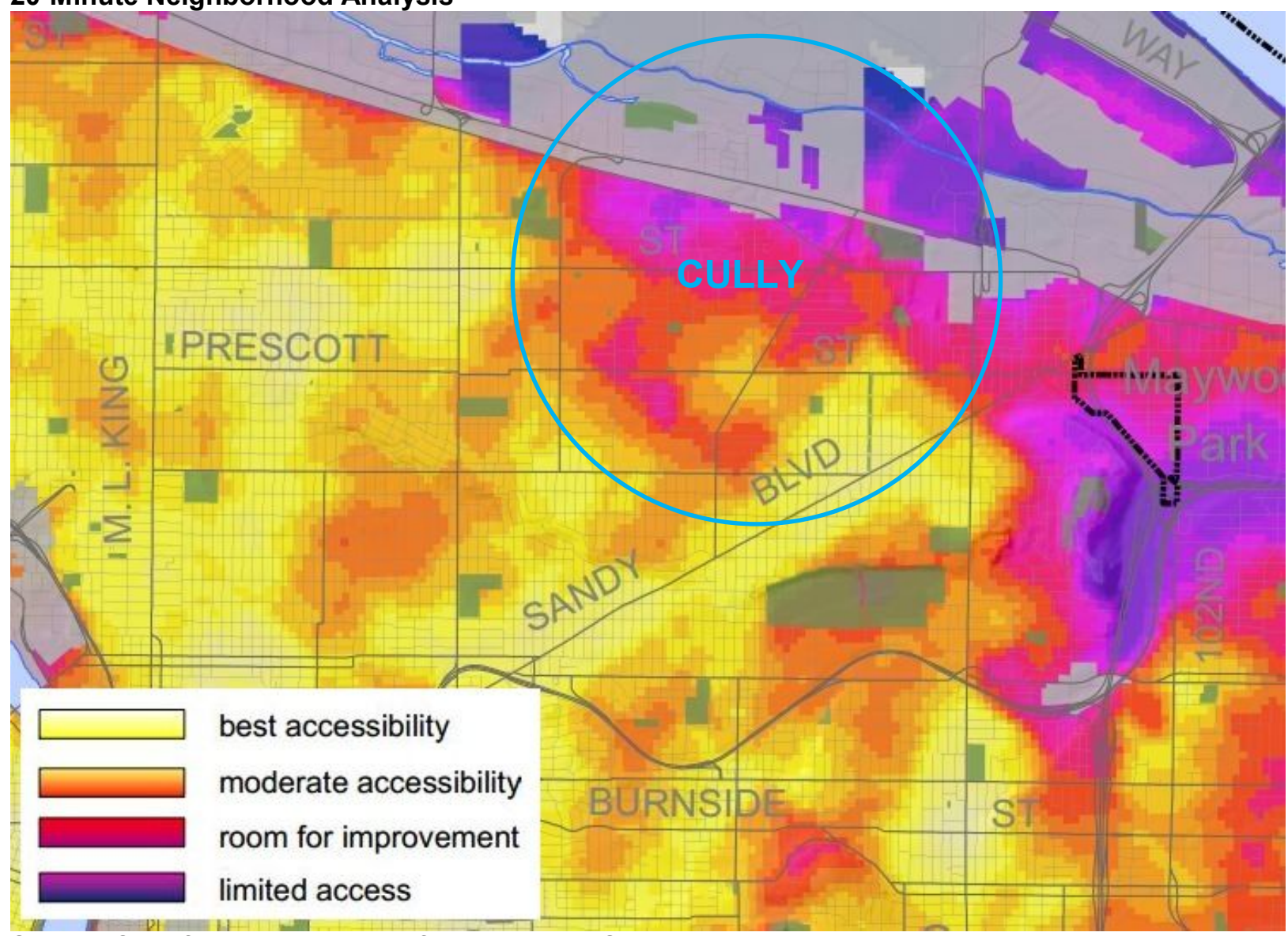

Source: City of Portland Bureau of Planning and Sustainability - 2010 20-Minute Neighborhood Analysis 


\section{Appendix D: Annotated Policy toolkit: best practices}

This section lists resources for specific tools and policies used as best practices for mitigating the harms of gentrification.

To simplify the implementation of a gentrification strategy, the 6 types of changing neighborhoods are collapsed into three categories. Early includes susceptible and both types of early gentrification neighborhoods; Mid includes dynamic neighborhoods; and Late are late and continued loss neighborhoods.

1 Plan for inclusive, equitable development

\begin{tabular}{|c|c|c|c|}
\hline Tool & Early & Mid & Late \\
\hline $\begin{array}{l}\text { Health Impact Assessment/Environmental Impact } \\
\text { Assessment }\end{array}$ & $x$ & $x$ & $x$ \\
\hline Community Impact Report & $\mathrm{X}$ & $\mathrm{X}$ & $x$ \\
\hline Community Benefits Agreement and tools & & $\mathrm{X}$ & $x$ \\
\hline Neighborhood planning process & $x$ & $\mathrm{X}$ & \\
\hline Support community building initiatives & $\mathrm{X}$ & $\mathrm{X}$ & \\
\hline Task force/community advisory committee & $\mathrm{X}$ & $\mathrm{X}$ & \\
\hline
\end{tabular}

2 Increase/preserve opportunities for affordable housing

\subsection{Generate revenue for housing programs}

\begin{tabular}{|l|l|l|l|}
\hline Strategy & Early & Mid & Late \\
\hline Housing levy & X & X & X \\
\hline Document recording fee & X & X & X \\
\hline Housing Trust Fund & X & X & X \\
\hline Developer exactions & X & $X$ & $X$ \\
\hline Tax Increment Financing & $X$ & $X$ & $X$ \\
\hline Real estate transfer taxes & $X$ & $X$ & \\
\hline
\end{tabular}


2.2 Create new affordable housing

\begin{tabular}{|l|l|l|l|}
\hline Tool & Early & Mid & Late \\
\hline Commercial linkage program & & X & X \\
\hline Inclusionary zoning & & $X$ & $X$ \\
\hline Vacant/underutilized land & $X$ & $X$ & \\
\hline Revise zoning & X & $X$ & $X$ \\
\hline
\end{tabular}

\subsection{Preserve affordable housing}

\begin{tabular}{|l|l|l|l|}
\hline Strategy & Early & Mid & Late \\
\hline Code enforcement & X & X & \\
\hline Replacement ordinance and "right to return" policy & & & X \\
\hline Retain expiring-subsidy units & X & $X$ & X \\
\hline Rent control & & $X$ & $X$ \\
\hline Eviction protection laws & $X$ & $X$ & \\
\hline
\end{tabular}


3 Build assets and retain residents and businesses

\begin{tabular}{|l|l|l|l|}
\hline Tool & Early & Mid & Late \\
\hline Homeownership programs & $X$ & $X$ & \\
\hline Commercial stabilization & $X$ & $X$ & \\
\hline Individual Development Accounts & $X$ & & \\
\hline Property tax relief & & $X$ & $X$ \\
\hline Resident ownership & $X$ & $X$ & \\
\hline Targeted economic development & $X$ & $X$ & \\
\hline Resident stakeholders & $X$ & $X$ & \\
\hline Preserve cultural facilities & $X$ & $X$ & \\
\hline
\end{tabular}

\section{Links to major online resources:}

Partnership for Working Families: Policy and Tools. http://www.forworkingfamilies.org/ HousingPolicy.org: Toolbox. http://www.housingpolicy.org

PolicyLink: Equitable Development Toolkit. http://www.policylink.org 


\section{Descriptions and resources for individual tools:}

\section{Plan for inclusive, equitable development}

Health Impact Assessment/Environmental Impact Assessment Modify Environmental and Health Impact Assessments to include socioeconomic impacts; use to minimize adverse effects of development.

Malekafzali, S. and Bergstrom, D. (2011). Healthy Corridor for All: A Community Health Impact Assessment of Transit-Oriented Development in Saint Paul, Minnesota (Summary). Washington, DC: PolicyLink.

The Healthy Corridor summary report describes the use of a Health Impact Assessment to measure risks and opportunities for communities near the Twin Cities' Central Corridor light rail project. It discusses the HIA process and methodology and presents findings related to economic development, affordable housing, and transportation for affected communities.

\section{Community Impact Report}

Utilize Community Impact Reports during early stages of development process to assess fiscal, employment, housing, neighborhood services, and smart growth impacts of projects.

Partnership for Working Families. (2012). Policy and Tools: Community Impact Reports. Washington, DC.

This tool provides an overview of Community Impact Reports and their benefits, and includes links to existing CIR measures and draft ordinance language.

Community benefits tools

Support community-negotiated Community Benefits Agreements (CBAs) with commercial developers to include living wage jobs, local hiring, and/or affordable housing; create incentives for large businesses to create employee-assisted housing programs; incorporate community benefits into City policies (e.g., first-source hiring for contracting jobs).

East Bay Alliance for a Sustainable Economy. (2008). Building a Better Bay Area: Community Benefits Tools and Case Studies to Achieve Responsible Development. Oakland, CA.

This report makes a case for a new framework for responsible development and discusses opportunities for communities to pursue project-based negotiated agreements and Community Benefits Agreements. It offers several examples of agreements formed around commercial, retail, mixed-use and residential projects. 
Good Jobs First and California Partnership for Working Families. (2005). Community Benefits Agreements: Making Development Projects Accountable. Washington, DC.

This handbook is intended to help community organizations understand how Community Benefits Agreements work. It covers CBA basics, pros and cons, implementation, monitoring and enforcement, and the range of benefits for which community groups can negotiate. Several examples are included as well as CBA language from existing agreements.

Partnership for Working Families. (2009). Community Benefits: Practical Tools for Proactive Development. Washington, DC.

This tool for local government officials describes the community benefits model and examples of Community Benefits Agreements that have created job and housing opportunities, neighborhood amenities, and environmental wealth for underserved communities. It discusses local government's role in encouraging private CBA negotiations and enacting citywide community benefits policies.

Partnership for Working Families (2010). The Tracking Toolbox. Washington, DC. The Tracking Toolbox is designed to help community groups and organizers understand the basics of the development process so they can engage with it to influence development outcomes. It maps out the involved actors and typical steps most large projects go through, and offers suggestions on ways for community groups to keep track of development projects.

Neighborhood planning process

Allow local residents to create neighborhood plan that guides development; proposals at odds with plan trigger review by neighborhood planning team.

Sobel, E. (2008). Austin, TX: The East Austin Neighborhood. Dallas, TX: Federal Reserve Bank of Dallas.

This case study of East Austin describes the City of Austin's neighborhood planning process, through which community members can create a neighborhood plan and review proposals that do not fit with their development vision. After review, the neighborhood team makes recommendations to the planning board regarding the proposed project.

Support community building initiatives

Support local community organizations working to empower residents through community building initiatives.

Task force/community advisory committee Convene a gentrification/affordable housing task force; create community advisory committee to guide development decisions 
Levy, D.K., Comey, J., \& Padilla, S. (2006). In the Face of Gentrification: Case Studies of Local Efforts to Mitigate Displacement. Washington, DC: The Urban Institute.

This report's case study of Atlanta's Reynoldstown neighborhood describes how local government created task forces to make policy recommendations related to gentrification and affordable housing, a strategy that complemented other antidisplacement efforts pursued by the City.

\section{Increase/preserve opportunities for affordable housing}

\subsection{Generate revenue for housing programs}

Housing Levy

Establish a property tax levy to raise funds for affordable housing development and preservation.

City of Seattle. (2012). Housing Levy Impact: 2011 Report of Accomplishments.

This progress report for Seattle's 2009 housing levy provides background information about the levy and the programs--used to create and preserve affordable housing, assist first-time homebuyers, and provide emergency rent assistance--that it supports. The report briefly describes levy policies regarding allocation of funds and program monitoring by the Housing Levy Oversight Committee, and provides 2011 funding summaries for each of the levy-funded programs.

Levy, D.K., Comey, J., \& Padilla, S. (2006). In the Face of Gentrification: Case Studies of Local Efforts to Mitigate Displacement. Washington, DC: The Urban Institute.

This report's case study of Seattle's Central Area provides more information about the housing levy, including the City's efforts to get it passed, the housing programs it funds, and various implementation challenges.

Document recording fee

Establish fee for filing of deeds, mortgages, real property contracts, etc. to finance affordable housing development and preservation.

Housing Trust Fund

Establish Housing Trust Fund as a dedicated funding source for affordable housing development and preservation.

PolicyLink. (2002). Equitable Development Toolkit: Housing Trust Fund. Washington, DC.

This report describes the creation of Housing Trust Funds as a stable funding source for a variety of uses, including acquisition, new construction, rehabilitation, emergency repairs, and housing-related programs such as rental assistance and homeownership education. It covers program administration and oversight, program design (including the awards process, disbursement options, eligible applicants, and income guidelines), and revenue sources; key players, implementation challenges, and related policy are also discussed. The report includes case studies of Housing 
Trust Fund programs at the local (Boulder, $\mathrm{CO}$ ), regional (King County, WA), and state (Florida) level along with links to additional resources.

Levy, D.K., Comey, J., \& Padilla, S. (2006). Keeping the Neighborhood Affordable: Housing Strategies for Gentrifying Areas. Washington, DC: The Urban Institute.

Section 2 of this report focuses on strategies to develop affordable housing, including creation of a Housing Trust Fund. The authors provide a brief description of the strategy and discuss anticipated outcomes, implementation challenges, and timing considerations.

Developer exactions

Use impact fees to finance affordable housing development and preservation.

PolicyLink. (2002). Equitable Development Toolkit: Developer Exactions. Washington, DC.

This report describes types of developer exactions and briefly discusses key players and implementation.

Tax Increment Financing

Dedicate a portion of tax increment funds to financing affordable housing development and preservation.

Levy, D.K., Comey, J., \& Padilla, S. (2006). Keeping the Neighborhood Affordable: Housing Strategies for Gentrifying Areas. Washington, DC: The Urban Institute.

Section 2 of this report focuses on strategies to develop affordable housing, including Tax Increment Financing. Traditionally used to finance economic development projects, some jurisdictions attach other requirements to TIF legislation, such as requiring a certain amount of revenue to be set aside for developing affordable housing. The authors find that TIF is a promising strategy for leveraging additional capital, and note that because the tax rate remains constant for the duration of the TIF period, existing property owners are protected from tax increases during the TIF lifetime and any additional revenue comes from new developments. Implementation challenges include the risk that the designated TIF area's values will not rise or that businesses attracted by TIF funds will go out of business, resulting in a shortfall for repayment of financing.

Real estate transfer taxes

Establish real estate transfer taxes to deter speculation in gentrifying areas; use funds to finance affordable housing development and preservation. 


\subsection{Create new affordable housing}

Commercial linkage program

Require commercial developers to construct affordable housing units or pay in-lieu fee.

PolicyLink. (2002). Equitable Development Toolkit: Commercial Linkage Strategies. Washington, DC.

This report describes commercial linkage programs and the variety of options available for designing a linkage strategy. It also discusses key players, financing, implementation, and related policy. Three case studies are included, including a regional variation of this strategy used in the Chicago metro area.

Inclusionary zoning

Require or incentivize inclusion of affordable units for new residential developments.

PolicyLink. (2002). Equitable Development Toolkit: Inclusionary Zoning. Washington, DC.

This report describes voluntary and mandatory inclusionary zoning and descriptions of cost-offsets for developers. It discusses key players, financing, implementation, and related policy, and offers four short case studies and links to additional resources.

California Homebuilders Association and the Nonprofit Housing Association of Northern California. (2005). On Common Ground: Joint Principles on Inclusionary Housing Policies.

This paper sets forth a set of recommended principles that the two organizations have agreed can be incorporated into inclusionary zoning programs to enhance their effectiveness in producing affordable units.

Levy, D.K., Comey, J., \& Padilla, S. (2006). Keeping the Neighborhood Affordable: Housing Strategies for Gentrifying Areas. Washington, DC: The Urban Institute.

Section 2 of this report focuses on strategies to develop affordable housing, including inclusionary zoning. The authors provide a brief description of the strategy and discuss anticipated outcomes, implementation challenges, and timing considerations.

\section{Vacant/underutilized land}

Utilize vacant property receivership; undertake housing rehab for vacant/boarded single-family homes; pursue infill development; land bank publicly owned vacant land.

Center for Community Progress. Toolkit: Vacant Property Receivership. Retrieved December 1, 2012 from:

This webpage provides a brief overview of receivership as a tool to restore vacant properties to productive use. It includes a link to a report on the use of receivership to revitalize neighborhoods and empower communities in Baltimore. 
Alexander, F. (2011).Land Banks and Land Banking. Washington, DC: Center for Community Progress.

This comprehensive report offers community leaders a step-by-step guide for creating land bank programs to take control of problem properties and leverage them for equitable development. It includes several case studies, provides examples of state enabling legislation, and discusses financing, implementation, and governance of land bank programs.

Revise zoning

Revise zoning code to allow for greater flexibility in affordable housing development.

Levy, D.K., Comey, J., \& Padilla, S. (2006). In the Face of Gentrification: Case Studies of Local Efforts to Mitigate Displacement. Washington, DC: The Urban Institute.

This report's case study of St. Petersburg's Bartlett Park neighborhood describes how, in conjunction with other strategies to increase affordable housing production, the local government changed its zoning code to allow for mixed-use developments and increased density.

\subsection{Preserve affordable housing}

\section{Code enforcement}

Use penalties attached to housing code enforcement to negotiate benefits for tenants of multi-family dwellings with negligent owners (e.g., reduce tenants' rent until compliance is achieved or transfer ownership to tenants or community organizations).

Levy, D.K., Comey, J., \& Padilla, S. (2006).Keeping the Neighborhood Affordable: Housing Strategies for Gentrifying Areas. Washington, DC: The Urban Institute.

Section 2 of this report focuses on strategies to develop and retain affordable housing, including the use of code enforcement policies to penalize negligent property owners, creating an opportunity to negotiate for the benefit of tenants. The authors note that because landlords may be required to pay for improvements to their properties, code enforcement could result in higher rents for tenants and therefore increase the risk of displacement unless used in connection with other strategies. Such strategies include programs requiring the retention of units as affordable housing or the inclusion of affordable units in rehabilitated buildings, and connecting tenants to a community organization that can help them navigate the negotiation process and/or the transfer of ownership to an entity that will preserve affordability.

PolicyLink. (2002). Equitable Development Toolkit: Code Enforcement. Washington, DC. Retrieved from:

This report describes the use of housing code enforcement as a tool to transfer ownership of multi-family dwellings to tenants or community organizations in cases where codes have been violated. It discusses implementation, key players, and related policy, and includes a case study for Washington DC's Columbia Heights neighborhood. 
Replacement ordinance and "right to return" policy

Enact replacement ordinance requiring one-for-one replacement of affordable units lost due to revitalization; enact "right to return" policy under which new affordable housing must give an admissions preference to persons displaced by revitalization.

Damewood, R. and Young-Laing, B. (2011).Strategies to Prevent Displacement of Residents and Businesses in Pittsburgh's Hill District.

- This paper provides an overview of the Hill District's history of disinvestment and recent development pressures. It reviews anti-displacement strategies that have been used throughout the country and discusses the efforts of a neighborhood advocacy group and community development law firm to have these strategies implemented in the Hill District. The paper includes Hamtramck, Michigan's "right to return" policy, the result of African American former residents' class action lawsuit against the city for discriminatory urban renewal efforts, that requires the city to develop affordable replacement housing and give children and grandchildren of displaced residents first priority for returning. The authors recommend adopting a right to return policy for the Hill District under which all new housing development plans much give admissions preference for displaced persons, including residents who were displaced by urban renewal and their descendants.

Retain expiring-subsidy units

Offer tax incentives to renew contracts for expiring affordable multi-family housing; encourage owners to seek federal incentives to renew contracts and/or restructure mortgages; grant local government, nonprofits, or tenants right of first refusal for purchase of property; require owners to pay a conversion fee to cover tenant relocation costs.

PolicyLink. (2002). Equitable Development Toolkit: Expiring Use. Washington, DC. This report describes the problem of expiring subsidies for affordable properties. The authors note that preservation of affordable units is an important strategy for maintaining housing for a mix of income levels in gentrifying areas and can be a cost-effective means of preventing displacement before it happens. They lay out a framework for a successful housing preservation campaign that includes picking and researching properties, helping tenants organize, and choosing a strategy (litigation, persuasion to renew, or purchase by a third party). The report offers case studies of San Francisco, which passed ordinances designed to prevent market-rate conversions, organized tenants, and committed significant funding to affordable housing preservation, and tenant-organizing in Anoka, $\mathrm{MN}$ to preserve an affordable multi-family building.

Achtenberg, E. (2002). Stemming the Tide: A Handbook on Preserving Subsidized Multifamily Housing. New York, NY: Local Initiatives Support Coalition.

This comprehensive report discusses ways to preserve the affordability of HUDassisted multifamily properties for low-income households. It includes tools and strategies available for preservation at all levels of government. 
Rent control

Enact rent control policies to maintain affordability.

Levy, D.K., Comey, J., \& Padilla, S. (2006). Keeping the Neighborhood Affordable: Housing Strategies for Gentrifying Areas. Washington, DC: The Urban Institute.

Section 2 of this report focuses on strategies to develop and retain affordable housing, including the use of rent control policies. The authors provide a brief description of the strategy and discuss anticipated outcomes, implementation challenges, and timing considerations.

PolicyLink. (2002). Equitable Development Toolkit: Rent Control. Washington, DC. This report describes elements of strong rent control laws to protect tenants from rising housing costs and provides counterarguments to the most common arguments against rent control policies. The authors provide brief case studies for Hoboken, NJ, Santa Monica, San Francisco, and Baltimore as well as links to rent control legislation and ordinances.

\section{Eviction protection laws}

Enact strong eviction protection laws to prevent eviction without just cause in neighborhoods experiencing speculation.

PolicyLink. (2002). Equitable Development Toolkit: Just Cause Eviction Controls. Washington, DC.

This report describes ordinances to protect renters by ensuring that landlords can evict only with just cause. Such controls typically apply to owners of buildings with more than a certain number of units, protect vulnerable tenants (e.g., low-income, elderly, people of color), and protect tenants in danger of eviction due to a bank foreclosure on the property. Effective just cause ordinances include enforcement mechanisms and expedited processes to deal with unjust evictions. The report discusses several advantages associated with this tool, including protection of tenants who have month-to-month leases, prevention of the steep rental increases that often accompany rapid resident turnover, and stabilization of communities. Challenges include a nationwide trend of dismantling laws that restrict property owner rights, the need for widespread tenant rights education, and the need to couple just cause eviction controls with other tools such as rent controls. The report includes two short case studies and links to additional resources. 


\section{Build assets and retain residents and businesses}

\section{Homeownership Programs}

Provide downpayment and closing-cost assistance to first-time homebuyers; support Section 8 Homeownership program; establish homeownership and foreclosure education and counseling programs; provide funds for home repair and rehab; provide assistance to owners to create accessory dwelling units to reduce financial burden of homeownership.

Levy, D.K., Comey, J., \& Padilla, S. (2006). Keeping the Neighborhood Affordable: Housing Strategies for Gentrifying Areas. Washington, DC: The Urban Institute.

See Section 3 of this report focuses on asset-building strategies, including homeownership education and counseling and the Section 8 Homeownership program. For each strategy, the authors provide a brief description and discuss outcomes, implementation challenges, and timing considerations.

\section{Commercial Stabilization}

Provide technical assistance, financial advising, microlending, design assistance, and storefront improvement funds to small businesses; undertake basic streetscape improvement projects.

PolicyLink. (2002). Equitable Development Toolkit: Commercial Stabilization. Washington, DC.

This report describes the range of available commercial stabilization tools, which can include capital investment, design guidelines, business attraction, facade improvement, and commercial development. It discusses key players, financing, implementation, and related policies and offers case studies of commercial stabilization efforts in Oakland and Berkeley.

Sobel, E. (2008). Austin, TX: The East Austin Neighborhood. Dallas, TX: Federal Reserve Bank of Dallas.

This case study of East Austin identifies several issues facing the gentrifying neighborhood, including challenges for small businesses. Faced with rising rents, business owners have reported a desire to increase their ability to network with other local businesses to create an East Austin business district with a distinct identity to draw customers, as well as a preference for working with microenterprise lenders rather than large banks. To help small businesses retain their viability in a changing market, local nonprofits provide technical assistance and microlending and run a forum series to inform owners about local economic and political trends. The city also provides loans of up to $\$ 20,000$ to nonprofits and new and existing neighborhood-serving small businesses that relocate to East Austin. 
Individual Development Accounts

Establish savings program that provides matching funds for contributions from residents; allowable uses include homeownership costs, education, entrepreneurship, etc.

Levy, D.K., Comey, J., \& Padilla, S. (2006). Keeping the Neighborhood Affordable: Housing Strategies for Gentrifying Areas. Washington, DC: The Urban Institute.

Section 3 of this report focuses on asset-building strategies, including Individual

Development Accounts. The authors provide a brief description of the strategy and discuss anticipated outcomes, implementation challenges, and timing considerations.

Property tax relief

Defer property taxes for lower-income homeowners facing rising property values.

Levy, D.K., Comey, J., \& Padilla, S. (2006). Keeping the Neighborhood Affordable: Housing Strategies for Gentrifying Areas. Washington, DC: The Urban Institute.

Section 2 of this report focuses on strategies to retain affordable housing, including tax relief for homeowners in the form of legislation that defers payment of property tax increases resulting from gentrification-related appreciation. When the home is sold, the deferred tax payments can be paid for using profits from the sale. Tax relief may be coupled with low-interest loans or grants to lower-income residents to assist with home maintenance costs. The authors note that elderly homeowners in particular may benefit from property tax deferral and financial assistance, as they often do not have sufficient income to cover increased tax payments or repairs. Garnering local support for tax deferment policies and financial assistance programs is cited as the primary challenge to implementation.

Resident ownership

Create financing program to enable tenants to purchase expiring-subsidy properties and maintain them as affordable housing; support creation of limited-equity housing co-ops with purchase priority given to current neighborhood residents; support Community Land Trust (CLT) programs.

PolicyLink. (2002). Equitable Development Toolkit: Limited Equity Housing Cooperatives. Washington, DC.

This report describes models of cooperative housing ownership and discusses financing strategies, key players, related policies, and implementation challenges. It includes a case study of limited-equity housing cooperatives in New York. 
Levy, D.K., Comey, J., \& Padilla, S. (2006). Keeping the Neighborhood Affordable: Housing Strategies for Gentrifying Areas. Washington, DC: The Urban Institute.

Section 3 of this report focuses on asset-building strategies, including limited-equity housing cooperatives and Community Land Trusts. The authors provide a brief description of the strategy and discuss anticipated outcomes, implementation challenges, and timing considerations.

PolicyLink. (2002). Equitable Development Toolkit: Community Land Trusts. Washington, DC.

This report describes the Community Land Trust model, under which a private nonprofit organization creates affordable homeownership opportunities by leasing land for a nominal fee to individuals who own the buildings on the land. By retaining ownership of the land, CLTs are able to greatly reduce the cost of purchasing a home. Buyers agree to limit the amount of profit they make on the sale of the home, ensuring permanent affordability. The authors discuss land acquisition, financing, related policies, and implementation challenges. Case studies of CLTs in Albuquerque, Portland, and Burlington, VT are included.

Targeted economic development Create organization or program dedicated to job training and business development for residents in at-risk areas.

Levy, D.K., Comey, J., \& Padilla, S. (2006). In the Face of Gentrification: Case Studies of Local Efforts to Mitigate Displacement. Washington, DC: The Urban Institute.

This report's case study of Seattle's Central Area describes how the local Chamber of Commerce created an Urban Enterprise Center focused on job training and business development for residents in that neighborhood.

Gibbons, A. and Haas, G. (2002). Redefining Redevelopment: Participatory Research for Equity in the Los Angeles Figueroa Corridor. Los Angeles, CA: Figueroa Corridor Coalition for Economic Justice.

This report summarizes research undertaken by the coalition to identify best practices for designing a community jobs program. Now operational, the program trains low-income residents for jobs generated by investment in the corridor. 
Resident shareholders

Offer residents stock ownership in CDC commercial real estate projects; support cooperative business enterprises in at-risk neighborhoods.

PolicyLink. (2001). Equitable Development Toolkit: CDCs with Resident Shareholders. Washington, DC.

This report describes the emerging strategy of offering residents stock ownership in CDC projects, and discusses financing, related policies, and implementation challenges. It includes a case study of Good Hope Marketplace, a retail shopping center in Washington, DC that is owned by a local economic development corporation that makes $10 \%$ of its stock available for purchase by neighborhood residents.

PolicyLink. (2002). Equitable Development Toolkit: Cooperative Ownership.

Washington, DC.

This report describes models of cooperative business ownership, including worker cooperatives, employee stock ownership plans, consumer cooperatives, and producer cooperatives. It covers financing, related policies, and implementation challenges and includes case studies for a worker cooperative temp agency in Baltimore and a producer cooperative in Puerto Rico.

Preserve cultural facilities and landmarks

Preserve culturally important institutions, sites, landmarks and art.

Indiana Landmarks.African American Landmarks. Retrieved December 1, 2012.

This website for Indiana Landmarks, a nonprofit historical preservation group, describes the work of its African American Landmarks Committee to find properties important to Indiana's African American history and offer technical assistance and grant funding to help owners preserve endangered landmarks.

Weber, J. (2003). Politics and Practice of Community Public Art: Whose Murals Get Saved? Los Angeles, CA: The Getty Conservation Institute.

This essay describes the loss of culturally historic murals through redevelopment processes and makes the case for their preservation. 


\section{Early}

Commercial stabilization

Homeownership programs

Individual Development Accounts

Preserve cultural facilities and landmarks

Resident ownership

Resident shareholders

Support community building initiatives

Targeted economic development

Task force

Revise zoning

Vacant/underutilized land

Developer exactions

Document recording fee

Housing levy

Housing Trust Fund

Tax Increment Financing

Eviction protection laws

Health Impact Assessment/Environmental Impact Assessment

Community Impact Report

Neighborhood planning process

Real estate transfer taxes

Code enforcement

Retain expiring-subsidy units

\section{Mid}

Commercial stabilization

Homeownership programs

Preserve cultural facilities and landmarks

Resident ownership

Resident shareholders

Support community building initiatives

Targeted economic development

Task force

Property tax relief

Revise zoning

Vacant/underutilized land

Commercial linkage program

Inclusionary zoning

Developer exactions

Document recording fee

Housing levy 
Housing Trust Fund

Tax Increment Financing

Eviction protection laws

Health Impact Assessment/Environmental Impact Assessment

Community Impact Report

Neighborhood planning process

Real estate transfer taxes

Community Benefits Agreement and tools

Rent control

Code enforcement

Retain expiring-subsidy units

\section{Late}

Property tax relief

Revise zoning

Commercial linkage program

Inclusionary zoning

Developer exactions

Document recording fee

Housing levy

Housing Trust Fund

Tax Increment Financing

Health Impact Assessment/Environmental Impact Assessment

Community Impact Report

Community Benefits Agreement and tools

Rent control

Retain expiring-subsidy units

Replacement ordinance and "right to return" policy 


\section{Works Cited}

Belfield, C. (2008). Preschool Education and Human Capital Development in Central Cities. In M. A. Turner, H. Wial, and E. Wolman (Eds.), Urban and Regional Policy and its Effects.

Washington, D.C.: The Brookings Institution.

Betancur, J. (2005). Gentrification before Gentrification? The Plight of Pilsen in Chicago [White paper]. Retrieved from

http://www.uic.edu/cuppa/voorheesctr/Publications/Gentrification\%20before\%20Gentrification.p $\underline{\mathrm{df}}$

Betancur, J. (2011). Gentrification and Community Fabric in Chicago. Urban Studies, 48(2): 383-406.

Crockett Jr., S. (2012, August 3). The Brixton: It's new, happening and another example of African-American historical 'swagger-jacking'. The Washington Post (The Roots DC Live blog). Retrieved from http://www.washingtonpost.com/blogs/therootdc/post/the-brixton-its-newhappening-and-another-example-of-african-american-historical-swaggerjacking/2012/08/03/b189b254-dcee-11e1-a894-af35ab98c616 blog.html

Damewood, R. and Young-Laing, B. (2011). Strategies to Prevent Displacement of Residents and Businesses in Pittsburgh's Hill District [White paper]. Retrieved from http://www.prrac.org/pdf/Hill District Anti-Displacement Strategies-final.pdf

Dyckhoff, T. (2012, January 20). The five best places to live in the world, and why. The Guardian. Retrieved from http://www.guardian.co.uk/money/2012/jan/20/five-best-places-to-live-inworld accessed 2/25/13

Essley, L. (2012, October 20). Parking conflicts prompting churches to flee to D.C. The Washington Examiner. Retrieved from http://washingtonexaminer.com/parking-conflictsprompting-churches-to-flee-d.c./article/2511270

Freeman, L. (2005). Displacement or Succession? Residential Mobility in Gentrifying Neighborhoods. Urban Affairs Review, 40(4), 463-491.

Guy, S. and Henneberry, J. (2000). Understanding urban development processes: Integrating the economic and the social in property research. Urban Studies, 37(13), 2399-2416.

Hamnett, C. (1991). The blind men and the elephant: The explanation of gentrification. Transactions of the Institute of British Geographers, 16(2), 173-189.

Healey, P. (1991). Urban Regeneration and the Development Industry. Regional Studies 25(2):97-110.

Healey, P. and Barrett, S. M. (1990). Structure and Agency in Land and Property Development Processes: Some Ideas for Research. Urban Studies 27(1):89-104.

Hopkinson, N. (2012, June 23). Farewell to Chocolate City. The New York Times. Retrieved from http://www.nytimes.com/2012/06/24/opinion/sunday/farewell-to-chocolate-city.html 
Jurjevich, J. and Schrock, G. (2012). Is Portland Really the Place Where Young People Go to Retire? Migration Patterns of Portland's Young and College Educated, 1980-2010 [White paper]. Retrieved from http://mkn.research.pdx.edu/wpcontent/uploads/2012/09/JurjevichSchrockMigrationReport1.pdf

Kennedy, M. and Leonard, P. (2001). Dealing with Neighborhood Change: A Primer on Gentrification and Policy Choices. Washington, D.C.: The Brookings Institution and PolicyLink.

Levy, D. K., Comey, J., and Padilla, S. (2006). In the Face of Gentrification: Case Studies of Local Efforts to Mitigate Displacement. Washington, D.C.: The Urban Institute.

Marcuse, Peter. (1985). Gentrification, Abandonment, and Displacement: Connections, Causes, and Policy Responses in New York City. Journal of Urban and Contemporary Law, 28, 195-240.

Mirk, S. (2012, February 16). It's Not About the Bikes: Pinning the North Williams Uproar over Bikes Misses the Point--and the History. Portland Mercury. Retrieved from: http://www.portlandmercury.com/portland/its-not-about-the-bikes/Content?oid=5619639

Myers, D. and Gearin, E. (2001). Current Preferences and Future Demand for Denser Residential Environments. Housing Policy Debate, 12(4), 633-659.

Myers, D. and Ryu, S. (2007). Aging Baby Boomers and the Generational Housing Bubble: Foresight and Mitigation of an Epic Transition. Journal of the American Planning Association, 74(1): 17-33.

Newman, K. and Wyly, E. (2006). The Right to Stay Put, Revisited: Gentrification and Resistance to Displacement in New York City. Urban Studies, 43(1), 23-57.

Partnership for Working Families. (2012). Policy and Tools: Community Impact Reports. Washington, D.C. Retrieved from http://www.forworkingfamilies.org/resources/policy-toolscommunity-impact-reports

Patillo, Mary. (2007). Black on the Block: The Politics of Race and Class in the City. Chicago, IL: University of Chicago Press.

Schuetz, Jenny, Rachel Meltzer, and Vicki Been. 2009. "31 flavors of Inclusionary Zoning." Journal of the American Planning Association.

Schwartz, Heather L., Liisa Ecola, Kristen J. Leuscher, and Aaron Kofner. 2012 "Is Inclusionary Zoning Inclusionary?: A Guide for Practitioners." RAND. Retrieved from:

http://www.rand.org/pubs/technical_reports/TR1231.html

Scott, A. (2012, February 17). By the Grace of God. Portland Monthly. Retrieved from:

http://www.portlandmonthlymag.com/news-and-profiles/culture/articles/african-americanchurches-north-portland-march-2012 
Slater, T. (2009). Missing Marcuse: On gentrification and displacement. City, 13(2), 292-311.

Tiesdell, S. and Allmendinger, P. (2005). Planning Tools and Markets: Towards an Extended Conceptualization. In D. Adams, C. Watkins, and M. White (Eds.), Planning, Public Policy and Property Markets. Oxford: Wiley-Blackwell.

Watkins, C. (2008). Microeconomic perspectives on the structure and operation of local housing markets. Housing Studies, 23(2), 163. 